\title{
CARDIOVASCULAR RISK AND STRESS ADAPTATION IN METABOLIC DISEASES
}

\author{
Ph.D. Thesis
}

Márta Julianna Sárközy MD

Cardiovascular Research Group

Department of Biochemistry

Faculty of Medicine

University of Szeged

Supervisor: Tamás Csont, MD, Ph.D.

Szeged

2013 


\section{TABLE OF CONTENTS}

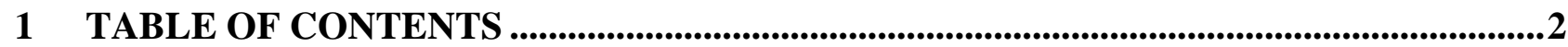

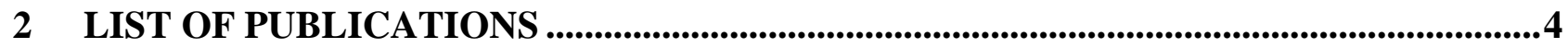

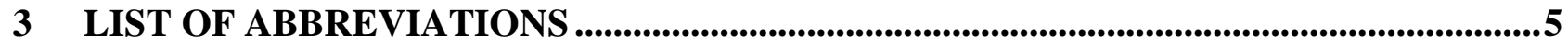

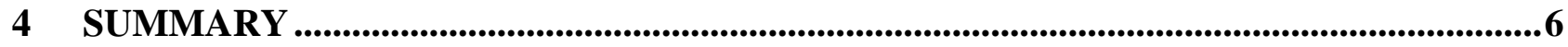

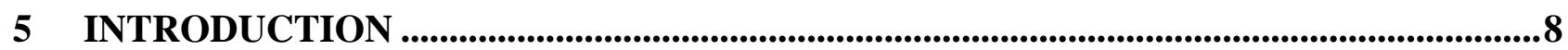

5.1 Epidemiology and metabolic risk factors for ischemic heart diseases ……................................. 8

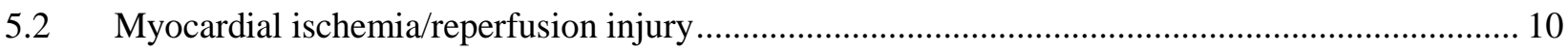

5.3 Endogenous cardioprotective mechanisms of the myocardium …................................................ 12

5.4 The effects of cardiovascular risk factors on IPre and IPost ..................................................... 14

5.5 Alterations in myocardial gene expression by IPre and IPost in normal and comorbid conditions 18

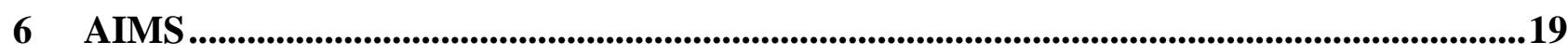

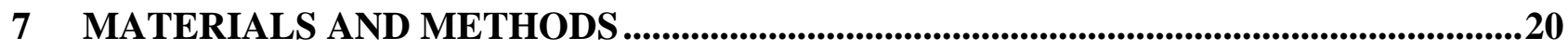

7.1 Experimental setup for investigation of cardiac gene expression pattern in metabolic syndrome .. 20

7.2 Experimental setup for examination of the influence of prolonged uremia on IPre....................... 23

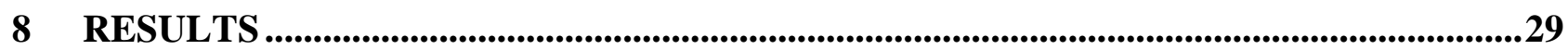

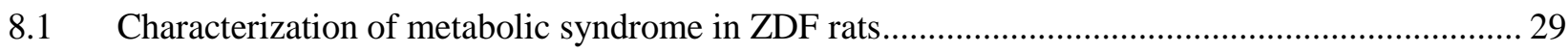

8.2 Cardiac gene expression profile in metabolic syndrome measured using cDNA microarrays and by

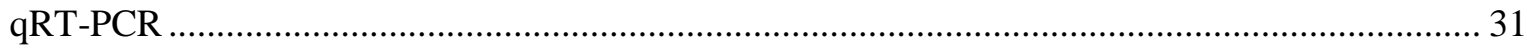

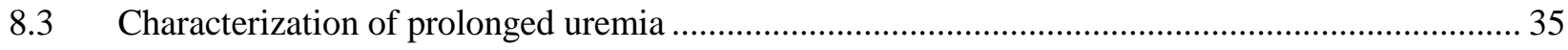

8.4 Effect of prolonged uremia on myocardial morphology and function ............................................ 36

8.5 Effect of prolonged uremia on ex vivo morphological and functional parameters ........................ 38

8.6 Effect of ischemic preconditioning on infarct size ...................................................................... 39

8.7 Effect of prolonged uremia on plasma angiotensin II, 3-nitrotyrosine and uric acid levels ............ 39

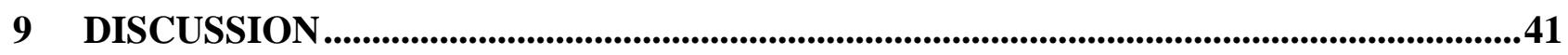

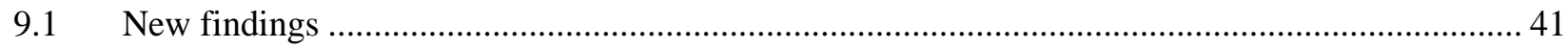

9.2 Effect of metabolic syndrome on cardiac gene expression pattern in male ZDF rats .................... 41

9.3 Effect of subacute and chronic renal failure on endogenous cardioprotective mechanisms ........... 45

9.4 Characteristic features and cardiac consequences of the prolonged uremic state ......................... 46 
9.5 Cardioprotection by IPre in prolonged uremia with increased nitrative stress .............................. 46

9.6 Cardioprotection by IPre in uremia-related minimal cardiac hypertrophy …................................. 47

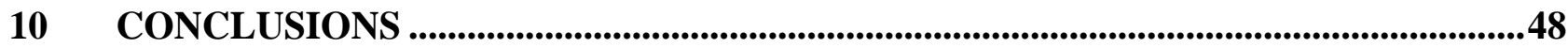

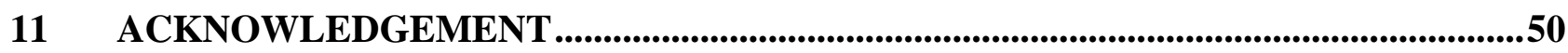

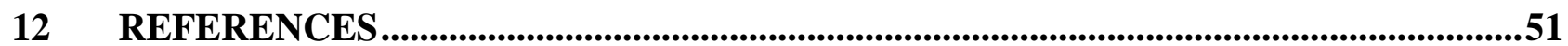

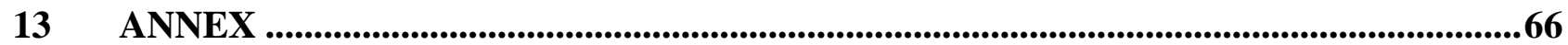




\section{LIST OF PUBLICATIONS}

\section{The subject of the thesis is based on the following full papers:}

I. Kocsis GF, Sárközy M, Bencsik P, Pipicz M, Varga ZV, Pálóczi J, Csonka C, Ferdinandy P, Csont T. Preconditioning protects the heart in a prolonged uremic condition. Am J Physiol Heart Circ Physiol. 2012, 303:H1229-1236, IF: 3.629

II. Sárközy M, Zvara Á, Gyémánt N, Fekete V, Kocsis GF, Pipis J, Szücs G, Csonka C, Puskás LG, Ferdinandy P, Csont T. Metabolic syndrome influences cardiac gene expression pattern at the transcript level in male ZDF rats. Cardiovasc Diabetol. 2013, 12:16, IF: 4.21

Cumulative impact factor of papers subjected in the thesis: $\mathbf{7 . 8 3 9}$

\section{Other full papers published during the Ph.D. fellowship:}

I. Monostori P, Kocsis GF, Okrös Z, Bencsik P, Czétényi O, Kiss Z, Gellén B, Bereczki C, Ocsovszki I, Pipis J, Pálóczi J, Sárközy M, Török S, Varga IS, Kiss I, Fodor E, Csont T, Ferdinandy P, Túri S. Different administration schedules of darbepoetin alfa affect oxidized and reduced glutathione levels to a similar extent in 5/6 nephrectomized rats. Clin Exp Nephrol. 2013, 17:569-574, IF: 1.246

II. Fekete V, Murlasits Z, Aypar E, Bencsik P, Sárközy M, Szénási G, Ferdinandy P, Csont T. Myocardial postconditioning is lost in vascular nitrate tolerance. J Cardiovasc Pharmacol. 2013, 62:298-303, IF: $\mathbf{2 . 2 9 0}$

III. Csont T, SárközyM, Szücs G, Szücs C, Bárkányi J, Bencsik P, Gáspár R, Csonka C, Kónya C, Ferdinandy P. Effect of a multivitamin preparation supplemented with phytosterol on serum lipids and infarct size in rats fed with normal and high cholesterol diet. Lipids Health Dis. 2013, 12:138, IF: 2.19

Cumulative impact factor of papers published during the Ph.D. fellowship: 5.726

Total impact factor: $\mathbf{1 3 . 5 6 5}$ 


\section{LIST OF ABBREVIATIONS}

ANOVA

Akt

ATP

CKD

CVD

DNA

ELISA

ERK

GFR

GSK3 $\beta$

HOMA-IR

IHD

IPost

IPre

$\mathrm{I} / \mathrm{R}$

JAK

$\mathrm{K}_{\mathrm{ATP}}$

LDL

MEK

mPTP

OGTT

PI3K

qRT-PCR

RISK

RNS

ROS

SAFE

STAT3

STZ

T2DM

TNF $\alpha$

ZDF analysis of variance

protein kinase B

adenosine triphosphate

chronic kidney disease

cardiovascular disease

deoxyribonucleic acid

enzyme linked immunosorbent assay

extracellular signal-regulated kinases

glomerular filtration rate

glycogen synthase kinase 3 beta

homeostasis model assessment-estimated insulin resistance

ischemic heart disease

ischemic precondonditioning

ischemic postconditioning

ischemia/reperfusion

Janus kinase

ATP-sensitive potassium channel

low density lipoprotein

mitogen activated protein kinase

mitochondrial permeability transition pore

oral glucose tolerance test

phosphatidylinositol 3-kinase

quantitative real time polymerase chain reaction

reperfusion injury salvage kinase

reactive nitrogen species

reactive oxygen species

survivor activating factor enhancement

signal transducer and activator of transcription 3 factor

streptozotocin

type 2 diabetes mellitus

tumor necrosis factor alpha

Zucker Diabetic Fatty 


\section{SUMMARY}

Ischemic heart disease (IHD) is the leading cause of death in developed countries. It is well known that IHD is a multifactorial pathological condition developing as a consequence of both genetic and environmental factors as well as various interactions between them. Furthermore, IHD generally coexists with other metabolic risk factors and comorbidities including hypercholesterolemia, metabolic syndrome, diabetes mellitus, etc. Moreover, increasing prevalence of hypercholesterolemia and diabetes mellitus in the aging population results in a dramatic rise in the prevalence of chronic kidney disease (CKD) characterized by severe metabolic changes generally termed as uremia. In addition, uremia has been shown to increase the risk of cardiovascular morbidity and mortality.

Brief periods of ischemia applied before or immediately after a potentially lethal myocardial ischemia confer remarkable cardioprotection. These endogenous cardioprotective mechanisms, termed as ischemic preconditioning (IPre) and postconditioning (IPost) have been demonstrated to be abolished by several metabolic risk factors and comorbidities e.g. hypercholesterolemia, metabolic syndrome, and diabetes mellitus.

Although, the key cellular events of IPre and IPost are extensively studied in normal and comorbid states, the exact mechanisms of myocardial changes in chronic metabolic disorders as well as loss of IPre and IPost are still unknown. Beside the traditional biochemical and pharmacological approaches, genomics may provide new potentials to investigate key molecular events in the mechanisms of myocardial changes in chronic metabolic disorders as well as in the cellular events of IPre and IPost both in normal and comorbid states.

Using DNA microarray, we have previously shown in separate studies that both IPre and IPost modify myocardial ischemia/reperfusion (I/R)-induced gene expression pattern in rats in the absence of any metabolic risk factor. Similarly, our group has previously shown that a cardiovascular risk factor, hypercholesterolemia alters cardiac gene expression profile in rats. Other cardiovascular risk factors including type 2 diabetes mellitus (T2DM) and CKD have been shown to influence cardiac gene expression profile. Therefore, in the present thesis we investigated the effect of another cardiovascular risk factor and comorbid state, the metabolic syndrome on cardiac gene expression pattern in order to examine the basic differences in cardiac metabolic changes in a complex metabolic disorder. We have found genes with significantly altered cardiac gene expression due to metabolic syndrome including functional clusters of metabolism, structural proteins, signal transduction, stress response, ion channels and receptors. Moreover, some other genes with no definite functional clusters were also changed. In conclusion, metabolic syndrome 
significantly alters myocardial gene expression profile which may be involved in the development of cardiac pathologies in the presence of metabolic syndrome.

We and others have previously shown that cardiovascular risk factors and comorbid states including hypercholesterolemia as well as T2DM attenuate the cardioprotective effect of IPre and IPost. However, it has been demonstrated previously that cardioprotective effect of both IPre and IPost are preserved in experimental subacute renal failure. Therefore, in the present thesis, we examined whether another cardiovascular risk factor and comorbid state, prolonged uremia, affects the $\mathrm{I} / \mathrm{R}$ injury and cardioprotection by IPre. We have found that although prolonged experimental uremia leads to severe metabolic changes and the development of a mild myocardial dysfunction, the cardioprotective effect of IPre is still preserved. In conclusion, our present study suggests that patients suffering from long-term uremia may also benefit from cardioprotection by IPre. Since uremic patients are regularly excluded from clinical trials, there is a need for clinical studies to investigate the cardioprotective effect of conditioning techniques in patients with chronic renal failure suffering from IHD. 


\section{INTRODUCTION}

\subsection{Epidemiology and metabolic risk factors for ischemic heart diseases}

Diseases related to the heart and circulatory system are termed as cardiovascular diseases (CVD) which are the major cause of morbidity and mortality in the industrialized world. In the USA, CVD accounted for 17 million of the total 57 million deaths in 2008 [1]. By 2030, the number of CVD deaths is expected to rise to 23.6 million in the USA [2]. There are different forms of CVD conditions, among which IHD is the most predominant form of all cases and deaths [1]. IHD develops due to atherosclerosis leading to different clinical phenotypes from a less severe angina to more severe forms including acute myocardial infarction, chronic ischemia or even sudden cardiac death [1]. IHD is a multifactorial pathological condition developing as a consequence of both genetic and environmental factors as well as interaction between them [1]. It is well known that IHD generally coexists with other metabolic risk factors and comorbidities [1, 3] including hyperlipidemia, metabolic syndrome (defined as the coexistence of visceral obesity, dyslipidemia, hyperglycemia, and systemic arterial hypertension), atherosclerosis, insulin resistance as well as diabetes mellitus, hypertension-related left ventricular hypertrophy, heart failure, and aging [3]. Moreover, increasing prevalence of hyperlipidemia and diabetes mellitus in the aging population results in a dramatic rise in the prevalence of chronic kidney disease characterized by severe metabolic changes generally termed as uremia [4]. In addition, uremia and especially end-stage renal failure have been shown to increase the risk of cardiovascular morbidity and mortality $[5,6]$.

\section{Hypercholesterolemia}

Hypercholesterolemia is defined as the presence of elevated serum cholesterol levels including total cholesterol (>5.2 $\mathrm{mmol} / \mathrm{L})$ and LDL-cholesterol $(>2.5 \mathrm{mmol} / \mathrm{L})$ [7, 8]. Large clinical studies showed that a significant population of adults is affected by hypercholesterolemia in the developed countries [9]. In the USA, approximately 100 million people (44.4\%) suffered from hypercholesterolemia ( $>5.2 \mathrm{mmol} / \mathrm{L}$ for total cholesterol level) in 2008 [2]. The role of an increased serum LDL-cholesterol level as a predictor of CVD is of great importance since every $1.0 \mathrm{mmol} / \mathrm{L}$ decrease in LDL-cholesterol level has been reported to be associated with a corresponding $22 \%$ reduction in CVD morbidity and mortality [8]. Moreover, several experimental studies have demonstrated that in addition to the well-known pro-atherogenic effect in the vasculature, hyperlipidemia may directly affect the heart causing contractile dysfunction $[10,11]$. 


\section{Type 2 diabetes mellitus}

Type 2 diabetes mellitus is defined as a metabolic disorder characterized by elevated serum glucose level $(>6.1 \mathrm{mmol} / \mathrm{L}$ fasting glucose concentration or $>11.1 \mathrm{mmol} / \mathrm{L}$ glucose concentration 2 hours after OGTT) with insulin resistance and relative insulin deficiency [12]. The rapid increase in the prevalence of T2DM across the world gives diabetes the status of an epidemic in the 21st century [13]. In the last decades, there was an explosive increase in the number of people diagnosed with T2DM worldwide due to aging as well as increasing prevalence of obesity and physical inactivity [13-15]. In the USA, an estimated 18 million people had diagnosed T2DM, representing 8.0\% of the adult population in 2008 [2]. In addition, $36.8 \%$ of the adult population had pre-diabetes, with abnormal fasting glucose levels in 2008 [2]. Worldwide, the total number of people with diabetes is projected to rise from 347 million in 2008 [16] to 552 million in 2030 [17]. Epidemiological studies and clinical trials [3, 18-20] have shown that T2DM patients are more prone to developing CVD (24 fold relative risk) [21], including acute myocardial infarction (7 fold relative risk) [21].

\section{Metabolic syndrome}

Metabolic syndrome is defined as the coexistence of visceral obesity, dyslipidemia, hyperglycemia, and hypertension [22, 23]. Most individuals with metabolic syndrome have abdominal obesity and develop insulin resistance, therefore the prevalence of metabolic syndrome and pre-diabetes overlap $[24,25]$. In addition, metabolic syndrome can be considered as a direct precursor state of T2DM [24] and CVD [24, 26]. Metabolic syndrome affects a large population including all ages from children to elderly and both sexes worldwide [27-29]. According to the Third National Health and Nutrition Examination Survey (NHANES III) criteria, about 47 million people (approximately 24\% of the US adult population) had metabolic syndrome in the USA in 2002 [30]. Its prevalence is raising both in developed [27, 30], and in developing countries [27, 30]. In addition, patients suffering from metabolic syndrome have an approximate 5-fold increase in diabetes [24, 31] and 2.5 fold increase in chronic renal failure [32] risk compared with persons without metabolic syndrome. It is well established that metabolic syndrome is a major risk factor for cardiovascular diseases [33-36]. Several epidemiological studies have demonstrated that metabolic syndrome was associated with an approximately 1.5-3 times greater risk of CVD and IHD mortality [37, 38]. 


\section{Chronic kidney disease}

Chronic kidney disease is defined as either kidney damage for more than 3 months confirmed by kidney biopsy or markers of kidney damage (e.g. albuminuria), with or without a decrease in glomerular filtration rate (GFR), or GFR $<60 \mathrm{~mL} \cdot \min ^{-1} / 1.73 \mathrm{~m}^{2}$ for more than 3 months, with or without kidney damage $[4,39]$. CKD is a worldwide public health problem due to the increasing prevalence of T2DM, hyperlipidemia and hypertension [4]. According to a meta-analysis, the prevalence of CKD was approximately $7.2 \%$ in people aged $30-64$ years and varied from $23.4 \%$ to $35.8 \%$ in patients 64 years or older worldwide [40]. In the USA, prevalence of CKD was $13.1 \%$ in 1999-2004 [41]. Despite the significant number of people with CKD, the majority of them remain unaware of their condition for several years until reaching late stages of CKD [4, 42]. According to the US National Kidney Foundation's Kidney Early Evaluation Program, only 9\% of patients with CKD were aware of their diagnosis from 2000 to 2009 [43]. CKD and especially end-stage renal failure have been shown to increase the risk of cardiovascular morbidity and mortality [5, 44]. The prevalence of IHD at the start of dialysis is approximately 40\% [45]. In fact, CVD is the main cause of death in patients with chronic renal failure $[39,44]$. Indeed, CVD mortality is approximately 10 to 30 times higher in CKD patients on dialysis than in patients in the general population irrespectively for age [39]. After stratification for age, CVD mortality remains approximately 5-fold higher in dialysis patients than in the general population [39]. The incidence of myocardial infarction is high in dialysis patients and the outcome after myocardial infarction is poor [46]. In dialysis patients, one and two year mortality rate after myocardial infarction was 59\% and $73 \%$, respectively, which is much higher than after acute myocardial infarction in the general population, even in subjects with other comorbid states e.g. diabetes mellitus [39]. In addition, left ventricular hypertrophy and dysfunction are notable in a significant number of patients on chronic dialysis [39, 46-48].

\subsection{Myocardial ischemia/reperfusion injury}

IHD means different clinical manifestations of myocardial ischemia including acute myocardial infarction [1]. Myocardial ischemia develops when coronary flow to the myocardium is relatively or absolutely reduced which results in myocardial ischemic injury [3]. During ischemia, oxygen supply to the mitochondria is inadequate to support oxidative phosphorylation and the related ATP synthesis [3]. The imbalance of intracellular oxygen and energy supply leads to intracellular accumulation of inorganic phosphate, lactate, $\mathrm{H}^{+}, \mathrm{Na}^{+}$and $\mathrm{Ca}^{2+}[3,49]$ (Figure 1). The increasing intracellular concentrations of solutes result in osmotic swelling with increased sarcolemmal 
fragility and cell disruption as well as activation of $\mathrm{Ca}^{2+}$-dependent nucleases, proteases and phospholipases (Figure 1) resulting in the destruction of membranes and leading to cell death [3, 49]. The process of irreversible cell injury is time-dependent and results in the pathological features of necrosis (Figure 1).

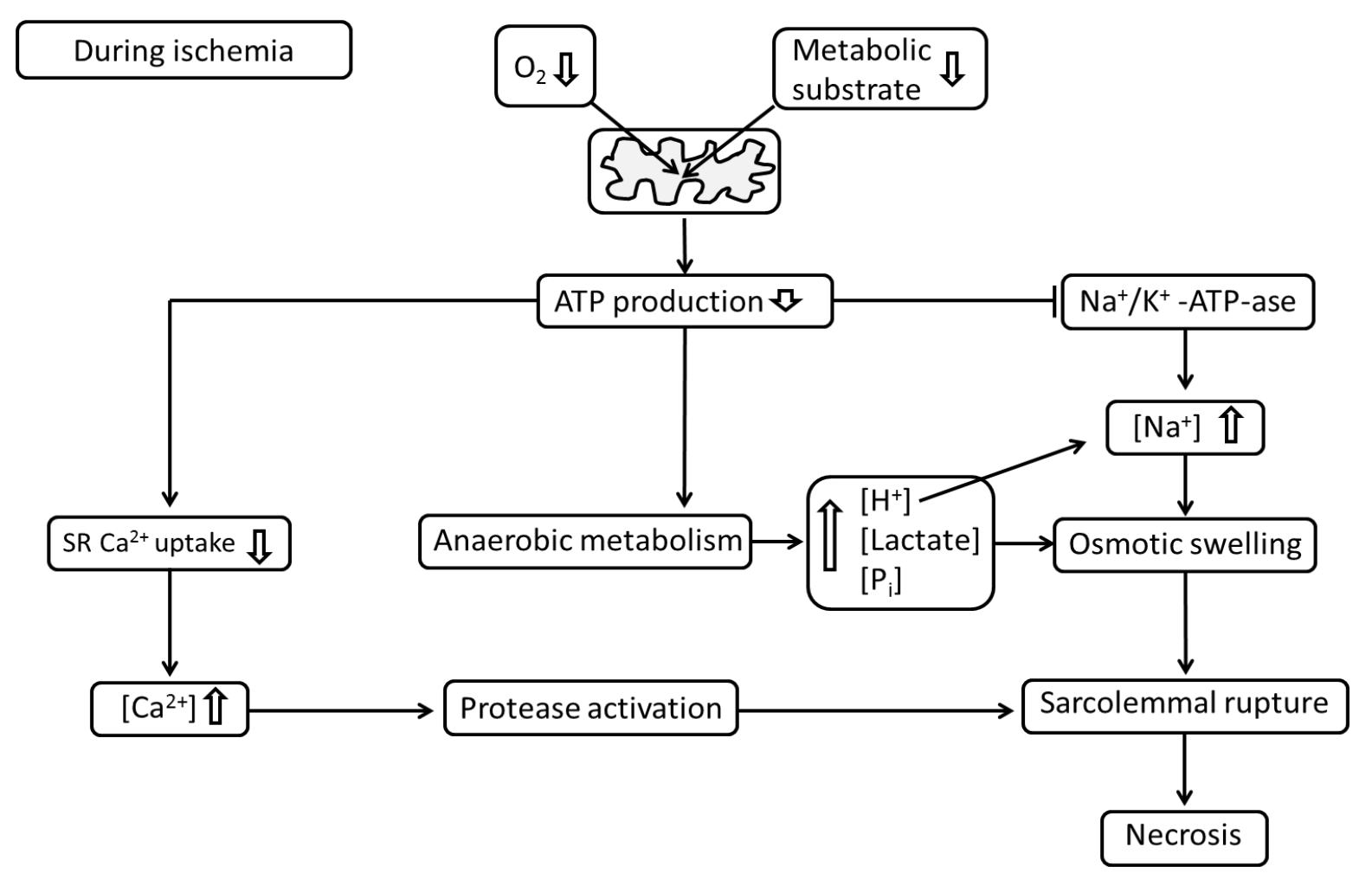

1. Figure. Myocardial injury during ischemia (modified from Ferdinandy et al., Pharmacol Rev. 2007).

Under experimental circumstances and in clinical situations, ischemia may be followed by reperfusion, that is, the readmission of oxygen and metabolic substrates with washout of ischemic metabolites [3] (Figure 2). Although, reperfusion is essential to salvage ischemic tissue, it has the potential to cause further irreversible cell damage termed as reperfusion injury [3]. Paradoxically, the sudden readmission of metabolic substrates and oxygen contributes to reperfusion injury [3]. Reperfusion leads to increasing intracellular $\mathrm{pH}$ due to $\mathrm{H}^{+}$washout and inadequately restored ATP synthesis [3], $\mathrm{Ca}^{2+}$ overload and reduced contractility, coronary endothelial dysfunction, low production of nitric oxide and oxidative stress, migration of inflammatory cells, disruption of membranes and induction of apoptotic and necrotic signals in the myocardium [49, 50] (Figure 2). The recovery of $\mathrm{pH}$, oxidative/nitrative stress and $\mathrm{Ca}^{2+}$ accumulation can induce the opening of the 
mitochondrial permeability transition pores (mPTP) which strongly contributes to myocardial apoptosis and necrosis [49] (Figure 2).

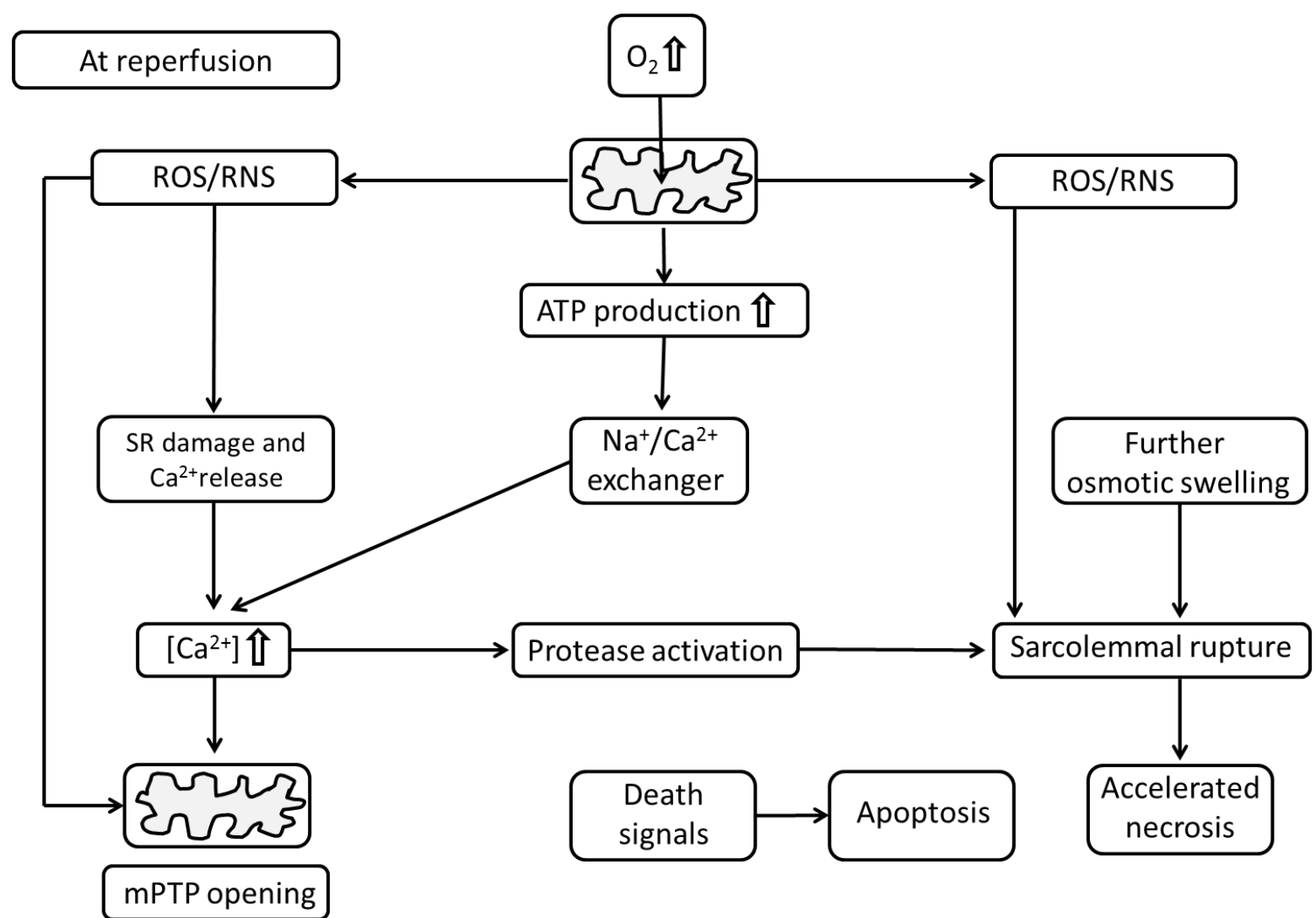

2. Figure Myocardial reperfusion injury (modified from Ferdinandy et al., Pharmacol Rev. 2007).

In summary, myocardial ischemia and reperfusion leads to "ischemia/reperfusion injury" which might result in the development of myocardial infarction, contractile dysfunction and arrhythmias.

\subsection{Endogenous cardioprotective mechanisms of the myocardium}

Coronary interventions and thrombolytic therapies are the most widely used clinical interventions to reduce infarct size by reopening the occluded arteries. Pharmacologic agents (e.g., nitrates and beta blockers) reducing energy demand and/or increasing coronary flow are also common strategies to ameliorate infarct size. An alternative approach to minimize the development of myocardial infarction is the triggering of endogenous adaptive mechanisms of the heart.

Experimentally, the most powerful endogenous adaptive cardioprotective mechanisms are the ischemic precondonditioning and postconditioning (Figure 3). IPre is a well described endogenous adaptive mechanism in which brief exposure to I/R markedly enhances the ability of the heart to withstand a subsequent, potentially lethal $\mathrm{I} / \mathrm{R}$ injury [3, 51]. Brief cycles of $\mathrm{I} / \mathrm{R}$ applied after a 
longer period of ischemia also confer cardioprotection against myocardial I/R injury. This phenomenon is termed as IPost [3, 52]. The cardioprotective effect of IPre and IPost results in attenuation of $\mathrm{I} / \mathrm{R}$ injury characterized by improvement of post-ischemic contractile function, a decrease in the occurrence and severity of arrhythmias, and a reduction in infarct size [3].

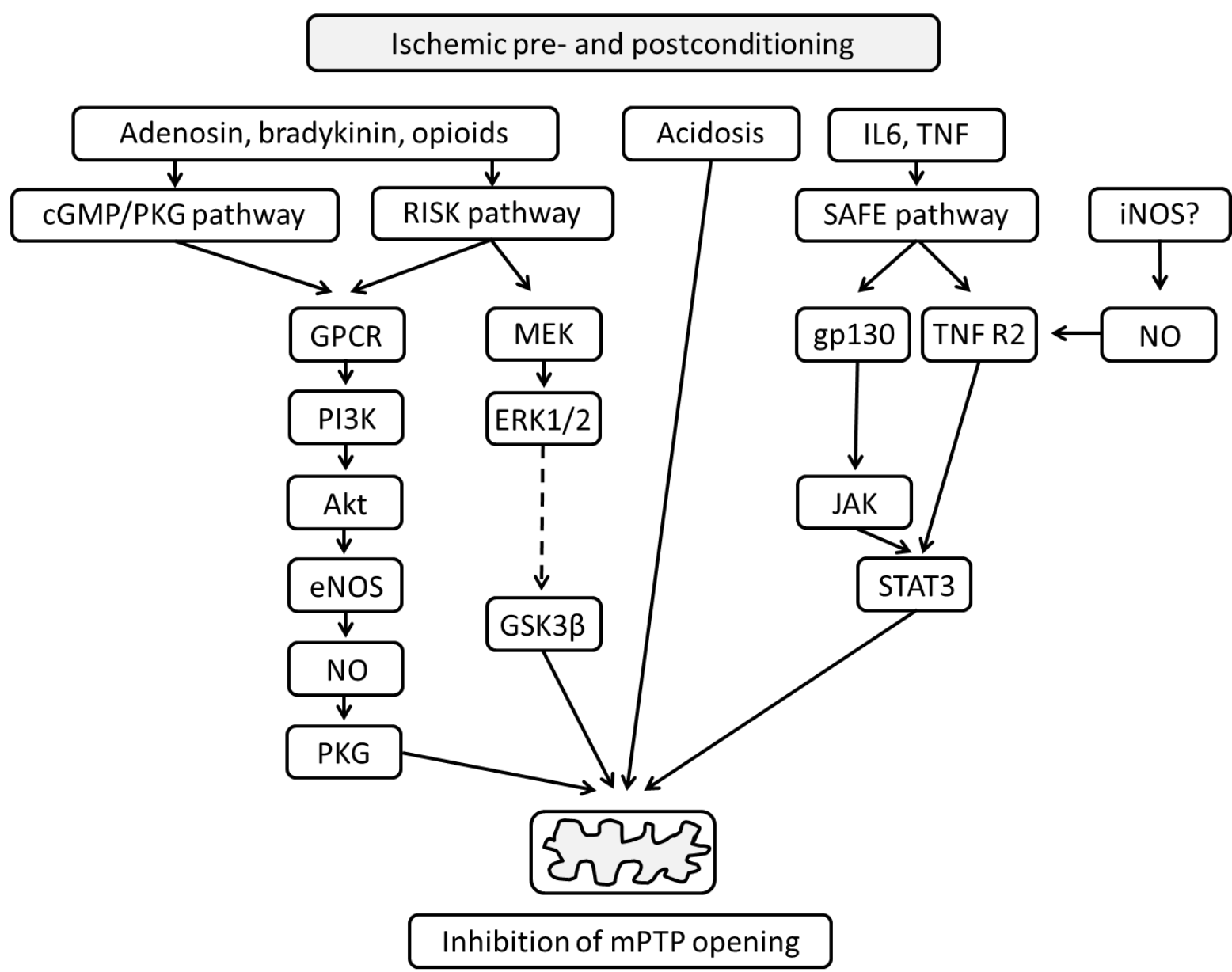

3. Figure Potential mechanism of ischemic pre- and postconditioning (modified from Perrelli MJ et al, World J Cardiol, 2011).

The exact mechanisms responsible for the cardioprotective mechanisms of IPre and IPost, are still not fully understood. Briefly, both IPre [3] and IPost [53] are considered to be triggered by a number of endogenous factors, including adenosine, bradykinin, and opioids (Figure 3). Two major intracellular signaling cascades have been proposed as mediators both of the preconditioning and postconditioning stimulus, the reperfusion injury salvage kinase (RISK) [54, 55] pathway and the survivor activating factor enhancement (SAFE) [55, 56] pathway (Figure 3). The RISK pathway is considered to consist of two arms, one of which involves mitogen activated protein kinase $1 / 2$ (MEK1/2) and extracellular signal-regulated kinases $1 / 2$ (ERK1/2) and the other involves 
phosphatidylinositide 3-kinase (PI3K) and Protein kinase B (Akt) (Figure 3) [55]. Both arms are thought to be triggered by the binding of specific ligands with G-protein-coupled receptors and terminate on glycogen synthase kinase 3 beta (GSK3 $\beta$ ) to reduce the likelihood of mitochondrial permeability transition pore (mPTP) opening and thus attenuate reperfusion injury $[54,55]$ (Figure 3). The activation of the SAFE pathway including the activation of the cytokine tumor necrosis factor alpha $(\mathrm{TNF} \alpha)$ [56] and the transcription factor signal transducer and activator of transcription-3 (STAT-3) [57] is now recognized as a "RISK-free" pathway that can confer cardioprotection by both in IPre and IPost (Figure 3). As with the RISK pathway, inhibition of the mPTP is thought to be the end effector of this pathway [56] (Figure 3). In addition, mitochondrial ATP-sensitive potassium channel ( $\left.\mathrm{K}_{\mathrm{ATP}}\right)$-mediated inhibition of mPTP opening also thought to play an important role both in the mechanism of IPre and IPost $[3,58]$. Moreover, another consequence of mitochondrial $\mathrm{K}_{\mathrm{ATP}}$ opening, the enhanced generation of reactive oxygen (ROS) and nitrogen species (RNS) seems to be an obligatory part of the signaling cascade [3, 59]. It is likely that ROS/RNS signal activates distal kinases which may include MEK, JAK and STAT [3].

\subsection{The effects of cardiovascular risk factors on IPre and IPost}

A number of evidence have demonstrated that IPre and IPost are powerful interventional strategies to limit I/R-induced myocardial injury [3]. Despite this fact, cardioprotection by ischemic conditioning techniques is affected in the presence of a number of cardiovascular risk factors and chronic metabolic diseases e.g. hyperlipidemia, atherosclerosis, metabolic syndrome, diabetes mellitus and insulin resistance [3]. This suggests that IPre and IPost are moderately "healthy heart protective phenomena" [3]. The mechanisms by which these cardiovascular risk factors and chronic metabolic diseases interfere with cardioprotective effects of ischemic conditioning techniques are uncertain and are not completely understood [3]. Therefore, the development of rational therapeutic strategies to protect the heart against ischemia requires preclinical studies that examine cardioprotection specifically in relation to complicating cardiovascular risk factors and chronic metabolic diseases [3]. 
Ischemic pre- and postconditioning and major risk factors

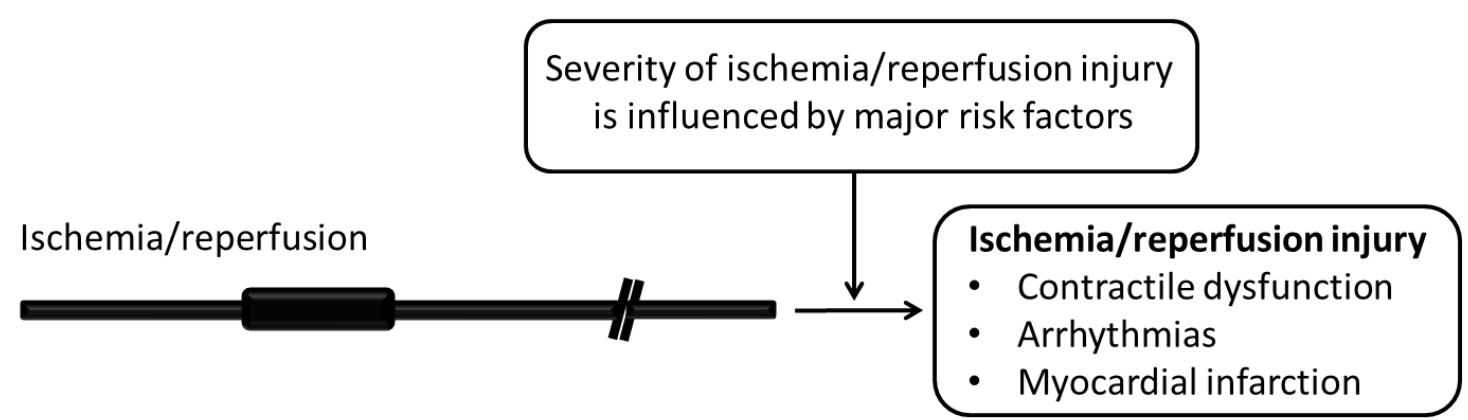

Ischemic preconditioning

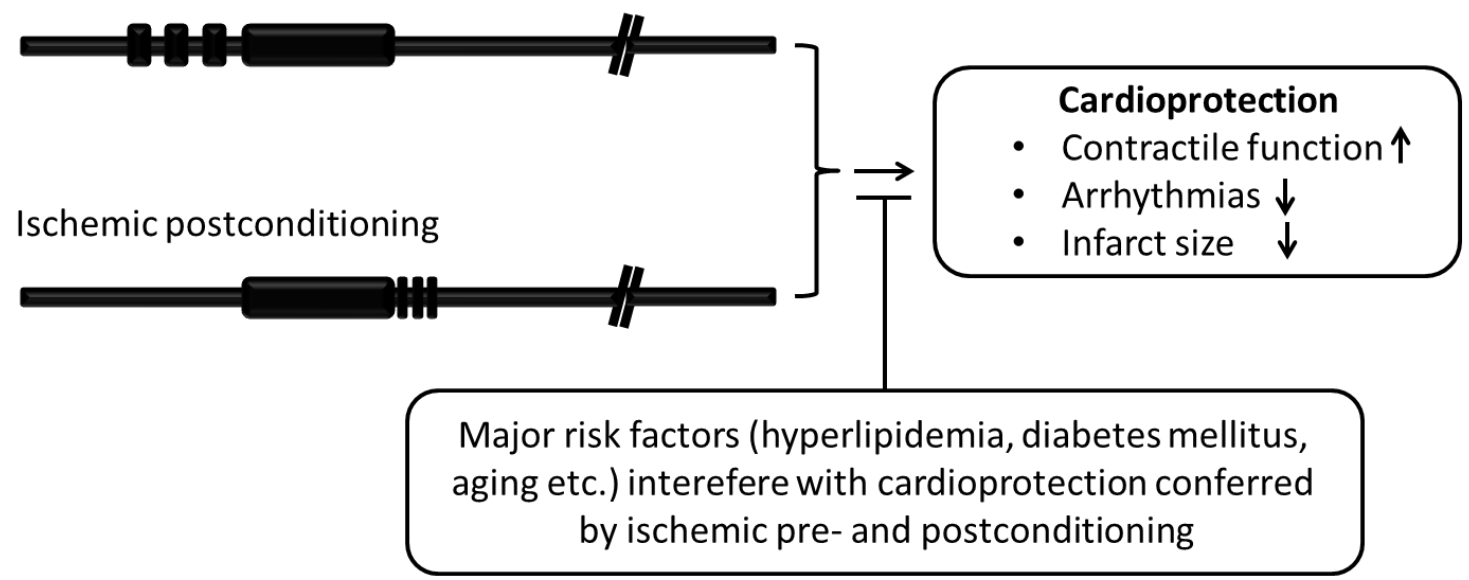

4. Figure Cardioprotective effects of ischemic pre-and postconditining are influenced by major cardiovascular risk factors and comorbidities (modified from Ferdinandy et al., Pharmacol Rev. 2007).

\section{Hyperlipidemia and ischemic pre- and postconditioning}

Although IPre confers remarkable cardioprotection in a variety of species [3, 53], including humans [60-62], we and others have shown that its effectiveness is attenuated by hyperlipidemia [3, 63] (Figure 4-5). Szilvassy et al. [3, 64] demonstrated for the first time in the literature that cardioprotection conferred by pacing-induced preconditioning was lost in rabbits developing hypercholesterolemia and atherosclerosis after 8 weeks of $1.5 \%$ cholesterol-enriched diet. After reexposure to a normal diet, reduction of serum cholesterol levels recaptured the cardioprotective effect of pacing-induced preconditioning despite the presence of atherosclerosis [3, 64]. This result proved that hypercholesterolemia, independently from the development of atherosclerosis, interferes with the cardioprotective mechanisms of pacing-induced preconditioning [3, 64]. The loss of pacing-induced preconditioning was subsequently confirmed in isolated hearts from rats fed with cholesterol-enriched diet without development of atherosclerosis, since rats do not develop significant atherosclerosis due to high-cholesterol diet $[3,65]$. The loss of the anti-ischemic effect of IPre (assessed by ST-segment elevation) in hyperlipidemia has been confirmed by two 
independent groups in patients undergoing repeated balloon inflations during coronary angioplasty $[3,62,66]$ as well. Limited literature data are available on the effect of IPost in hyperlipidemia. Iliodromitis et al. [3, 67] showed that the infarct size-limiting effect of IPost is lost in rabbits with experimental hyperlipidemia and atherosclerosis. The loss of the infarct size-limiting effect of IPost has been also confirmed by our group in hearts isolated from cholesterol-fed rats [59].

Though the precise mechanisms involved in the loss of cardioprotective effects of ischemic conditioning techniques in hypercholesterolemia are uncertain, reduced activation of Akt signals, redistribution of both sarcolemmal and mitochondrial Connexin 43, down-regulation of tetrahydrobiopterin and subsequent inactivation of NOS, impaired opening of mitochondrial-K $\mathrm{K}_{\mathrm{ATP}}$ channels, eNOS uncoupling, increased oxidative and nitrosative stress and high incidence of proapoptotic signaling could play pivotal roles in the loss of cardioprotective effects of ischemic conditioning techniques in hyperlipidemic myocardium [50].

\section{Diabetes mellitus and ischemic pre-and postconditioning}

A number of preclinical and clinical studies have examined the cardioprotective effect of IPre and IPost in T2DM [3]. The majority of these studies showed that diabetes interferes with cardioprotective mechanisms, attenuating the effectiveness of cardioprotective strategies (Figure 45) [3].

The first preclinical study to examine the IPre in experimental streptozotocin (STZ)-induced diabetes was reported by Liu et al. [3, 68]. Two weeks after STZ injection, hearts of diabetic rats were found to be more resistant to myocardial infarction in vivo as compared to normal control hearts, and IPre afforded additional cardioprotection [3, 68]. Another study by Tosaki et al. reported that brief cycles of preconditioning ischemia did not confer protection against $\mathrm{I} / \mathrm{R}$ induced arrhythmias, stunning, and intracellular $\mathrm{Na}^{+}$accumulation and $\mathrm{K}^{+}$efflux in diabetic rats 4 or 8 weeks after the STZ-treatment in isolated rat hearts $[3,69]$. In addition, IPre failed to reduce the infarct size in dogs 3 weeks after diabetes induction [3, 70]. Therefore, the duration of the diabetic state is a crucial factor in the efficacy of IPre. Some clinical observations suggest that IPre or preconditioning-like phenomena are impaired in diabetic patients with ischemic heart disease [3]. Angina, considered to be a correlation factor of IPre in patients, failed to limit infarct size, enhance recovery after myocardial function, or improve survival in diabetic patients with myocardial infarction as compared to non-diabetic patients [3, 71]. Impairment of IPre during coronary angioplasty was observed in diabetic patients as well $[3,72]$.

In fact, literature data on the efficacy of IPost in T2DM are controversial. Some preclinical studies have shown that the cardioprotective effect of IPost is lost in murine model of T2DM [3, 73]. 
Another preclinical study has shown that IPost confers infarct size limiting effect in STZ-induced diabetic mice [74]. Though the precise mechanisms involved in loss of cardioprotection by IPre and IPost in diabetes mellitus are uncertain, GSK-3 $\beta$ phosphorylation and mPTP opening upon reperfusion seem to be crucial points [75]. However, multiple protective signaling pathways appear to converge on GSK-3 $\beta$ regulation and inhibition of $\mathrm{mPTP}$ opening, T2DM-induced defects in these protective signaling pathways may be different depending on the model and/or phase of T2DM [75].

\section{Metabolic syndrome and ischemic pre-and postconditioning}

Although, the effect of metabolic syndrome on gene expression pattern in various tissue types has been investigated in a few studies (liver, skeletal muscle, adipose tissue [76] and pancreatic $\beta$-cells [77] obtained from the well-known metabolic syndrome model Zucker Diabetic Fatty (ZDF) rat, limited or no data are available on the effect of metabolic syndrome on cardiac gene expression pattern in relation to differences in basic cardiac metabolic features, susceptibility to myocardial I/R injury or endogenous cardioprotective mechanisms (Figure 5). The degree to which metabolic syndrome or its components contribute to myocardial I/R injury is unknown. However, the efficacy of cardioprotective mechanisms appears to be abolished in the presence of pathological conditions associated with metabolic syndrome such as obesity, hyperlipidemia and hyperglycemia. In hearts from ZDF rat, IPre did not afford protection against I/R injury [78]. In another well-known model of metabolic syndrome, in the ob/ob mice cardioprotection by IPost was also lost $[79,80]$.

\section{Chronic kidney disease and ischemic pre-and postconditioning}

One may speculate that the severe metabolic changes seen in uremia may interfere with endogenous cardioprotective mechanisms as seen with other metabolic diseases (Figure 5). However, there are limited data on the possible interaction of CKD with endogenous adaptive cardioprotective mechanisms including IPre and IPost. In a preliminary study, we have demonstrated for the first time in the literature that the infarct size limiting effect of IPost was still present 10 weeks after subtotal nephrectomy resulting in uremia in rats [81]. Moreover, an extensive study published by Byrne et al. [55] has reported that IPre, IPost, and remote ischemic conditioning are still cardioprotective after 4 weeks of subtotal nephrectomy. In addition, in the same study IPre was shown to limit infarct size in an adenine-enriched diet-induced model of uremia in rats [55]. It has been shown in this study, that IPre and IPost in a subacute renal failure model were associated with an increase in phospho-STAT3 and phospho-ERK1/2 representing key mediators of RISK and 
SAFE pathways [55]. Although the uremic state seems to be too short and was not characterized thoroughly in Byrne's aforementioned studies [55], they may suggest that the uremic heart can be still protected by conditioning techniques. Indeed, an experimental model of 4 weeks of uremia probably may not properly reflect the clinical situation, since uremia may remain unexplored for a long time in patients $[4,82]$. Additionally, it has been shown that $5 / 6$ partial nephrectomy followed by a postoperative duration of 3 weeks does not lead to advanced uremia in rats [83]. However, it is not known if a substantially longer period of uremia may influence endogenous cardioprotective mechanisms. Therefore, in the present thesis we examined the influence of prolonged uremia (30 weeks) on the severity of I/R injury and the infarct size limiting effect of IPre.

\subsection{Alterations in myocardial gene expression by IPre and IPost in normal and comorbid conditions}

Although, the molecular mechanisms of IPre and IPost are extensively studied, the exact signal transduction pathways of IPre and IPost are still unknown due to the complexity of these mechanisms. Beside the traditional biochemical and pharmacological approaches, genomics may provide new potentials to investigate key molecular events in the mechanisms of IPre and IPost. We and others have previously shown that IPre significantly influenced myocardial gene expression pattern as assessed by miRNA chip [84] as well as DNA microarray and qRT-PCR [85, 86]. We have previously demonstrated that hypercholesterolemia resulted in marked changes in preconditioning-induced gene expression which might lead to significant alterations of oxidative/nitrative stress signaling and to the loss of the cardioprotective effect of IPre [86] (Figure 5). However, another cardiovascular risk factors and comorbid conditions including T2DM [87, 88] and CKD [89] have been shown to influence cardiac gene expression profile (Figure 5), the alterations in myocardial gene expression by IPre and IPost in the presence of these cardiovascular risk factors and comorbid conditions are not investigated yet. Therefore, in the present thesis we investigated the effect of another cardiovascular risk factor, the metabolic syndrome on cardiac gene expression pattern in order to examine the basic differences in cardiac metabolic changes which might provide a new potential to understand the mechanisms of different susceptibility to myocardial I/R injury in metabolic syndrome. 


\section{AIMS}

The aims of our present thesis were to

1. investigate the effect of metabolic syndrome on cardiac gene expression pattern in male ZDF rats which is a well-known model of metabolic syndrome.

2. examine the influence of another severe metabolic state, the prolonged uremia (30 weeks) on the severity of

a. myocardial I/R injury and

b. the infarct size limiting effect of IPre.

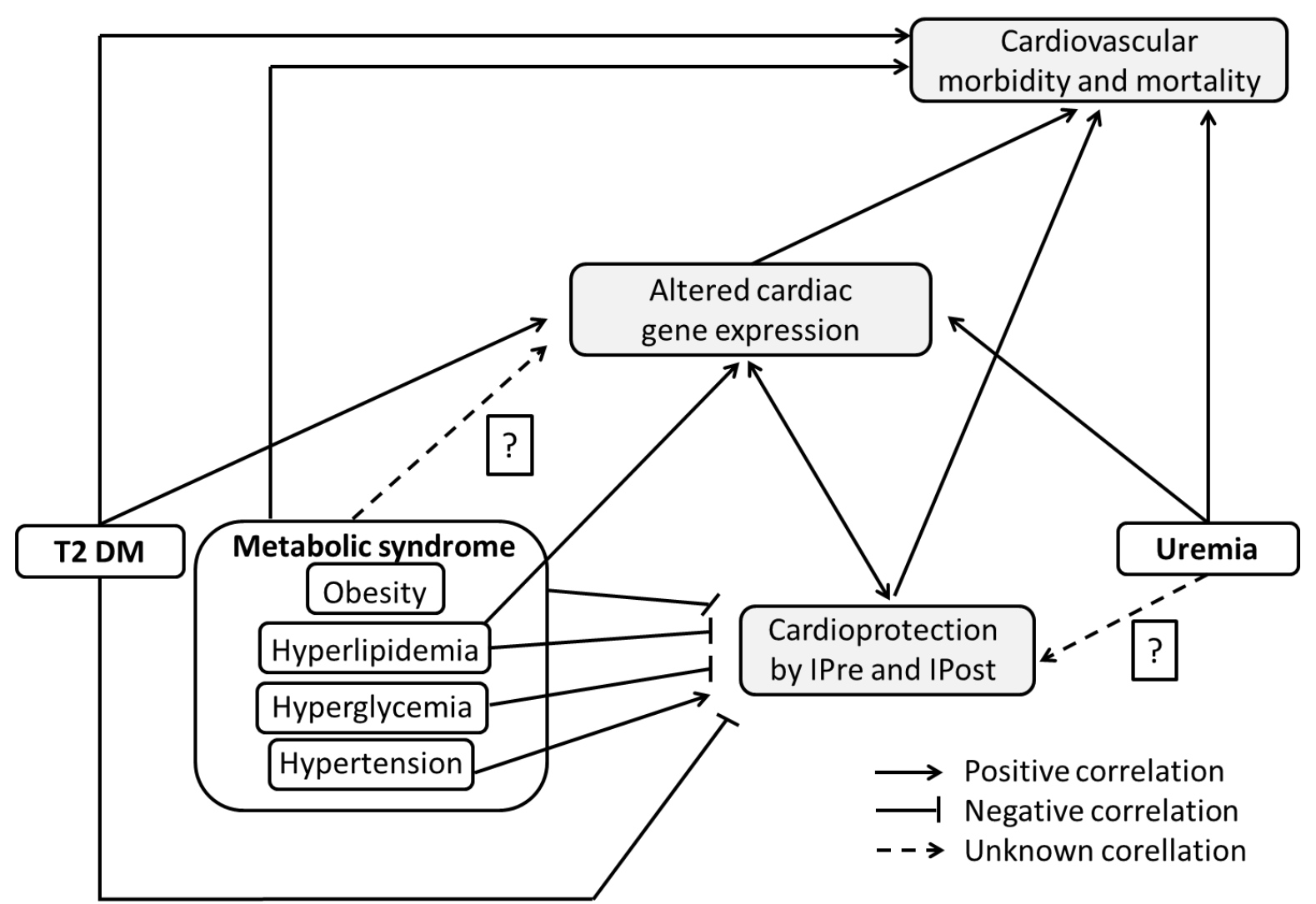

5. Figure Effects of comorbidities on cardiovascular morbidity and mortality, cardiac gene expression and cardioprotection conferred by IPre and IPost. 


\section{MATERIALS AND METHODS}

These investigations conformed to the National Institutes of Health Guide for the Care and Use of Laboratory Animals (NIH Pub. No. 85-23, Revised 1996) and was approved by the Animal Research Ethics Committee of the University of Szeged.

\subsection{Experimental setup for investigation of cardiac gene expression pattern in metabolic syndrome}

Male Zucker Diabetic Fatty (ZDF/Gmi-fa/fa) rats and their lean controls were obtained from Charles River Laboratories at the age of 5 weeks and were housed at $22 \pm 2^{\circ} \mathrm{C}$ with a 12 :12-h lightdark cycle. The rats received Purina 5008 chow and water ad libitum for 20 weeks after their arrival. The Zucker diabetic fatty rat with a point mutation in the leptin receptor is a recognized model of obesity, hyperlipidemia, hyperglycemia and hypertension [90-92]. In the present study, only male rats were used, since female ZDF rats are less prone to the development of metabolic syndrome [93, 94]. Male ZDF rats develop an age-dependent obese and hyperglycemic phenotype at 10-12 weeks of age accompanied by a metabolic state of obesity, dyslipidemia, hyperinsulinemia and insulin resistance [95, 96] which develops to a hyperglycemic insulin-deficient state [95]. The metabolic features manifested in this animal model are in many ways similar to the pathogenesis of metabolic syndrome in humans $[95,97]$. Therefore, the ZDF rat is an ideal model for investigation of cardiac gene expression pattern changes related to human metabolic syndrome.

Body weight, serum glucose, insulin, cholesterol and triglyceride levels and homeostasis model assessment-estimated insulin resistance (HOMA-IR) were determined at 6, 16 and 25 weeks of age in order to monitor the basic parameters of glucose and lipid metabolism and insulin resistance in ZDF and lean rats (Figure 6). Oral glucose tolerance test (OGTT) was performed at week 16 and 25 in order to further characterize glucose homeostasis in ZDF and lean rats (Figure 6). At 25 weeks of age, rats were anaesthetized using diethyl ether. Hearts and pancreata were isolated (Figure 6), and then hearts were perfused according to Langendorff as described earlier [98]. After 10 min perfusion, ventricular tissue was frozen and stored at $-80^{\circ} \mathrm{C}$ until DNA microarray investigation and gene expression analysis (Figure 6). To validate the well-known nitrative stress-inducing effect of metabolic syndrome on the heart, frozen ventricular tissue was used for determination of cardiac free 3-nitrotyrosine level (Figure 6). 


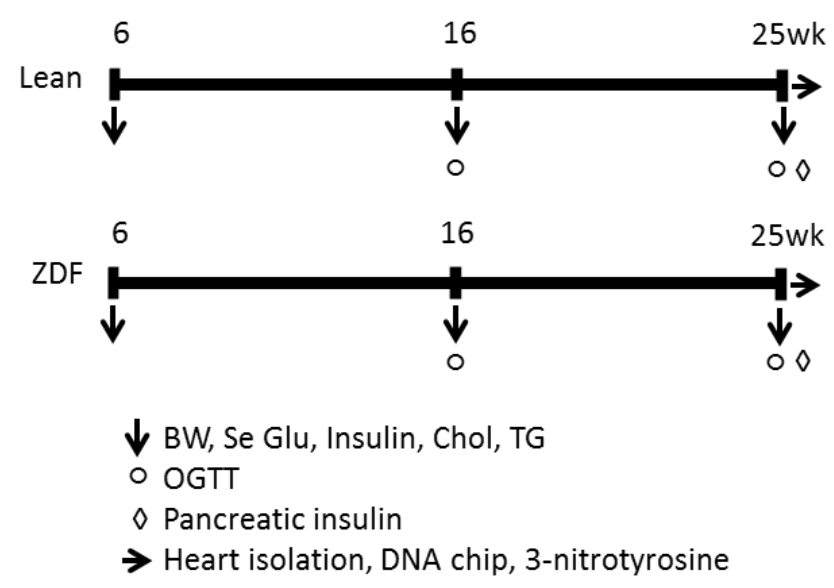

6. Figure Experimental protocol. Male ZDF rats and their lean controls were followed up from 6 weeks of age until 25 weeks of age. Body weight (BW), serum glucose (Se Glu), insulin (Insulin), cholesterol (Chol) and triglyceride (TG) levels were determined at week 6, 16 and 25. Oral glucose tolerance test (OGTT) was performed at week 16 and 25 . At week 25, hearts and pancreata were isolated. Pancreata were frozen and homogenized to measure pancreatic insulin levels. Hearts were perfused according to Langendorff for 10 minutes using Krebs Henseleit buffer. Then ventricular tissue was frozen and used for DNA microarray analysis and cardiac free 3-nitrotyrosine level measurements.

\section{$\underline{\text { Serum glucose level measurements and OGTT }}$}

Rats were fasted overnight (12 h) prior to serum glucose level measurements (week 6, 16 and 25) and OGTTs (week16 and 25) to verify the development of hyperglycemia as a diagnostic criterion of metabolic syndrome. Blood samples were collected from the v. saphena. Blood glucose levels were measured using AccuCheck blood glucose monitoring systems (Roche Diagnostics Corporation, USA, Indianapolis). In case of OGTT, after the measurement of baseline glucose concentrations, a standard dose of glucose $(1.5 \mathrm{~g} / \mathrm{kg}$ body weight) was administered per os via gavage and plasma glucose levels were checked 30,60 and 120 minutes later. Area under the curve values for OGTT was also calculated.

\section{Measurement of serum and pancreatic insulin levels}

Serum and pancreatic insulin levels were measured by an enzyme linked immunosorbent assay (Mercodia, Ultrasensitive Rat Insulin ELISA) in order to verify the development of hyperinsulinemia and decreased pancreatic insulin content as a consequence of beta cell damage in metabolic syndrome. Insulin ELISA was carried out according to the instructions of the manufacturer from either sera or homogenized pancreatic tissue samples of ZDF and lean control rats. Sera were centrifuged $\left(4500 \mathrm{rpm}\right.$ for $10 \mathrm{~min}$ at $\left.4{ }^{\circ} \mathrm{C}\right)$ and kept at $-20^{\circ} \mathrm{C}$ until further investigation. Pancreata were removed, trimmed free of adipose tissue and weighed. Pancreata were 
homogenized in $6 \mathrm{ml}$ cold acidified-ethanol $(0.7 \mathrm{M} \mathrm{HCl}$ : ethanol $(1: 3 \mathrm{v} / \mathrm{v})$ with an Ultraturrax homogenizer and were kept at $4^{\circ} \mathrm{C}$ for $24 \mathrm{~h}$. Then pancreas homogenates were centrifuged $(900 \mathrm{~g}$ for $15 \mathrm{~min}$ at $4^{\circ} \mathrm{C}$ ), and the supernatants were stored at $4^{\circ} \mathrm{C}$. The pellet was extracted again with 3 $\mathrm{ml}$ acidified ethanol for $24 \mathrm{~h}$ at $4^{\circ} \mathrm{C}$. The supernatant obtained after centrifugation was pooled with the previous one and kept at $-20^{\circ} \mathrm{C}$ until assayed.

\section{$\underline{H O M A-I R \text { index }}$}

To estimate insulin resistance in ZDF or lean rats the widely used HOMA-IR index was calculated [99-101] by multiplying fasting plasma insulin $(\mu \mathrm{IU} / \mathrm{mL})$ with fasting plasma glucose $(\mathrm{mmol} / \mathrm{L})$, then dividing by the constant 22.5 , i.e. HOMA-IR $=$ (fasting plasma insulin concentration $\times$ fasting plasma glucose concentration)/22.5.

\section{Measurement of serum lipid levels}

Serum cholesterol and triglyceride levels were measured at week 6, 16 and 25 using a test kit supplied by Diagnosticum Zrt. (Budapest, Hungary) as described previously [11] in order to follow up the development of hyperlipidemia which is a diagnostic criterion of metabolic syndrome.

\section{Cardiac 3-nitrotyrosine level}

To verify the well-known increased oxidative/nitrative stress [102, 103] in the heart in metabolic syndrome, cardiac free 3-nitrotyrosine level, an indirect marker of nitrative stress, was measured by ELISA (Cayman Chemical) from ZDF and lean control heart tissue samples at week 25 as described earlier [11]. Briefly, supernatants of ventricular tissue homogenates were incubated overnight with anti-nitrotyrosine rabbit $\mathrm{IgG}$ specific to free 3-nitrotyrosine and nitrotyrosine acetylcholinesterase tracer in precoated (mouse anti-rabbit $\mathrm{IgG}$ ) microplates followed by development with Ellman's reagent. Free nitrotyrosine content was normalized to protein content of the cardiac homogenate and expressed as nanograms per milligram protein [11]. 
RNA preparation, DNA microarray analysis and quantitative real-time $P C R(q R T-P C R)$

RNA preparation, DNA microarray analysis and qRT-PCR were performed in the Department of Functional Genomics, Biological Research Center, Szeged, Hungary as described in the article related to the subject of the thesis [104].

\section{$\underline{\text { Statistical analysis }}$}

For characterization of the ZDF model and lean controls, all values (body weight, serum glucose, insulin, HOMA-IR, cholesterol and triglyceride levels, pancreas weight and insulin content, myocardial 3-nitrotyrosine levels and microarray experiments) are presented as mean $\pm \mathrm{SEM}$. Significance between groups was determined with unpaired t-test. $\mathrm{P}<0.05$ was accepted as a statistically significant difference. Gene expression ratio with p- value $<0.05$ and $\log 2$ ratio $<-0.75$ or $\log 2$ ratio $>0.75$ ( 1.7 fold change) were considered as repression or overexpression respectively in gene activity.

\subsection{Experimental setup for examination of the influence of prolonged uremia on IPre}

Adult male Wistar rats were used in the study. Animals were housed in pairs in individually ventilated cages (Sealsafe IVC system, Italy) and were maintained in a temperature controlled room with a 12:12 h light: dark cycles throughout the study. Standard rat chow and tap water were supplied ad libitum. Drinking water contained $1 \mathrm{mg} / 100 \mathrm{~g}$ body weight iron (II) sulfate to attenuate the development of severe anemia.

Experimental prolonged uremia was induced by partial (5/6) nephrectomy. Animals underwent sham operation or partial nephrectomy in two phases (Figure 7) [105]. There was no difference in mortality between sham operated and partially nephrectomized groups. At week 29, cardiac function was assessed by transthoracic echocardiographic examination (Figure 7). At week 29, a group of animals were placed for 24 hours in metabolic cages in order to estimate creatinine clearance and to measure urine creatinine and protein levels (Figure 7). At week 30, rats were anesthetized, hearts were isolated and perfused ex vivo by oxygenated Krebs-Henseleit solution according to Langendorff as described previously [106] (Figure 7). Immediately after excision of the heart, blood was collected from the thoracic cavity to measure plasma uric acid, carbamide and creatinine levels in order to verify the development of uremia. Some plasma was used for determination of angiotensin II as an indirect marker of hypertension and hypertrophy [107-111] and nitrotyrosine as a marker of systemic nitrative stress [98]. To assess the cardioprotective effect 
of IPre in the hearts of uremic and sham operated animals, the perfused hearts were subjected to I/R with or without preconditioning protocol (Figure 7). At the end of the appropriate perfusion protocol, the coronary artery was reoccluded and the area at risk and the infarcted area were delineated using an Evans blue/triphenyltetrazolium chloride double staining method [112].

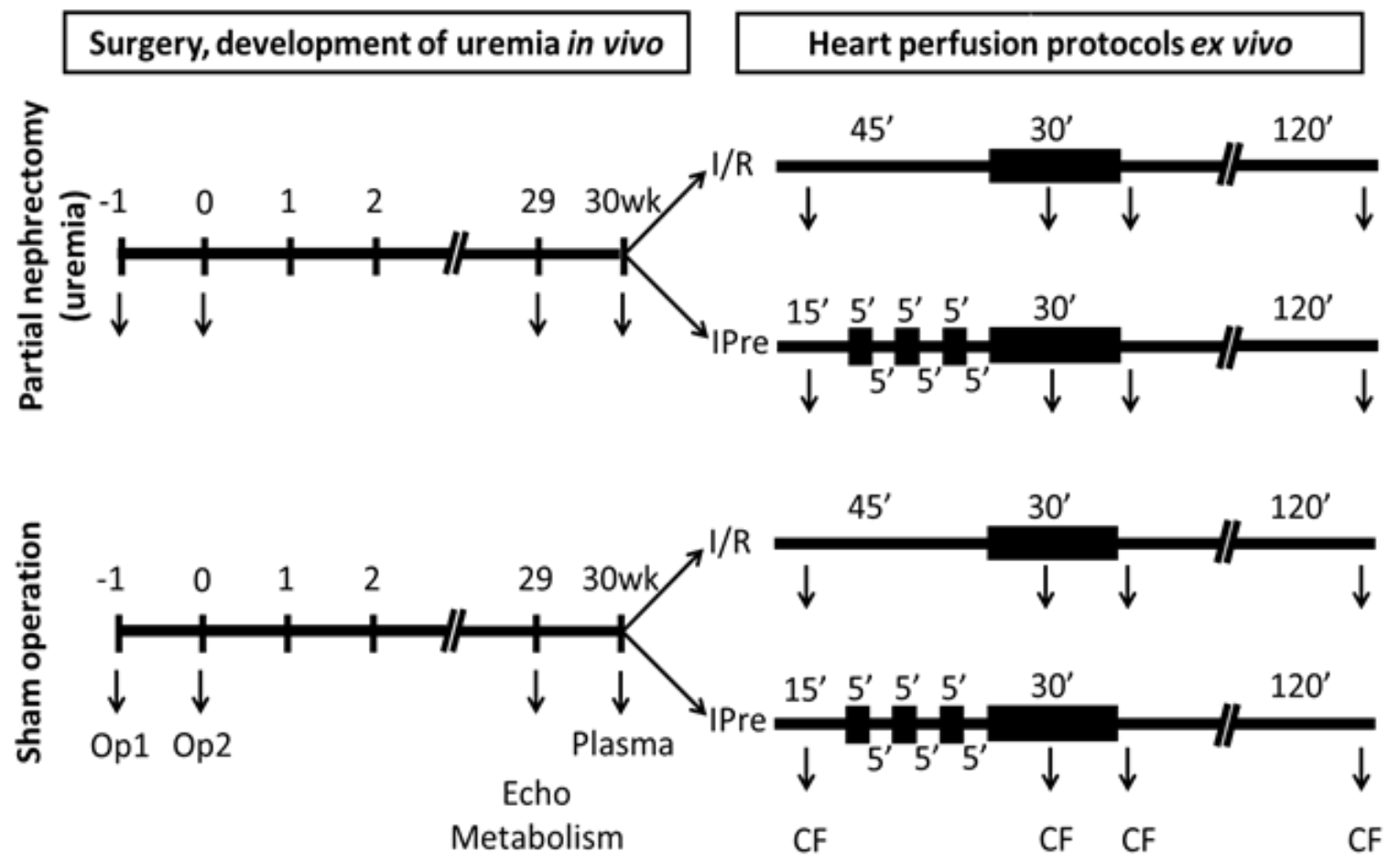

7. Figure Wistar rats underwent sham operation or partial nephrectomy in two phases. First, $2 / 3$ of the left kidney was ligated and excised (Op1). One week later, the right kidney was removed (Op2). Corresponding time-matched sham operations were performed in the sham group. At week 29, cardiac function was assessed by transthoracic echocardiographic examination (Echo). In this week the animals (12-12 in uremia and sham groups) were placed for 24 hours in metabolic cage (Metabolism) to determine urine creatinine and protein levels. At week 30, rats were anesthetized and blood was collected from thoracic cavity to measure plasma carbamide and creatinine levels (Plasma). Hearts were then isolated and perfused according to Langendorff. After 15 minutes of aerobic perfusion, hearts were subjected to either preconditioning induced by three intermittent periods of $5 \mathrm{~min}$ ischemia/reperfusion cycles or a timematched $(30 \mathrm{~min})$ aerobic perfusion, both followed by a 30-min coronary occlusion and 2-hour reperfusion ( $\mathrm{n}=6-9$ in each group). Coronary flow (CF) was measured 10 minutes after the start of perfusion, in the 15th minute of ischemia, in the first 5 minutes of reperfusion and at the end of the reperfusion.

\section{$\underline{\text { Partial nephrectomy }}$}

Anesthesia was induced by intraperitoneal injection of sodium pentobarbital (Euthasol, $50 \mathrm{mg} / \mathrm{kg}$, Produlab Pharma b.v., Raamsdonksveer, The Netherlands). After depilation and a ventral midline incision in the abdominal wall, the intestines were retracted laterally to expose the animal's left kidney. The kidney was freed from the perirenal adipose tissue and renal capsule. Two pieces of sutures (5-0 Mersilk, Ethicon, Sommerville, NJ, USA) were placed around both poles of the kidney approximately at their $1 / 3$ position. The sutures were gently ligated around the kidney. The $1 / 3$ 
kidney on both ends were excised right beyond the ligatures. The abdominal incision was closed with running sutures. One week after the first operation, animals were anesthetized and prepared as described above [105]. The right kidney was freed from the surrounding adipose tissue and renal capsule, and then it was pulled out of the incision gently. The adrenal gland, which is attached loosely to the anterior pole of the kidney, was gently freed and was placed back into the abdominal cavity. The renal blood vessels and the ureter were ligated and the right kidney was removed [113]. Then the incision was closed with running sutures and povidone iodide was applied on the surface of the skin. After operation, animals were placed on a warm heat-pad until they become conscious again. As a post-operative medication, $0.3 \mathrm{mg} / \mathrm{kg}$ nalbuphine hydrochloride (Nalbuphine 10 mg/mL, TEVA, Debrecen, Hungary) was administered subcutaneously. Antibiotics (Enroxil, 75 $\mathrm{mg} / \mathrm{L}$ (Krka, Slovenia) and analgesics (10 mg/L of nalbuphine hydrochloride, Nalbuphine, TEVA, Debrecen, Hungary) were administered in tap water for 2 days after both surgeries.

\section{Transthoracic echocardiography}

Cardiac function was assessed by transthoracic echocardiographic examination 29 weeks after the second surgery. Echocardiography was performed as described previously [114]. The rats were anesthetized with sodium pentobarbital (Euthasol, $40 \mathrm{mg} / \mathrm{kg}$ body weight, ip.), the chest was shaved and the animal was placed in supine position onto a heating pad. Two-dimensional, M-mode and Doppler echocardiographic examinations were performed in accordance with the criteria of the American Society of Echocardiography with a Vivid 7 Dimension ultrasound system (General Electric Medical Systems, USA ) using a phased array 5.5-12 MHz transducer (10S probe). Data of three consecutive heart cycles were analyzed (EchoPac Dimension software, General Electric Medical Systems, USA) by an experienced investigator in a blinded manner. The mean values of three measurements were calculated and used for statistical evaluation. Systolic and diastolic wall thickness parameters were obtained from parasternal short-axis view at the level of the papillary muscles and long-axis view at the level of the mitral valve. The left ventricle diameters were measured by means of M-mode echocardiography from long-axis and short-axis views between the endocardial borders. Functional parameters including left ventricular end-diastolic volume, left ventricular end-systolic volume, and ejection fraction were calculated on four chamber view images. Diastolic function was assessed using pulse-wave Doppler across the mitral valve from the apical four chamber view. Early (E) and atrial (A) flow velocity as well as mitral valve deceleration time and isovolumic relaxation time provide an indication of diastolic function. 
$\underline{\text { Urine creatinine and total protein levels }}$

At week 29, the animals were placed in a metabolic cage (Tecniplast, Italy) for 24 hours in order to collect urine for the measurement of urine creatinine and protein levels to verify the development of advanced uremia. Urine creatinine and urine protein levels were measured by standard laboratory methods as described previously by others $[115,116]$.

\section{Plasma carbamide and creatinine levels}

Blood was collected from the thoracic cavity after isolation of the heart to measure plasma carbamide and creatinine levels in order to verify the development of chronic uremia at week 30. Plasma carbamide and creatinine levels were measured in triplicate, using commercially available colorimetric assay kits (Diagnosticum Ltd., Budapest, Hungary) applying enzymatic determinations adapted to 96-well plates.

\section{Creatinine clearance}

Creatinine clearance, an indicator of renal function, was calculated according to the standard formula (urine creatinine concentration $[\mu \mathrm{M}] \times$ urine volume for $24 \mathrm{hr}[\mathrm{mL}]) /($ plasma creatinine concentration $[\mu \mathrm{M}]$ X $24 \times 60 \mathrm{~min})$.

\section{Hematocrit and hemoglobin level}

Hematocrit and hemoglobin were measured from whole blood by means of a blood gas analyzer (Radiometer ABL 77, Radiometer Medical, Bronshoj, Denmark) at week 30 in order to verify the development of renal anemia.

\section{Ex vivo cardiac perfusions and infarct size determination}

At week 30, rats were anesthetized and hearts were isolated and perfused at $37^{\circ} \mathrm{C}$ according to Langendorff with oxygenated Krebs-Henseleit buffer as previously described [63, 106]. Hearts from the sham-operated and the uremic groups were further subdivided into two subgroups ( $\mathrm{n}=6-9$ ) and subjected to either a non-conditioning or a preconditioning perfusion protocol, respectively (Figure 7). Non-conditioned hearts were subjected to time-matched aerobic perfusion followed by test ischemia-reperfusion induced by a 30-min occlusion of the left descending coronary artery. 
Preconditioned hearts were subjected to 3 intermittent periods of 5 -min I/R followed by test I/R. A 3-0 silk suture was placed around the origin of the left descending coronary artery and passed through a plastic tube to form a snare. After stabilization of the heart, coronary occlusion was induced by pulling the ends of the suture taut and clamping the snare onto the epicardial surface. Reperfusion was achieved by releasing the snare as previously described [106]. Heart rate and coronary flow were monitored throughout the perfusion protocol (Figure 7). At the end of the 2 hour reperfusion protocol, the coronary artery was reoccluded and $5 \mathrm{~mL}$ of $0.1 \%$ Evans blue dye (Merk, Germany) was injected into the aorta to delineate the area at risk zone. Stained hearts were weighed, frozen, sliced and incubated at $37^{\circ} \mathrm{C}$ in $1 \%$ triphenyl-tetrazolium chloride (Sigma Aldrich, Germany) to delineate infarcted tissue. Slices were then fixed and quantified by planimetry using Infarctsize 2.5 software ${ }^{\mathrm{TM}}$ (Pharmahungary, Szeged, Hungary) [106]. Infarct size was expressed as a percentage of the area at risk zone [112]. The area at risk was calculated as a percentage of total ventricular area [112].

\section{Plasma angiotensin II level}

Plasma angiotensin II level was determined as a marker of hypertension and left ventricular hypertrophy. The level of angiotensin II in blood plasma of uremic and sham operated rats was determined with ELISA kits that recognize rat peptides (Phoenix Pharmaceuticals) in accordance with the manufacturer's instructions.

\section{Plasma 3-Nitrotyrosine level}

Plasma 3-nitrotyrosine level was determined as a marker of systemic nitrosative stress. Free 3nitrotyrosine level was measured by ELISA (Cayman Chemical) as described earlier [97] from sham and uremic plasma samples taken at week 30. Briefly, plasma samples were deproteinized by the addition of ice-cold ethanol. After centrifugation, the supernatants were evaporated in nitrogen flow, dissolved in phosphate buffer, and incubated overnight with anti-nitrotyrosine rabbit IgG and nitrotyrosine acetylcholinesterase tracer in precoated (mouse anti-rabbit IgG) microplates, followed by development with Ellman's reagent [98]. 


\section{Plasma uric acid level}

Plasma uric acid level was measured in order to further characterize our uremic model. Plasma uric acid level was measured in duplicate, using a commercially available colorimetric assay kit (Diagnosticum Ltd., Budapest, Hungary) according to the manufacturer's instructions.

\section{$\underline{\text { Statistical analysis }}$}

All values are presented as mean \pm SEM. Two-way ANOVA was used to determine the effect of uremia or preconditioning on infarct size, area at risk, and coronary flow. Then to analyze the effect of preconditioning on infarct size within sham as well as uremic groups an unpaired t-test was applied. All other parameters were analyzed by unpaired t-tests comparing data in the uremic groups to sham controls. $\mathrm{P}<0.05$ was accepted as a statistically significant difference. 


\section{RESULTS}

\subsection{Characterization of metabolic syndrome in ZDF rats}

In order to verify the development of metabolic syndrome in male ZDF rats, concentrations of several plasma metabolites and body weight were measured at week 6, 16 and 25 (Figure 8). ZDF rats showed a significant rise in serum fasting glucose level starting from week 16 as compared to lean controls (Figure 8A). Parallel with hyperglycemia, serum insulin levels were significantly increased in ZDF rats compared to lean ones during the 25 weeks showing the presence of hyperinsulinemia in ZDF animals (Figure 8B). However, serum insulin concentration in ZDF rats was significantly lower at week 25 as compared to serum insulin level measured at week 16 indicating beta-cell damage. HOMA-IR was significantly higher at week 6, 16 and 25 in ZDF rats when compared to lean controls showing insulin resistance in ZDF animals (Figure 8C). Body weight increased throughout the study and was significantly higher in ZDF animals compared to lean ones showing obesity (Figure 8D). Both serum cholesterol and triglyceride levels were significantly increased in ZDF rats as compared to lean ones throughout the study duration representing hyperlipidemia (Figure $8 \mathrm{E}$ and $8 \mathrm{~F}$ ).

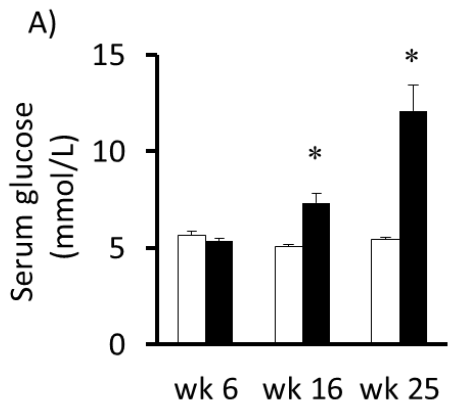

D)

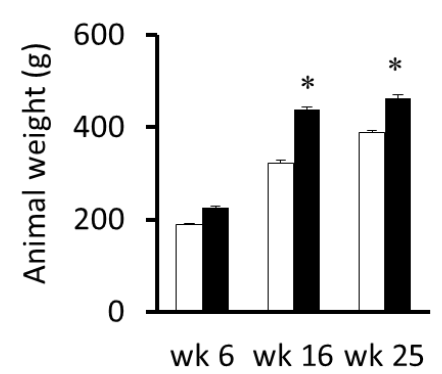

B)

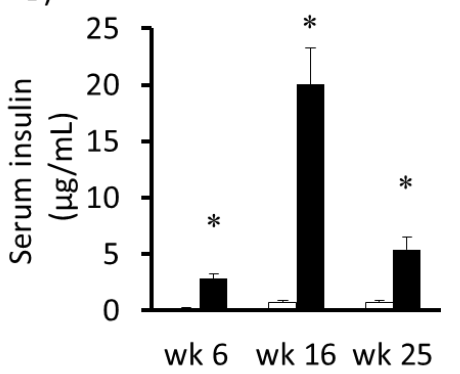

E)

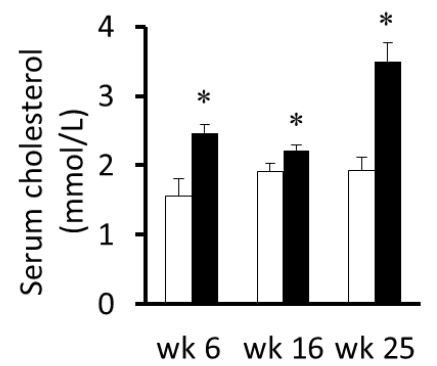

C)

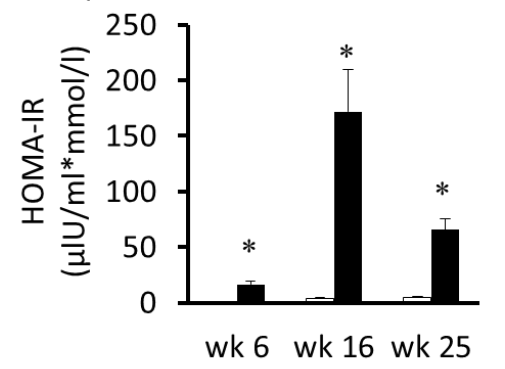

F)

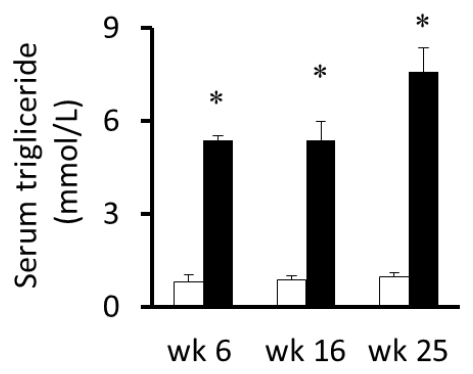

8. Figure Serum glucose (A, $n=6-8)$ and insulin levels (B, $n=6-8)$, HOMA-IR (C), animal weight (D), serum cholesterol $(\mathrm{E}, \mathrm{n}=6-8)$ and triglyceride $(\mathrm{F}, \mathrm{n}=6-8)$ shown at week 6,16 and 25 in both lean and ZDF rats. White bars: Lean; black bars: ZDF. Values are means \pm SEM, ${ }^{*} \mathrm{p}<0.05$. 
Oral glucose tolerance test (OGTT) was performed at week 16 and 25 in order to verify the development of impaired glucose tolerance in ZDF rats. Glucose levels during OGTTs were markedly increased in ZDF rats in every time point of blood glucose measurements both at weeks 16 and 25 (Figure 9A-9B). Area under the curve (AUC) of blood glucose concentration during OGTTs was significantly elevated in ZDF rats at both weeks 16 and 25 representing impaired glucose tolerance (Figure 9C-9D).
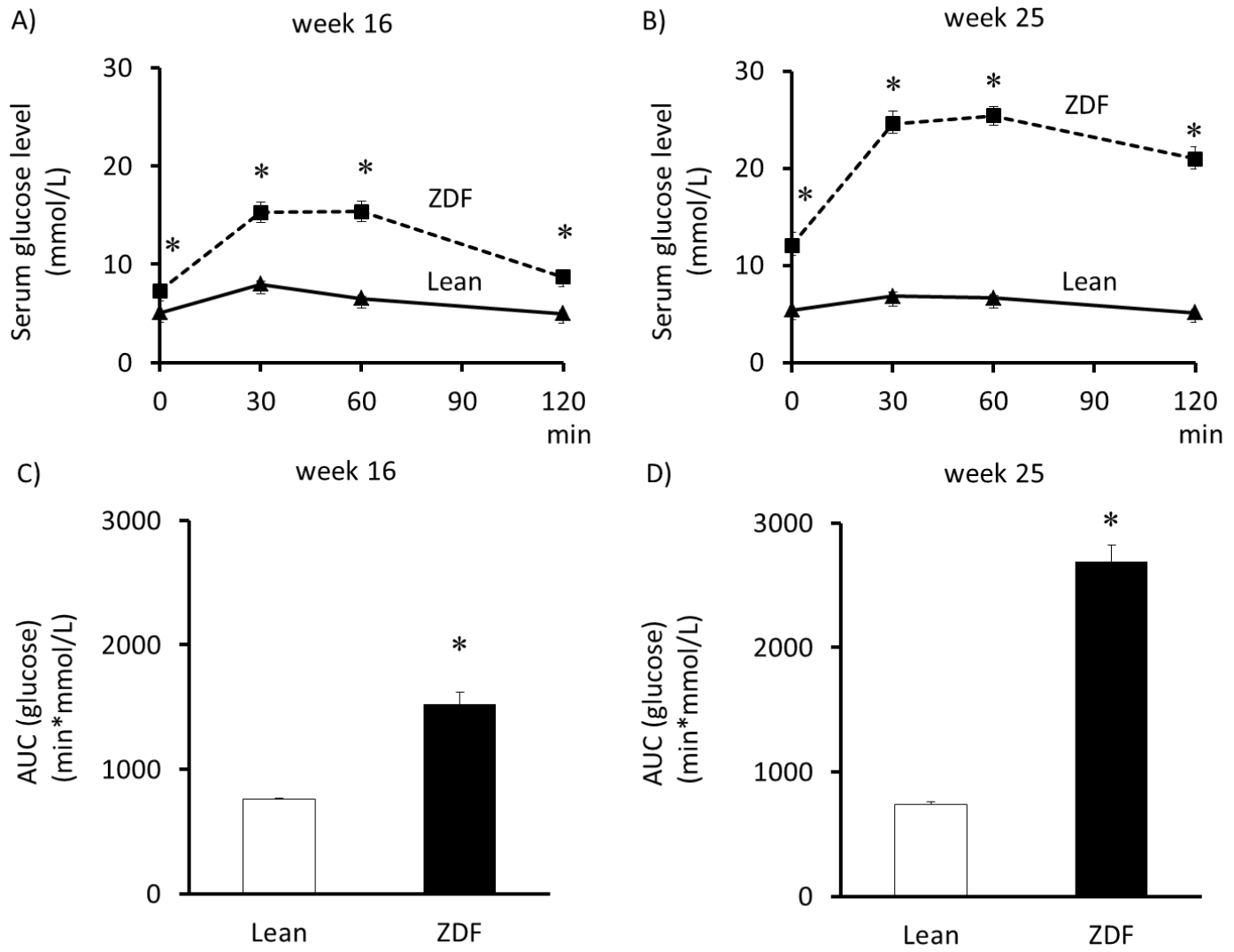

9. Figure Glucose levels during OGTT. Glucose levels during OGTT at week 16 (A) and week 25 (B) in both lean and ZDF rats. Solid line: Lean; dashed line: ZDF. Area under the curve (AUC) of blood glucose concentration during OGTT at week 16 (C) and week 25 (D) in both lean and ZDF rats. Values are means \pm SEM, $n=6-8, * p<0.05$.

Pancreas weight and pancreatic insulin content were measured at the end of the experiment in order to investigate the severity of diabetes mellitus in ZDF rats. Pancreas weight and pancreatic insulin concentration were significantly decreased in ZDF rats at week 25 showing impaired pancreatic function (Figure 10A and 10B). 
A)

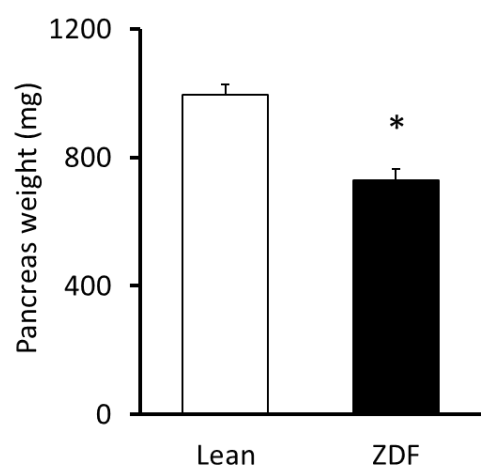

B)

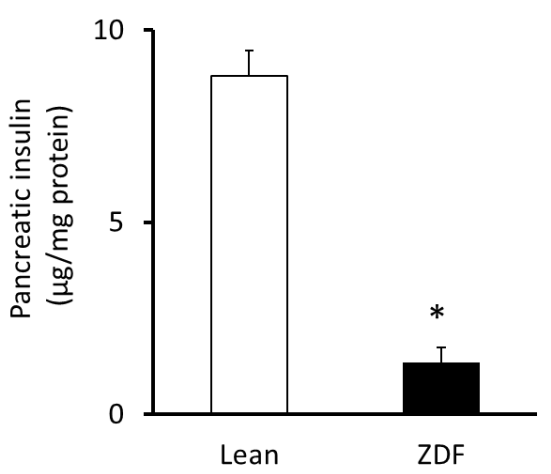

10. Figure Pancreas weight and pancreas insulin content. Pancreas weight (A) at week 25 and pancreatic insulin content (B) in both lean and ZDF rats. Values are means \pm SEM, $n=6-8,{ }^{*} \mathrm{p}<0.05$.

In order to verify the increased oxidative/nitrative stress in ZDF animals, myocardial 3nitrotyrosine levels were determined in both groups at week 25. A marker molecule of peroxynitrite, 3-nitrotyrosine level was significantly elevated in the heart of ZDF animals showing increased cardiac oxidative/nitrative stress (Figure 11).

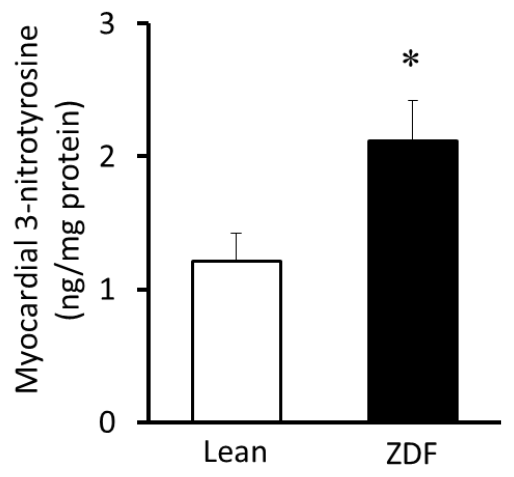

11. Figure Myocardial 3-nitrotyrosine level. Myocardial 3-nitrotyrosine level at week 25 in both lean and ZDF rats. Values are means \pm SEM, ${ }^{*} \mathrm{p}<0.05$.

\subsection{Cardiac gene expression profile in metabolic syndrome measured using cDNA microarrays and by $q R T-P C R$}

In order to determine alterations in cardiac gene expression profile, a DNA microarray was carried out. Among the 14921 genes surveyed, 10244 genes were expressed on the cDNA microarray, and 85 genes whose expression was $>\sim 1.7$-fold up- or down-regulated (log2 ratio $<-0.75$ or $\log 2$ ratio $>0.75$ ) in hearts of ZDF rats relative to levels of lean control rats showed significant change in expression. According to our results, 49 genes showed down-regulation (Table 1) and 36 genes showed up-regulation in hearts of ZDF rats (Table 2). Many of these differentially expressed genes are known to be involved in multiple cell functions, including metabolism, stress response, signal transduction, regulation of transcription, cytoskeletal structure, cell adhesion, membrane proteins, receptors and others. 
1. Table Down-regulated genes on DNA microarray in the heart of ZDF rats

\begin{tabular}{|c|c|c|c|c|c|}
\hline Gene function & Description [Gene symbol] & $\begin{array}{l}\mathrm{AVE} \\
\log _{2} \\
\end{array}$ & SD & $\begin{array}{c}\mathbf{P} \\
\text { value }\end{array}$ & $\begin{array}{c}\text { Fold } \\
\text { change }\end{array}$ \\
\hline \multirow{5}{*}{ Metabolism } & Argininosuccinate synthetase [Ass] & -1.33 & 0.06 & 0.001 & -2.51 \\
\hline & Glycine C-acetyltransferase (2-amino-3-ketobutyrate-coenzyme A ligase) [Gcat] & -1.15 & 0.34 & 0.006 & -2.22 \\
\hline & 3-hydroxybutyrate dehydrogenase, type 1 [Bdh1] & -1.14 & 0.44 & 0.014 & -2.21 \\
\hline & Thymidylate synthase [Tyms] & -0.92 & 0.08 & 0.041 & -1.89 \\
\hline & Dicarbonyl L-xylulose reductase [Dcxr] & -0.76 & 0.30 & 0.015 & -1.70 \\
\hline \multirow{3}{*}{ Stress response } & Heat shock 70kd protein 1A [Hspa1a] & -1.84 & 0.48 & 0.005 & -3.59 \\
\hline & $\begin{array}{l}\text { Similar to } 60 \mathrm{kDa} \text { heat shock protein, mitochondrial precursor (Hsp60) } 60 \mathrm{kda} \\
\text { heat shock protein [LOC294396Hspa1a] }\end{array}$ & -1.64 & 0.24 & 0.057 & -3.11 \\
\hline & Interleukin 18 [il18] & -1.38 & 0.02 & 0.007 & -2.60 \\
\hline \multirow{9}{*}{$\begin{array}{l}\text { Signal } \\
\text { transduction, } \\
\text { regulation of } \\
\text { transcription }\end{array}$} & Hairy/anhancer-of-split-related with YRPW motif2 [Hey2] & -1.40 & 0.15 & 0.049 & -2.64 \\
\hline & Aryl hydrocarbon receptor nuclear translocator-like [Adra1d] & -1.33 & 0.07 & 0.001 & -2.52 \\
\hline & Activating transcription factor 3 [Atf3] & -1.03 & 0.26 & 0.004 & -2.05 \\
\hline & RAB7, member RAS oncogene family [Rab7] & -0.98 & 0.48 & 0.026 & -1.97 \\
\hline & B-cell leukemia/lymphoma 2 related protein A1 [Bcl2a1] & -0.89 & 0.04 & 0.019 & -1.85 \\
\hline & Sushi, nidogen and EGF-like domains 1 [Sned1] & -0.87 & 0.51 & 0.041 & -1.83 \\
\hline & Spermatid perinuclear RNA binding protein [Strbp] & -0.87 & 0.25 & 0.027 & -1.82 \\
\hline & TRAF3 interacting protein 3 [Traf3ip3] & -0.85 & 0.25 & 0.028 & -1.81 \\
\hline & Putative bhlh transcription factor (Fragment) [Ascl3] & -0.79 & 0.15 & 0.013 & -1.73 \\
\hline \multirow{6}{*}{$\begin{array}{l}\text { Membrane } \\
\text { proteins, receptors }\end{array}$} & ATPase, $\left(\mathrm{Na}^{+}\right) / \mathrm{K}^{+}$transporting, beta 4 polypeptide [Atp1b4] & -1.38 & 0.13 & 0.003 & -2.60 \\
\hline & Nerve growth factor receptor (TNFR superfamily, member 16) [Ngfr] & -0.91 & 0.05 & 0.027 & -1.88 \\
\hline & Cholinergic receptor, nicotinic, gamma polypeptide [Chrng] & -0.99 & 0.39 & 0.048 & -1.98 \\
\hline & G protein-coupled receptor 37 [Gpr37] & -0.87 & 0.06 & 0.030 & -1.82 \\
\hline & Adrenergic receptor, alpha 1d [Adra1d] & -0.79 & 0.43 & 0.036 & -1.73 \\
\hline & Neurotensin receptor 2 [Ntsr2] & -0.77 & 0.32 & 0.018 & -1.70 \\
\hline \multirow{3}{*}{$\begin{array}{l}\text { Structural protein, } \\
\text { cell adhesion }\end{array}$} & Myosin IXa [myo9a] & -1.26 & 0.01 & 0.002 & -2.40 \\
\hline & ST8 alpha-N-acetyl-neuraminide alpha-2,8-sialyltransferase 4 [St8sia4] & -1.00 & 0.07 & 0.032 & -2.01 \\
\hline & Similar to collagen, type XXIV, alpha 1 [RGD1565539_predicted] & -1.16 & 0.03 & 0.011 & -2.24 \\
\hline \multirow{25}{*}{ Others } & ADAM metallopeptidase with thrombospondin type 1 motif, 1 [Adamts1] & -2.84 & 0.90 & $\begin{array}{c}0.123 \\
0\end{array}$ & -7.16 \\
\hline & Similar to tatd DNAase domain containing 1 [RGD1566244_predicted] & -1.86 & 0.16 & 0.038 & -3.63 \\
\hline & Aryl hydrocarbon receptor nuclear translocator-like protein [Arntl] & -1.33 & 0.67 & 0.001 & -2.52 \\
\hline & $\begin{array}{l}\text { TAF13 RNA polymerase II, TATA box binding protein (TBP)-associated factor } \\
\text { [Taf13_predicted] }\end{array}$ & -1.22 & 0.11 & 0.039 & -2.34 \\
\hline & G protein-coupled receptor 107 [Gpr107_predicted] & -1.18 & 0.02 & 0.007 & -2.26 \\
\hline & CDK5 regulatory subunit associated protein 1-like 1 [Cdkal1_predicted] & -0.92 & 0.06 & 0.041 & -1.89 \\
\hline & $\begin{array}{l}\text { Similar to chondroitin beta1,4 N-acetylgalactosaminyltransferase } 2 \\
\text { [RGD1563660_predicted] }\end{array}$ & -0.91 & 0.03 & 0.017 & -1.87 \\
\hline & S100 calcium binding protein A3 [S100a3] & -0.90 & 0.06 & 0.028 & -1.87 \\
\hline & Similar to TPR repeat-containing protein KIAA1043 [LOC304558] & -0.89 & 0.08 & 0.003 & -1.85 \\
\hline & Similar to Ten-m4 [Odz4_predicted] & -0.88 & 0.34 & 0.047 & -1.84 \\
\hline & Kallikrein 14 [Klk14_predicted] & -0.88 & 0.09 & 0.047 & -1.84 \\
\hline & Mucin 19 [Muc19_predicted] & -0.84 & 0.33 & 0.048 & 1.79 \\
\hline & Copine family member IX [Cpne9] & -0.84 & 0.11 & 0.006 & -1.79 \\
\hline & Suppressor of Ty 16 homolog (S. Cerevisiae) [Supt16h_predicted] & -0.81 & 1.57 & 0.021 & -1.75 \\
\hline & Heterogeneous nuclear ribonucleoprotein L-like [Hnrpll_predicted] & -0.81 & 0.01 & 0.008 & -1.75 \\
\hline & cDNA clone UI-R-BJ0p-afn-b-03-0-UI 3' [Sln] & -0.81 & 0.30 & 0.013 & -1.75 \\
\hline & Discs, large homolog 4 (Drosophila) [Dlgh4] & -0.80 & 0.23 & 0.026 & -1.75 \\
\hline & $\begin{array}{l}\text { Similar to chondroitin beta1,4 N-acetylgalactosaminyltransferase } \\
\text { [RGD1307618_predicted] }\end{array}$ & -0.80 & 0.25 & 0.031 & -1.74 \\
\hline & Sterile alpha motif domain containing 4 [Samd4_predicted] & -0.80 & 0.02 & 0.012 & -1.74 \\
\hline & Similar to RIKEN cdna 1190005B03 [Cdkal1_predicted] & -0.79 & 0.06 & 0.035 & -1.73 \\
\hline & WDNM1 homolog [LOC360228] & -0.78 & 0.24 & 0.007 & -1.72 \\
\hline & CD300 antigen like family member E [Cd300le_predicted] & -0.78 & 0.362 & 0.023 & -1.71 \\
\hline & Neuronatin [nnat] & -0.77 & 0.35 & 0.022 & -1.71 \\
\hline & Connective tissue growth factor [Ctgf] & -0.77 & 0.47 & 0.049 & -1.69 \\
\hline & Chemokine (C-X-C motif) ligand 11 [Cxcl11] & -0.75 & 0.17 & 0.003 & -1.68 \\
\hline
\end{tabular}


2. Table Up-regulated genes on DNA microarray in the heart of ZDF rats

\begin{tabular}{|c|c|c|c|c|c|}
\hline Gene function & Description [Gene symbol] & $\begin{array}{c}\text { AVE } \\
\log _{2}\end{array}$ & SD & $\begin{array}{c}\mathbf{P} \\
\text { value }\end{array}$ & $\begin{array}{c}\text { Fold } \\
\text { change }\end{array}$ \\
\hline \multirow{7}{*}{ Metabolism } & Acyl-CoA thioesterase $7[$ Acot7] & 0.75 & 0.34 & 0.021 & 1.69 \\
\hline & Angiopoietin-like 4 [Angpt14] & 0.83 & 0.25 & 0.007 & 1.78 \\
\hline & $\begin{array}{l}\text { Mannosyl (alpha-1,3-)-glycoprotein beta-1,4-N-acetylglucosaminyltransferase, } \\
\text { isozyme C [Mgat4c_predicted] }\end{array}$ & 0.87 & 0.29 & 0.037 & 1.82 \\
\hline & Carbonyl reductase $1[\mathrm{Cbr} 1]$ & 0.99 & 0.40 & 0.016 & 1.99 \\
\hline & 3-hydroxy-3-methylglutaryl-Coenzyme A synthase 2 [Hmgcs2] & 1.05 & 0.25 & 0.004 & 2.07 \\
\hline & Transglutaminase 1 [tgm1] & 1.35 & 0.13 & 0.044 & 2.55 \\
\hline & Cytosolic acyl-CoA thioesterase 1 [Cte1] & 1.88 & 0.41 & 0.003 & 3.69 \\
\hline \multirow{2}{*}{ Stress response } & Cold inducible RNA binding protein [Cirbp] & 0.77 & 0.21 & 0.005 & 1.71 \\
\hline & Glutathione S-transferase Yc2 subunit [Yc2] & 0.86 & 0.16 & 0.002 & 1.82 \\
\hline \multirow{4}{*}{$\begin{array}{l}\text { Signal } \\
\text { transduction, } \\
\text { regulation of } \\
\text { transcription }\end{array}$} & Calcium/calmodulin-dependent protein kinase II gamma [Camk2g] & $\overline{0.75}$ & 0.21 & 0.006 & 1.68 \\
\hline & $\begin{array}{l}\text { Phospholipase A2, group VII (platelet-activating factor acetylhydrolase, plasma) } \\
\text { [Pla2g7] }\end{array}$ & 1.45 & 0.84 & 0.041 & 2.74 \\
\hline & Brain expressed X-linked $1[$ Bex 1$]$ & 0.92 & 0.57 & 0.048 & 1.90 \\
\hline & Fibroblast growth factor receptor substrate 3 [Frs3] & 1.05 & 0.04 & 0.018 & 2.07 \\
\hline \multirow{3}{*}{$\begin{array}{l}\text { Membrane } \\
\text { proteins, } \\
\text { receptors }\end{array}$} & Huntingtin-associated protein 1 [Hap1] & 0.77 & 0.29 & 0.043 & 1.71 \\
\hline & $\begin{array}{l}\text { Membrane protein, palmitoylated } 3 \text { (MAGUK p55 subfamily member 3) } \\
\text { [RGD1560049_predicted] }\end{array}$ & 1.10 & 0.45 & 0.016 & 2.15 \\
\hline & ATPase, $\mathrm{H}^{+} / \mathrm{K}^{+}$transporting, nongastric, alpha polypeptide [Atp12a] & 1.39 & 0.19 & 0.006 & 2.61 \\
\hline \multirow{2}{*}{$\begin{array}{l}\text { Structural } \\
\text { protein, cell } \\
\text { adhesion }\end{array}$} & Spectrin beta $3[\mathrm{Spnb} 3]$ & 0.95 & 0.05 & 0.026 & 1.93 \\
\hline & Aggrecan 1 [agc1] & 1.06 & 0.09 & 0.037 & 2.08 \\
\hline \multirow{18}{*}{ Others } & Similar to mucin 7, salivary [RGD1311530_predicted] & 0.75 & 0.22 & 0.007 & 1.69 \\
\hline & Leukocyte tyrosine kinase [Ltk_predicted] & 0.77 & 0.04 & 0.021 & 1.70 \\
\hline & Similar to RIKEN cDNA 9130022B02 [Pck2_predicted] & 0.78 & 0.28 & 0.042 & 1.72 \\
\hline & Similar to hypothetical protein [Arid2_predicted] & 0.79 & 0.20 & 0.004 & 1.73 \\
\hline & Iroquois related homeobox 3 (Drosophila) [Irx3_predicted] & 0.809 & 0.41 & 0.031 & 1.74 \\
\hline & Hdac5 protein (Fragment) [Hdac5] & 0.86 & 0.70 & 0.022 & 1.81 \\
\hline & Ribonuclease, RNAase A family, 1 (pancreatic) [Rnase1] & 0.90 & 0.22 & 0.004 & 1.86 \\
\hline & Ring finger protein 24 [Rnf24_predicted] & 0.92 & 0.22 & 0.037 & 1.89 \\
\hline & Amyloid beta (A4) precursor protein-binding, family A, member 1 [Apba1] & 0.96 & 0.36 & 0.044 & 1.94 \\
\hline & CWF19-like 1, cell cycle control (S. Pombe) [Cwf1911_predicted] & 0.97 & 0.09 & 0.044 & 1.95 \\
\hline & Similar to high density lipoprotein-binding protein [RGD1564237_predicted] & 0.98 & 0.19 & 0.002 & 1.97 \\
\hline & P21 (CDKN1A)-activated kinase 6 [Pak6_predicted] & 0.10 & 0.08 & 0.036 & 2.00 \\
\hline & Similar to nuclear body associated kinase 1a [Hipk2_predicted] & 1.06 & 0.66 & 0.049 & 2.09 \\
\hline & Cationic trypsinogen [LOC286911] & 1.08 & 0.07 & 0.031 & 2.11 \\
\hline & Chac, cation transport regulator-like 1 (E. Coli) [RGD1560049_predicted] & 1.10 & 0.08 & 0.033 & 2.15 \\
\hline & NTAK alpha2 [Nrg2] & 1.13 & 0.10 & 0.042 & 2.18 \\
\hline & Ubiquitin carboxy-terminal hydrolase L1 [Uchl1] & 1.24 & 0.26 & 0.014 & 2.37 \\
\hline & Claudin 19 [cldn19] & 1.43 & 0.12 & 0.037 & 2.70 \\
\hline
\end{tabular}


The expression change of selected 23 genes was validated by qRT-PCR (Table 3), 18 of these 23 genes have been confirmed by qRT PCR (Table 3). Most of these genes have not been shown to be involved in the development of cardiovascular complications of metabolic syndrome yet.

3. Table qRT-PCR in the heart of ZDF rats

\begin{tabular}{|c|c|c|c|c|c|c|}
\hline \multirow{2}{*}{ Description [Gene symbol] } & \multicolumn{2}{|c|}{$\begin{array}{c}\text { DNA } \\
\text { MICROARRAY }\end{array}$} & \multicolumn{3}{|c|}{ qRT-PCR } & \multirow{2}{*}{ confirmed } \\
\hline & $\begin{array}{l}\text { fold } \\
\text { change }\end{array}$ & $\underset{\text { value }}{\mathbf{p}}$ & ratio (SD) & $\begin{array}{l}\text { fold } \\
\text { change }\end{array}$ & regulation & \\
\hline $\begin{array}{l}\text { ADAM metallopeptidase with thrombospondin type } 1 \\
\text { motif, } 1 \text { [Adamts1] }\end{array}$ & -7.16 & 0.1295 & $0.58(0.09)$ & -1.72 & down & yes \\
\hline heat shock $70 \mathrm{kD}$ protein $1 \mathrm{~A}$ [Hspa1a] & -3.59 & 0.0045 & $0.34(0.06)$ & -2.94 & down & yes \\
\hline $60 \mathrm{kDa}$ heat shock protein [Hsp60] & -3.11 & 0.0565 & $0.64(0.10)$ & -1.56 & down & yes \\
\hline interleukin 18 [Il18] & -2.60 & 0.0066 & $0.91(0.15)$ & -1.10 & no change & no \\
\hline $\begin{array}{c}\text { ATPase, }\left(\mathrm{Na}^{+}\right) / \mathrm{K}^{+} \text {transporting, beta } 4 \text { polypeptide } \\
\text { [Atp1b4] }\end{array}$ & -2.60 & 0.0031 & $0.37(0.06)$ & -2.70 & down & yes \\
\hline argininosuccinate synthetase [Ass] & -2.51 & 0.0007 & $0.29(0.05)$ & -3.42 & down & yes \\
\hline myosin IXA [Myo9a] & -2.40 & 0.0018 & $0.90(0.15)$ & -1.11 & no change & no \\
\hline $\begin{array}{c}\text { glycine C-acetyltransferase (2-amino-3-ketobutyrate- } \\
\text { coenzyme A ligase) [Gcat] }\end{array}$ & -2.22 & 0.0063 & $0.33(0.03)$ & -3.07 & down & yes \\
\hline activating transcription factor 3 [Atf3] & -2.05 & 0.0044 & $0.35(0.06)$ & -2.85 & down & yes \\
\hline $\begin{array}{l}\text { similar to chondroitin sulfate GalNAcT-2 } \\
\text { [RGD1563660_predicted] }\end{array}$ & -1.87 & 0.0170 & $0.92(0.15)$ & -1.09 & no change & no \\
\hline S100 calcium binding protein A3 [S100a3] & -1.87 & 0.0281 & $1.74(0.28)$ & 1.74 & up & no \\
\hline sushi, nidogen and EGF-like domains 1 [Sned1] & -1.83 & 0.0407 & $0.42(0.07)$ & -2.36 & down & yes \\
\hline G protein-coupled receptor 37 [Gpr37] & -1.82 & 0.0297 & $1.08(0.18)$ & 1.08 & no change & no \\
\hline angiopoietin-like 4 [Angptl4] & 1.78 & 0.0073 & $2.90(0.47)$ & 2.90 & up & yes \\
\hline glutathione S-transferase Yc2 subunit [Yc2] & 1.82 & 0.0017 & $2.21(0.36)$ & 2.21 & up & yes \\
\hline ribonuclease, RNase A family, 1 (pancreatic) [Rnase1] & 1.86 & 0.0039 & $2.68(0.44)$ & 2.68 & up & yes \\
\hline $\begin{array}{l}\text { similar to high density lipoprotein-binding protein } \\
\text { [RGD1564237_predicted] }\end{array}$ & 1.97 & 0.0020 & $2.73(0.44)$ & 2.73 & up & yes \\
\hline $\begin{array}{l}\text { 3-hydroxy-3-methylglutaryl-Coenzyme A synthase } \\
\text { 2[Hmgcs2] }\end{array}$ & 2.07 & 0.0036 & $2.42(0.39)$ & 2.42 & up & yes \\
\hline $\begin{array}{l}\text { similar to tetracycline transporter-like protein } \\
\text { [RGD1311900_predicted] }\end{array}$ & 2.24 & 0.1671 & $1.29(0.21)$ & 1.29 & no change & no \\
\hline ubiquitin carboxy-terminal hydrolase L1 [Uchl1] & 2.37 & 0.0144 & $2.50(0.41)$ & 2.50 & up & yes \\
\hline $\begin{array}{l}\text { ATPase, } \mathrm{H}^{+} / \mathrm{K}^{+} \text {transporting, nongastric, alpha } \\
\text { polypeptide [Atp12a] }\end{array}$ & 2.61 & 0.0061 & $3.06(0.50)$ & 3.06 & up & yes \\
\hline $\begin{array}{l}\text { phospholipase A2, group VII (platelet-activating factor } \\
\text { acetylhydrolase, plasma) [Pla2g7] }\end{array}$ & 2.74 & 0.0411 & $4.25(0.69)$ & 4.25 & up & yes \\
\hline cytosolic acyl-CoA thioesterase 1 [Cte1] & 3.69 & 0.0028 & $3.16(0.51)$ & 3.16 & up & yes \\
\hline
\end{tabular}




\subsection{Characterization of prolonged uremia}

In order to verify the development of long term uremia induced by partial nephrectomy, body weight was monitored during the experiment and concentrations of several plasma and urine metabolites were measured at week 29. Partially nephrectomized rats showed significantly lower body weights starting from week 7 (Figure 12A). Plasma carbamide and creatinine levels were markedly increased in partially nephrectomized rats representing the uremic state of these animals (Figure 12B and 12C). Plasma glucose levels were similar in both the sham-operated and the partially nephrectomized groups $(5.7 \pm 0.1$ vs. $5.0 \pm 0.2, n=13-16$, ns). Urine protein concentration was significantly increased in the partially nephrectomized rats as compared to sham-operated controls (Figure 12E) showing an impaired renal function. Moreover, urine creatinine level and creatinine clearance showed a marked but statistically not significant decrease at the level of $p<0.05$ in partially nephrectomized rats (Figure 12D and 12F). Hematocrit and hemoglobin levels were significantly decreased in uremic animals when compared to sham rats showing renal anemia (Table 4). There was no difference in plasma sodium, potassium, calcium, chloride, standard bicarbonate, $\mathrm{pH}$ and anion gap between the groups (Table 4).
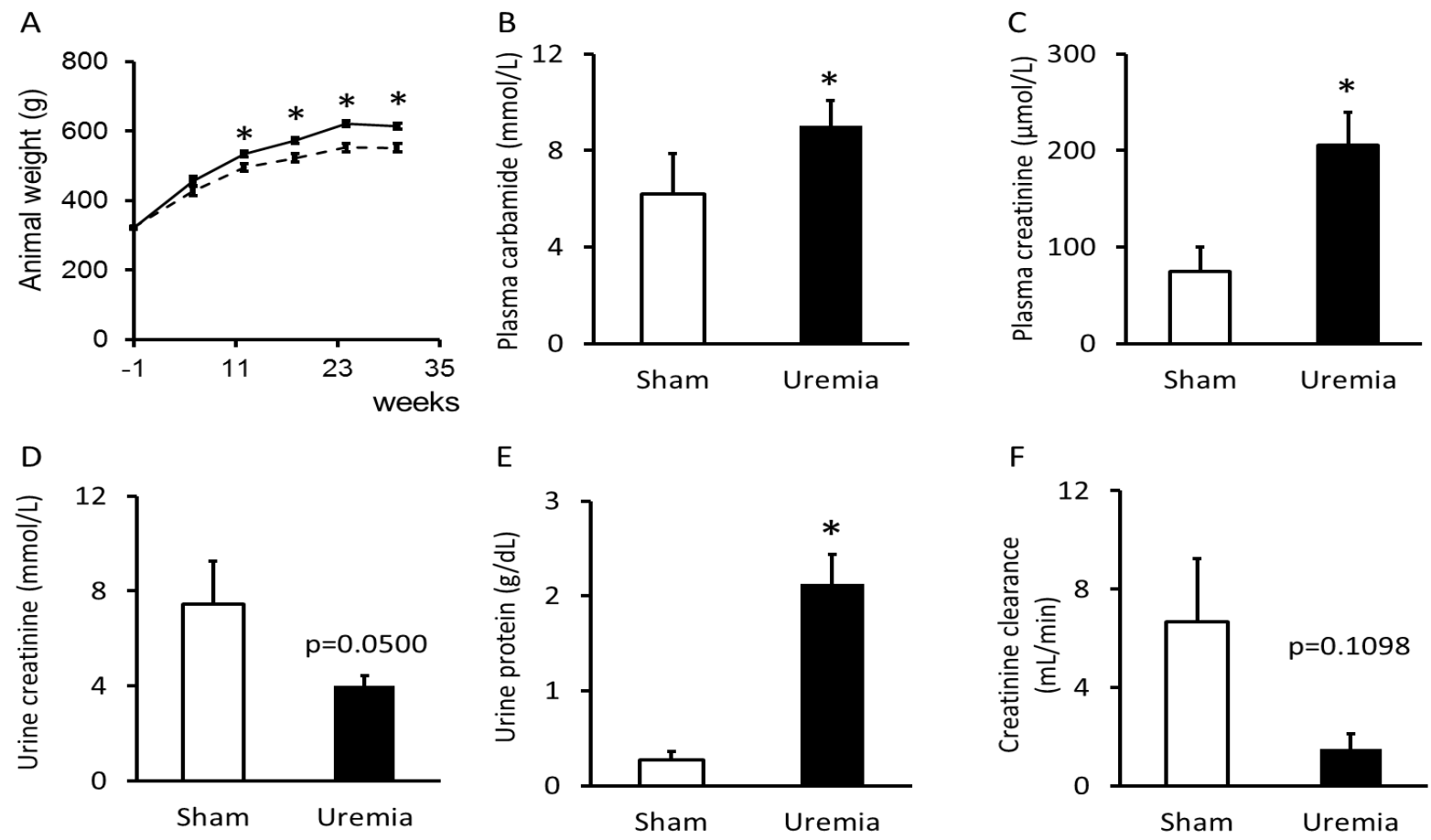

12. Figure Animal weight (Panel A) shown in every six weeks. Solid line: Sham; dashed line: uremia. Plasma carbamide (Panel B, n=14 in both groups) and creatinine (Panel C, n=12-15), urine creatinine (Panel D, n=12 in each groups) and protein concentrations (Panel E, $\mathrm{n}=10-12$ ) and creatinine clearance (Panel $\mathrm{F}, \mathrm{n}=9-10)$ in both shamoperated and uremic rats. Values are means \pm SEM, ${ }^{*} \mathrm{p}<0.05$. 
4. Table Effect of uremia on haematocrite, haemoglobin and blood gas parameters at week 29.

\begin{tabular}{|l|c|c|c|}
\hline Measurement & Sham $(\mathbf{n = 6})$ & Uremia $(\mathbf{n = 1 0})$ & p-value \\
\hline Haematocrite $(\%)$ & $\mathbf{5 4 . 2} \pm \mathbf{1 . 0}$ & $\mathbf{4 4 . 7} \pm \mathbf{2 . 2} *$ & $\mathbf{0 . 0 0 7}$ \\
\hline Haemoglobin $(\mathrm{g} / \mathrm{dL})$ & $\mathbf{1 7 . 7} \pm \mathbf{0 . 3}$ & $\mathbf{1 5 . 0} \pm \mathbf{0 . 7} *$ & $\mathbf{0 . 0 0 6}$ \\
\hline Plasma sodium (mmol/L) & $139 \pm 2$ & $134 \pm 3$ & 0.409 \\
\hline Plasma potassium (mmol/L) & $6.50 \pm 0.50$ & $6.30 \pm 0.25$ & 0.694 \\
\hline Plasma calcium (mmol/L) & $1.10 \pm 0.05$ & $1.19 \pm 0.04$ & 0.174 \\
\hline Plasma chloride (mmol/L) & $107 \pm 3$ & $102 \pm 3$ & 0.267 \\
\hline Plasma standard bicarbonate (mmol/L) & $25.8 \pm 0.4$ & $24.3 \pm 0.5$ & 0.051 \\
\hline pH & $7.38 \pm 0.01$ & $7.36 \pm 0.01$ & 0.069 \\
\hline Anion gap (mmol/L) & $11.5 \pm 0.8$ & $12.9 \pm 0.7$ & 0.213 \\
\hline
\end{tabular}

Studies were performed before ex vivo Langendorff heart perfusion $30 \mathrm{wk}$ after sham-operation or partial nephrectomy; Values are mean \pm SEM, $n=6$ - $10, * p<0.05$ vs. sham, unpaired t-test.

\subsection{Effect of prolonged uremia on myocardial morphology and function}

Transthoracic echocardiography was performed at week 29 in order to investigate whether the development of prolonged uremia leads to alteration of myocardial morphology and function. Left ventricular systolic anterior and septal wall thicknesses were increased in uremic rats as compared to sham-operated controls (Table 5). However, there was no difference in diastolic anterior and septal wall thickness between the uremic and sham operated group. In addition, left ventricular lateral and posterior wall thickness both in systole and diastole were similar in the uremic and the sham operated groups (Table 5). Uremic animals demonstrated a mild reduction both in left ventricular systolic and diastolic function at week 29. Ejection fraction was significantly reduced in the uremic group as compared to the sham-operated control group (Table 5). Stroke volume showed a tendency of decrease in uremic animals as compared to sham-operated controls (Table 5). Heart rate and left ventricular end-systolic and end-diastolic volumes were similar in both uremic and sham-operated groups (Table 5). Isovolumic relaxation time was decreased in uremic rats as compared to sham-operated controls (Table 4). Other diastolic functional parameters including early and late ventricular filling velocity, E/A ratio, deceleration time, maximal and mean left ventricular gradient were not changed in the uremic group as compared to sham-operated controls (Table 5). 
5. Table Effects of uremia on various in vivo left ventricular morphological and functional parameters measured by transthoracic echocardiography.

\begin{tabular}{|c|c|c|c|c|}
\hline \multicolumn{5}{|c|}{ Echocardiography } \\
\hline Morphology & View/Mode & Sham $(n=14)$ & Uremia $(n=16)$ & p-value \\
\hline Anterior wall thickness-systolic (mm) & short axis/MM & $3.31 \pm 0.05$ & $3.59 \pm 0.11 *$ & 0.032 \\
\hline Anterior wall thickness-diastolic (mm) & short axis/MM & $1.87 \pm 0.07$ & $1.97 \pm 0.09$ & 0.371 \\
\hline Lateral wall thickness-systolic (mm) & short axis/MM & $3.47 \pm 0.11$ & $3.38 \pm 0.18$ & 0.796 \\
\hline Lateral wall thickness-diastolic (mm) & short axis/MM & $2.14 \pm 0.40$ & $1.98 \pm 0.08$ & 0.270 \\
\hline Posterior wall thickness-systolic (mm) & long axis/MM & $3.77 \pm 0.11$ & $3.81 \pm 0.11$ & 0.781 \\
\hline Posterior wall thickness-diastolic (mm) & long axis/MM & $2.18 \pm 0.07$ & $2.30 \pm 0.08$ & 0.287 \\
\hline Septal wall thickness-systolic (mm) & long axis/MM & $2.70 \pm 0.12$ & $3.04 \pm 0.13 *$ & 0.046 \\
\hline Septal wall thickness-diastolic (mm) & long axis/MM & $2.25 \pm 0.10$ & $2.26 \pm 0.08$ & 0.961 \\
\hline Left ventricular end diastolic diameter (mm) & long axis/MM & $7.25 \pm 0.17$ & $6.95 \pm 0.14$ & 0.176 \\
\hline Left ventricular end diastolic diameter (mm) & short axis/MM & $7.23 \pm 0.18$ & $7.23 \pm 0.19$ & 0.967 \\
\hline Left ventricular end systolic diameter (mm) & long axis/MM & $3.82 \pm 0.16$ & $3.55 \pm 0.15$ & 0.237 \\
\hline Left ventricular end systolic diameter (mm) & short axix/MM & $3.77 \pm 0.20$ & $3.53 \pm 0.19$ & 0.400 \\
\hline Systolic function & & Sham $(n=14)$ & Uremia $(n=16)$ & p-value \\
\hline Ejection fraction $(\%)$ & four chamber/2D & $54.9 \pm 1.7$ & $48.9 \pm 1.4 *$ & 0.012 \\
\hline Stroke volume $(\mu \mathrm{L})$ & four chamber/2D & $252.2 \pm 13.8$ & $222.9 \pm 10.1$ & 0.093 \\
\hline Left ventricular end-systolic volume $(\mu \mathrm{L})$ & four chamber/2D & $219.3 \pm 23.1$ & $240.0 \pm 18.7$ & 0.487 \\
\hline Left ventricular end-diastolic volume $(\mu \mathrm{L})$ & four chamber/2D & $477.0 \pm 36.1$ & $461.7 \pm 27.3$ & 0.736 \\
\hline Heart rate (beats/min) & four chamber/2D & $391.1 \pm 6.9$ & $396.1 \pm 4.9$ & 0.565 \\
\hline Diastolic function - Doppler imaging & & Sham $(n=13)$ & $\begin{array}{c}\text { Uremia } \\
(n=14)\end{array}$ & p-value \\
\hline E-wave $(\mathrm{m} / \mathrm{s})$ & four chamber/PW & $0.82 \pm 0.03$ & $0.85 \pm 0.03$ & 0.664 \\
\hline A-wave $(\mathrm{m} / \mathrm{s})$ & four chamber/PW & $0.50 \pm 0.03$ & $0.51 \pm 0.02$ & 0.889 \\
\hline E/A ratio & four chamber/PW & $1.69 \pm 0.07$ & $1.72 \pm 0.09$ & 0.830 \\
\hline Deceleration time (ms) & four chamber/PW & $33.98 \pm 1.95$ & $34.39 \pm 1.75$ & 0.885 \\
\hline Isovolumic relaxation time $(\mathrm{ms})$ & four chamber/PW & $25.05 \pm 0.89$ & $21.69 \pm 0.9 *$ & 0.025 \\
\hline Maximal left ventricular gradient $(\mathrm{mmHg})$ & four chamber/PW & $2.89 \pm 0.25$ & $3.09 \pm 0.24$ & 0.598 \\
\hline Mean left ventricular gradient $(\mathrm{mmHg})$ & four chamber/PW & $1.31 \pm 0.10$ & $1.47 \pm 0.12$ & 0.351 \\
\hline
\end{tabular}

Transthoracic echocardiographic measurements were performed 29 wk after sham-operation or partial nephrectomy; Values are mean \pm SEM, $n=13-16$, ${ }^{*} \mathrm{p}<0.05$ vs. sham, unpaired t-test. MM, M (motion) Mode; 2D, two dimensional; PW, pulse wave, E-wave, early ventricular filling velocity; A-wave, late or atrial ventricular filling velocity. 


\subsection{Effect of prolonged uremia on ex vivo morphological and functional parameters}

Coronary flow and morphological parameters including heart weight, left kidney weight and tibia length were measured at week 30 to investigate whether advanced uremia influences ex vivo functional and morphological parameters of the heart. Coronary flow was significantly reduced in uremic groups when compared to corresponding sham-operated control groups as assessed by twoway ANOVA (Table 6).

6. Table Effects of uremia on ex vivo coronary flow data

\begin{tabular}{|c|c|c|c|}
\hline \multicolumn{4}{|c|}{ Coronary flow } \\
\hline \multicolumn{4}{|c|}{ During non-conditioning perfusion protocol } \\
\hline Time points of the measurements & Sham $(n=8)$ & Uremia $(n=9)$ & p-value \\
\hline Base line, $\mathrm{mL} / \mathrm{min}$ & $16.9 \pm 1.3$ & $13.1 \pm 1.1 *$ & 0.044 \\
\hline $15^{\text {th }}$ min of ischemia $(\mathrm{mL} / \mathrm{min})$ & $8.6 \pm 0.9$ & $7.4 \pm 0.5$ & 0.260 \\
\hline First $5 \mathrm{~min}$ of reperfusion $(\mathrm{mL} / \mathrm{min})$ & $19.0 \pm 1.3$ & $16.9 \pm 1.6$ & 0.367 \\
\hline End of reperfusion $(\mathrm{mL} / \mathrm{min})$ & $13.0 \pm 0.7$ & $9.4 \pm 1.1 *$ & 0.023 \\
\hline \multicolumn{4}{|c|}{ During preconditioning perfusion protocol } \\
\hline Time point of the measurement & Sham $(n=6)$ & Uremia $(n=7)$ & p-value \\
\hline Base line, $\mathrm{mL} / \mathrm{min}$ & $17.5 \pm 1.1$ & $13.0 \pm 0.6 *$ & 0.007 \\
\hline $15^{\text {th }}$ min of ischemia $(\mathrm{mL} / \mathrm{min})$ & $8.6 \pm 0.7$ & $6.4 \pm 0.7$ & 0.071 \\
\hline First 5 min of reperfusion $(\mathrm{mL} / \mathrm{min})$ & $22.2 \pm 1.1$ & $15.5 \pm 1.7 *$ & 0.016 \\
\hline End of reperfusion $(\mathrm{mL} / \mathrm{min})$ & $14.1 \pm 0.9$ & $8.4 \pm 0.8^{*}$ & 0.003 \\
\hline
\end{tabular}

Studies were performed on ex vivo Langendorff heart perfusion system 30 wk after sham-operation or partial nephrectomy; $\mathrm{n}=6-9$, ${ }^{*} \mathrm{p}<0.05$ vs. sham, unpaired t-test. Values are mean \pm SEM.

The ratio of heart weight to body weight showed a tendency of increase in uremic animals (Table 7), as a result of a significantly lower body weight in the uremic group (Figure 12A). However, there was no difference in heart weight and heart weight to tibia length ratio between the uremic and the sham-operated control group (Table 7). In addition, the weight of the whole left kidney in the sham-operated group and the remaining one third of the left kidney in the uremic group were similar suggesting a marked renal hypertrophy in the uremic animals (Table 7).

7. Table Effect of uremia on various ex vivo morphological parameters

\begin{tabular}{|l|c|c|c|}
\hline Measurement & Sham $(\mathbf{n}=\mathbf{1 4})$ & Uremia $(\mathbf{n}=\mathbf{1 2})$ & p-value \\
\hline Heart weight $(\mathrm{g})$ & $2.10 \pm 0.09$ & $2.10 \pm 0.10$ & 0.980 \\
\hline Heart weight/body weight $\times 10^{3}$ & $3.40 \pm 0.17$ & $3.77 \pm 0.15$ & 0.126 \\
\hline Heart weight/tibia length $\times 10^{2}$ & $4.00 \pm 0.20$ & $4.20 \pm 0.20$ & 0.483 \\
\hline Left kidney weight $(\mathrm{g})$ & Full kidney weight & $1 / 3$ kidney weight & - \\
& $1.90 \pm 0.11$ & $2.04 \pm 0.09$ & - \\
\hline
\end{tabular}

Measurements were performed $30 \mathrm{wk}$ after sham-operation or partial nephrectomy. Values are mean $\pm \mathrm{SEM}, \mathrm{n}=12-14$, unpaired t-test. 


\subsection{Effect of ischemic preconditioning on infarct size}

Infarct size was measured at week 30 to investigate the severity of ischemia/reperfusion injury and the cardioprotective effect of IPre in prolonged uremia (Figure 13A). Preconditioning significantly decreased infarct size, however, the presence of prolonged uremia did not significantly influence the size of infarction as assessed by two-way ANOVA. Additional analysis with unpaired t-tests showed a significant infarct size limiting effect of preconditioning in hearts of both uremic and sham-operated rats (Figure 13B). The area at risk zone was not affected significantly in any of the groups (Figure 13A).

A

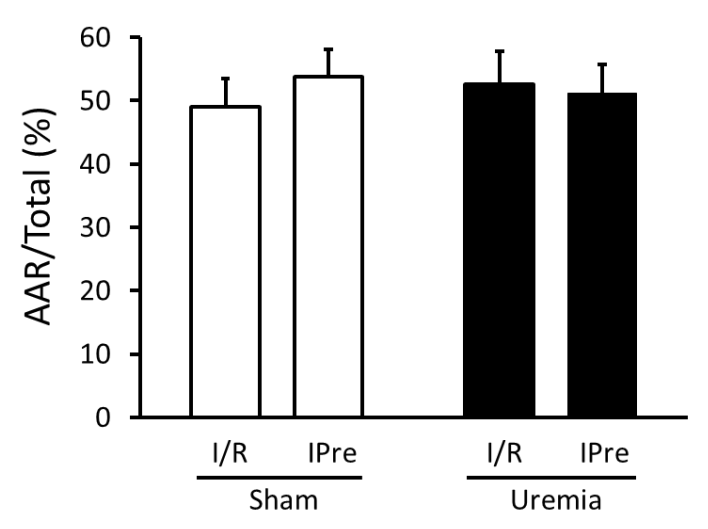

B

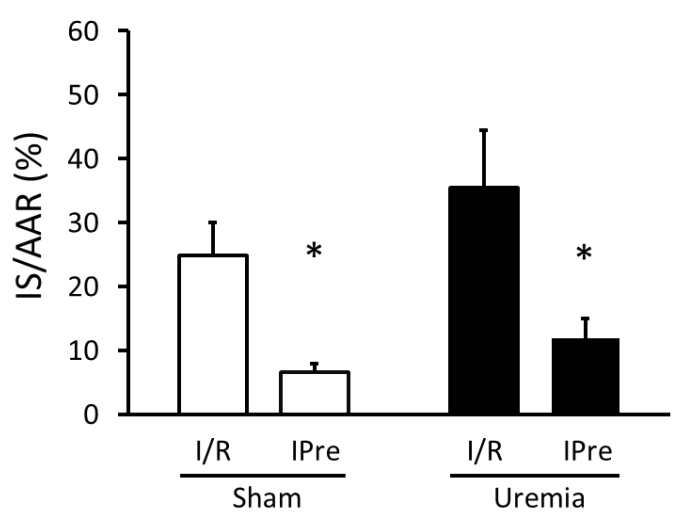

13. Figure Area at risk (Panel A) and infarct size (Panel $B$ ) after ischemia/reperfusion (I/R) or ischemic preconditioning (IPre) in both sham and uremic groups. Values are means \pm SEM, $n=6-9$ in each group. Two-way ANOVA on all groups showed that preconditioning significantly decreased infarct size, however, uremia did not influence infarct size. $* \mathrm{p}<0.05, *$ represents significance due to unpaired t-test between I/R and IPre groups.

\subsection{Effect of prolonged uremia on plasma angiotensin II, 3-nitrotyrosine and uric acid levels}

Partially nephrectomized rats showed significantly higher plasma angiotensin II level (Figure 14A) which is a well-known marker of hypertension and left ventricular hypertrophy. Plasma 3nitrotyrosine level was determined as a marker of peroxynitrite and systemic nitrative stress. Plasma 3-nitrotyrosine level was markedly increased in uremic rats as compared to sham operated controls representing increased systemic nitrative stress in uremic animals (Figure 14B). Plasma level of uric acid, a well-known anti-oxidant, was significantly increased in the partially nephrectomized 
rats as compared to sham-operated controls (Figure 14C) showing increased anti-oxidant capacity in uremic rats.

A

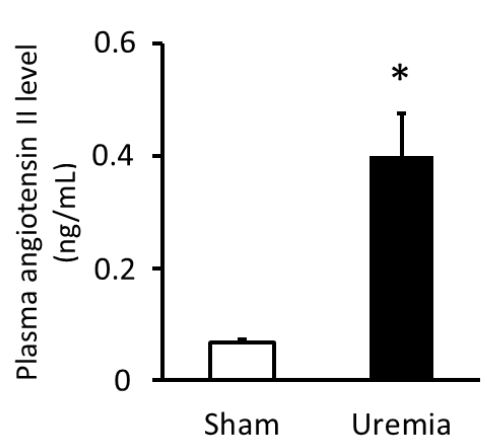

B

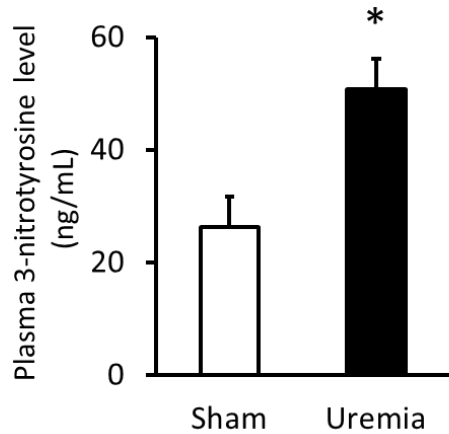

C

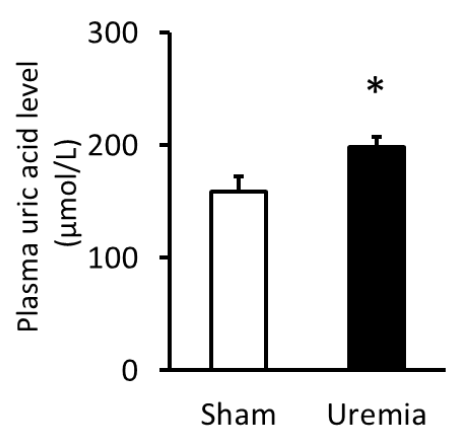

14. Figure Plasma angiotensin II (Panel A, n=9-10), nitrotyrosine (Panel B, $n=9-10)$, and uric acid (Panel C, $n=9-10$ ) levels in both sham-operated and uremic rats. Values are means \pm SEM, ${ }^{*} \mathrm{p}<0.05$. 


\section{DISCUSSION}

\subsection{New findings}

1. Our novel finding is that metabolic syndrome is associated with profound modifications of the cardiac transcriptom. In hearts of ZDF rats, 36 genes showed significant up-regulation and 49 genes showed down-regulation as compared to lean controls. Several of the genes showing altered expression in the hearts of ZDF rats have not been implicated in metabolic syndrome previously.

2. We have also found here that 30 weeks of experimental renal failure although leads to severe metabolic changes and the development of myocardial dysfunction, prolonged uremia does not interfere with the severity of myocardial $\mathrm{I} / \mathrm{R}$ and the cardioprotective effect of IPre.

\subsection{Effect of metabolic syndrome on cardiac gene expression pattern in male ZDF rats}

\section{Components of metabolic syndrome and their effects on cardiac gene expression}

Here we show several characteristics of metabolic syndrome in ZDF rats including obesity, fasting hyperglycemia, hyperlipidemia, hyperinsulinemia, insulin resistance, and impaired glucose tolerance as well as increased cardiac nitrative stress. Here we have shown that 25 week old male ZDF rats develop insulin resistance with hyperinsulinemia, hyperglycemia and impaired HOMAindex in line with other studies [95-97, 117-119]. Both metabolic syndrome and type 2 diabetes mellitus are associated with insulin resistance, hyperinsulinemia and hyperglycemia. Insulin resistance has been reported to be influenced by certain genetic factors and nutrients in patients suffering from metabolic syndrome [120]. Some groups have proposed that hyperinsulinemia stimulated myocardial SERCA2a overexpression plays an important role in the cardiac adaptation process at early phase of type 2 diabetes mellitus in ZDF animals [121]. Others have shown that GLUT4 content decreases along with the development of insulin resistance in the myocardium and other insulin sensitive tissues which might play a key role in the impaired glycemic homeostasis in metabolic syndrome [122]. Interestingly, hyperglycemia has been reported to activate p53 and p53regulated genes involving the local renin-angiotensin system which leads to increased apoptosis of cardiomyocytes [123]. Moreover, postprandial hyperglycemia has been shown to play an important 
role in the onset and development of heart failure in several large-scale clinical trials [124]. Chronic hyperglycemia has been reported to enhance the vasoconstrictor response by Rho-kinase [125]. Hyperglycemia itself has been shown to increase rat aortic smooth muscle cell growth and gene expression in diabetes mellitus [126]. Some drugs e.g. statins [125] and nitrates [127] have been reported to abolish hyperglycemia induced vasoconstriction. These aforementioned studies clearly demonstrate that metabolic serum parameters could influence cardiac gene expression pattern and may lead to functional consequences. Although we have not measured blood pressure in our study, ZDF rats are well known to develop elevated blood pressure at ages similar to that of used in the present study [128-130].

\section{Groups of altered cardiac genes in metabolic syndrome}

We identified 85 genes which were differentially expressed dominantly in the myocardium of 25 weeks old ZDF rats compared to normal controls. Many of these differentially expressed genes are known to be involved in multiple cell functions, including metabolism, stress response, signal transduction, regulation of transcription, cytoskeletal structure, cell adhesion, membrane proteins, receptors and others.

\section{Altered cardiac genes related to metabolism}

It is not surprising that the expression of several genes related to metabolism were found to be affected in the hearts of ZDF rats as compared to controls in our present study. A group of these altered genes is involved in ketone body metabolism (down-regulation of 3-hydroxybutyrate dehydrogenase, type 1; up-regulation of 2-amino-3-ketobutyrate-coenzyme A ligase and 3-hydroxy3-methylglutaryl-coenzyme A synthase 2). Decreased rate of ketone body oxidation and decreased activity of 3-hydroxybutyrate dehydrogenase activity in streptozotocin-induced diabetic rat hearts have been shown previously [131]. Another group of differentially regulated metabolic genes in ZDF hearts in our present study plays a role in the metabolism of carbohydrates (down-regulation of dicarbonyl L-xylulose reductase and up-regulation of mannosyl (alpha-1,3-)-glycoprotein beta1,4-N-acetylglucosaminyltransferase, isoenzyme $\mathrm{C}$, predicted) as well as lipids (up-regulation of acyl-CoA thioesterase 1 and cytosolic acyl-CoA thioesterase 1). Gene expression of cytosolic acylCoA thioesterase 1 has been reported to be up-regulated by high fat diet [132] or STZ-induced diabetes [130] in the rat myocardium. A third group of differentially expressed metabolic genes in our present study (down-regulation of argininosuccinate synthetase and up-regulation of angiopoietin-like 4) in ZDF hearts is potentially regulated by oxidative and nitrative stress which is 
increased in metabolic diseases e.g. hyperlipidemia [133], hypertension [134], insulin resistance [135], diabetes mellitus [136] and in the heart of ZDF rats as well [103]. High TNF-alpha concentrations [137] and insulin resistance [138, 139] in endothelial cells have been reported to reduce the expression of the arginine recycling enzyme, argininosuccinate synthetase. Overexpression of hepatic angiopoietin-like 4 gene has been shown in diabetic mice [140] and upregulation of this gene has reported to be induced by fatty acids via PPAR-gamma in muscle tissue [141]. Additionally, insulin has been shown to down-regulate angiopoietin-like 4 in adipocytes [142] and this down-regulation could be attenuated in insulin resistance [142].

\section{Altered cardiac genes related to stress response}

Members of another functional gene cluster that is related to stress response showed altered expression in ZDF hearts as compared to controls (down-regulation of heat shock 70kD protein 1A; $60 \mathrm{kDa}$ heat shock protein; interleukin 18 and up-regulation of cold inducible RNA binding protein; glutathione S-transferase Yc2 subunit) in the present study. We have previously shown that hyperlipidemia inhibits cardiac heat shock response [98]. Moreover, heat shock proteins, especially Hsp60, were found to have protective effect against cardiac oxidative and nitrative stress [143]. According to the attenuated expression of heat shock protein 60 and 70 in our present study, metabolic syndrome with well-known increased cardiovascular oxidative and nitrative stress [102, 103] due to hyperlipidemia [133], hypertension [134] and hyperglycemia [135] might interfere with cardiac heat shock response. Glutathion S-transferase catalyzes the conjugation of reduced glutathione on a wide variety of substrates [144] including reactive oxygen and nitrogen species [145]. Interestingly, we have found here the overexpression of glutathione S-transferase in metabolic syndrome similarly to the up-regulation of this gene in cholesterol diet-induced hyperlipidemia in our previous study [146]. Additionally, the absence of cardiomyopathy in diabetes has been reported to be accompanied by increased glutathione S-transferase activity in rat hearts [147]. These results suggest that up-regulation of glutathione S-transferase may be an adaptive response in metabolic syndrome to antagonize elevated oxidative/nitrative stress in the myocardium. Elevated circulating interleukin 18 levels have been reported to be associated with metabolic syndrome independent of obesity and insulin resistance [148], however, in our present study; the myocardial gene expression of interleukin 18 was down-regulated.

\section{Altered cardiac genes related to signal transduction and regulation of transcription}

In the present study, we have also shown altered expression of several genes related to signal transduction and regulation of transcription in the hearts of ZDF rats as compared to controls (e.g. down-regulation of activating transcription factor 3; sushi, nidogen and EGF-like domains 1 
(insulin responsive sequence DNA binding protein-1) and up-regulation of calcium/calmodulindependent protein kinase II gamma; phospholipase A2, group VII). Interestingly, in our present study, an adaptive and oxidative stress-responsive transcription factor [149-151], activating transcription factor 3 showed down-regulation in the heart in metabolic syndrome. Although, enhanced expression of activating transcription factor 3 has been reported to play a role in diabetic angiopathy [149], in stress-induced beta cell dysfunction [152, 153] and hepatic LDL receptor down-regulation [154, 155], its cardiac role in metabolic syndrome has not been implicated yet. Another stress inducible and regulator gene of eicosanoid biosynthesis, the phospholipase A2, group VII gene was up-regulated in our present study in ZDF rat hearts. Increase of the expression of this gene was previously shown in ZDF rats in the liver and suggested to be a factor in the development of chronic low-grade inflammation in metabolic syndrome [156]. In our present study, a regulator gene of insulin action, the insulin responsive sequence DNA binding protein-1 showed down-regulation in metabolic syndrome in ZDF rat hearts. Down-regulation of this gene has been previously shown in the liver of diabetic [157] and obese [157] rats. However, it is unclear whether decreased expression of insulin responsive sequence DNA binding protein-1 is a consequence of insulin resistance or contributes to hyperglycemic phenotype. Calcium/calmodulin-dependent protein kinase II gamma showed up-regulation in ZDF hearts in our present study. This gene was reported to potentially mediate cardiac hypertrophy in pressure overload hypertension in mouse hearts [158].

\section{Altered cardiac genes related to functional cluster of membrane proteins or receptors}

In the present study, several genes related to the functional cluster of membrane proteins or receptors showed altered expression in ZDF hearts as compared to controls (e.g. down-regulation of ATPase, $\mathrm{Na}^{+} / \mathrm{K}^{+}$transporting, beta 4 polypeptide; $\mathrm{G}$ protein-coupled receptor 37 and up-regulation of ATPase, $\mathrm{H}^{+} / \mathrm{K}^{+}$transporting, nongastric, alpha polypeptide; Huntingtin-associated protein 1). Interestingly, here we have found gene expression changes of two members of the X,K-ATPase family due to metabolic syndrome. Surprisingly, ATPase, $\mathrm{Na}^{+} / \mathrm{K}^{+}$transporting, beta 4 polypeptide showed down-regulation in obese ZDF rat hearts characterized by marked hyperlipidemia in the current study, however, this gene showed up-regulation in our previous study in cholesterol-induced hyperlipidemia in the rat myocardium [146]. Additionally, it has been shown in the heart of spontaneously hypertensive rats that the microsomal $\mathrm{Na}^{+} / \mathrm{K}^{+}$-ATPase activity is reduced [159].

\section{Altered cardiac genes related to functional cluster of structural proteins}

Another set of genes related to the functional cluster of structural proteins was found to be regulated differentially in hearts of ZDF rats as compared to controls (e.g. down-regulation of myosin IXA 
and similar to collagen, type XXIV, alpha 1 (pred) and up-regulation of spectrin beta 3 and aggrecan 1). To our current knowledge, we are the first in the literature demonstrating cardiac gene expression changes of a novel epithelial extracellular matrix component [160], similar to collagen type XXIV; a cell migration regulator molecule [161], myosin IXA; a membrane stabilizer molecule [162], spectrin beta 3 and an extracellular matrix component proteoglycan [163], aggrecan 1 , due to metabolic syndrome.

\section{Altered cardiac genes not related to specific functional clusters}

Some of the genes showing altered expression in ZDF rat hearts in the present study were not related to specific functional clusters or indicated as yet uncharacterized, predicted genes and fragments. Many of these genes are reported for the first time in the literature to show altered expression in the heart due to metabolic syndrome including down-regulation e.g. of disintegrinlike and metallopeptidse (reprolysin type) with thrombospondin type 1 motif; G protein-coupled receptor 107 (predicted); S100 calcium binding protein A3; kallikrein 14 (predicted); neuronatin; connective tissue growth factor and up-regulation e.g. of amyloid beta (A4) precursor proteinbinding, family A, member 1; similar to high density lipoprotein-binding protein (predicted); cationic trypsinogen; ubiquitin carboxy-terminal hydrolase L1.

\subsection{Effect of subacute and chronic renal failure on endogenous cardioprotective mechanisms}

The cardioprotective effect of ischemic pre- and postconditioning is inhibited by several co-morbid conditions and risk factors such as e.g. aging [164-166] hyperlipidemia [59, 62, 63, 167-169] and diabetes $[69,78,170]$. However, recent evidence suggests that the cardioprotective effect of preand postconditioning is maintained in subacute renal failure (4 weeks) [55] and short-term (10 weeks) [81] model of uremia. In a preliminary study, we have demonstrated for the first time in the literature that the infarct size limiting effect of postconditioning was still present 10 weeks after subtotal nephrectomy resulting in uremia in rats [81]. Moreover, an extensive study published by Byrne et al. [55] has reported that IPre, remote ischemic conditioning, and IPost are still cardioprotective after 4 weeks of subtotal nephrectomy. In addition, in the same study IPre was shown to limit infarct size in an adenine-enriched diet-induced model of uremia in rats [55]. Although the uremic state seems to be too short and was not characterized thoroughly in Byrne's aforementioned studies [55], they may suggest that the uremic heart can be still protected by conditioning techniques. Indeed, an experimental model of 4 weeks of uremia probably may not properly reflect the clinical situation, [4, 82]. Additionally, it has been shown that 5/6 partial 
nephrectomy followed by a postoperative duration of 3 weeks does not lead to advanced uremia in rats [83]. Therefore, in the present study we used a prolonged (30 weeks) postoperative duration following partial nephrectomy to induce a more severe long-term uremic condition for investigating the cardioprotective effect of preconditioning.

\subsection{Characteristic features and cardiac consequences of the prolonged uremic state}

In this prolonged uremic model, here we have found characteristic biochemical and pathophysiological signs of prolonged uremia, including increased plasma uric acid, carbamide and creatinine levels, decreased hematocrit and hemoglobin, increased urine protein and decreased creatinine concentration, as well as diminished creatinine clearance. In patients with end-stage renal failure, uremic cardiomyopathy is a common complication and reported to be a prognostic factor of cardiovascular mortality [5, 39, 171]. In the present study, we have found increased septal and anterior wall thickness in uremic animals. Additionally, plasma angiotensin II level which is an indirect marker of hypertension and left ventricular hypertrophy [107-111] was also higher in uremic rats. These results together with literature data [172-175] suggest the development of a minimal left ventricular hypertrophy in uremic animals at week 30 in our present study. In this model, we have found here that IPre is still effective in prolonged uremic condition. This is a refreshingly interesting result in the light of the fact that several metabolic diseases including diabetes and hyperlipidemia inhibit the endogenous cardioprotective mechanisms of ischemic conditioning.

\subsection{Cardioprotection by IPre in prolonged uremia with increased nitrative stress}

The reason why the complex metabolic changes of uremia which significantly affect several intracellular signaling pathways in the heart and leads to myocardial dysfunction do not affect the overall efficacy of cardioprotection by IPre is unknown. It has been previously shown that 6-8 week long chronic renal failure leads to increased oxidative and nitrative stress in the rat heart [45, 173, $176,177]$. Here we have also shown increased nitrative stress in a 30 -week model of prolonged uremia. It is well known that the cardioprotective effect of IPre is lost in metabolic diseases associated with increased myocardial oxidative and nitrative stress [3]. Therefore, our present findings showing that the cardioprotective effect of IPre is surprisingly still preserved in uremic animals in spite of the increased systemic nitrative stress are particularly exciting. These results suggest that even though prolonged uremia leads to some deleterious effects (e.g. mild cardiac 
dysfunction and minimal hypertrophy, tendency of increased infarct size) it likely induces some complex compensatory alterations supporting maintained cardioprotection by IPre. However, further studies should be carried out to determine the precise role of oxidative/nitrative stress in the mechanism of preconditioning in uremia.

\subsection{Cardioprotection by IPre in uremia-related minimal cardiac hypertrophy}

Up-regulation of renal renin-angiotensin-aldosteron system was also shown in rats with partial nephrectomy in our present study similarly to findings of other research groups $[172,175,178]$. In our present study, increased plasma angiotensin II levels together with echocardiographic data suggest the development of a minimal left ventricular hypertrophy at week 30 in uremic animals. In this aspect our study is in line with other studies showing that IPre is still cardioprotective in case of left ventricular hypertrophy [179, 180] and hypertension [181, 182] associated with increased plasma angiotensin II level [3]. Therefore, we believe that the presence of a minimal cardiac hypertrophy and mild left ventricular dysfunction in uremic animals might not interfere with the cardioprotective mechanism of IPre. However, it cannot be excluded that the cardioprotection by preconditioning may be lost with the progression of the disease and development of severe heart failure in end-stage renal failure, as it has been shown that endogenous cardioprotection is lost in severe heart failure [183-185]. In addition, renal failure seems to interact with some protein kinases $[172,174]$ suggested to be involved in the mechanism of IPre. The overall net changes in uremia seem to preserve the cardioprotective effect of IPre, however, the exact mechanisms remain to be elucidated. 


\section{CONCLUSIONS}

In the present thesis, we investigated the effect of a cardiovascular risk factor, the metabolic syndrome on cardiac gene expression pattern, and we examined whether another cardiovascular risk factor and comorbid state, prolonged uremia, affects the I/R injury and cardioprotection by IPre.

1. In the present thesis we have found that 25 weeks old ZDF rats develop severe metabolic syndrome (dyslipidemia, obesity, hyperglycemia, hyperinsulinemia, impaired glucose tolerance and insulin resistance). We have demonstrated for the first time that metabolic syndrome is associated with profound modifications of the cardiac transcriptom. Several of the genes showing altered expression in the hearts of ZDF rats have not been implicated in metabolic syndrome previously. We conclude that metabolic syndrome alters the gene expression pattern of the myocardium which may be involved in the development of cardiac pathologies in the presence of metabolic syndrome (Figure 15). The precise role of these genes in the cardiac consequences of metabolic syndrome needs to be further investigated in future studies.

2. We have also found here that another metabolic disease, chronic renal failure although leads to severe metabolic changes and the development of myocardial dysfunction as well as minimal cardiac hypertrophy, the cardioprotective effect of IPre is still observed. In conclusion, our present study suggests that patients suffering from long-term uremia may also benefit from cardioprotection by IPre. This is particularly important as acute myocardial infarction frequently occurs in patients with late stages of renal failure. Since uremic patients are regularly excluded from clinical trials, there is a need for clinical studies to investigate the cardioprotective effect of conditioning techniques in patients with chronic renal failure suffering from acute myocardial infarction (Figure 15). 


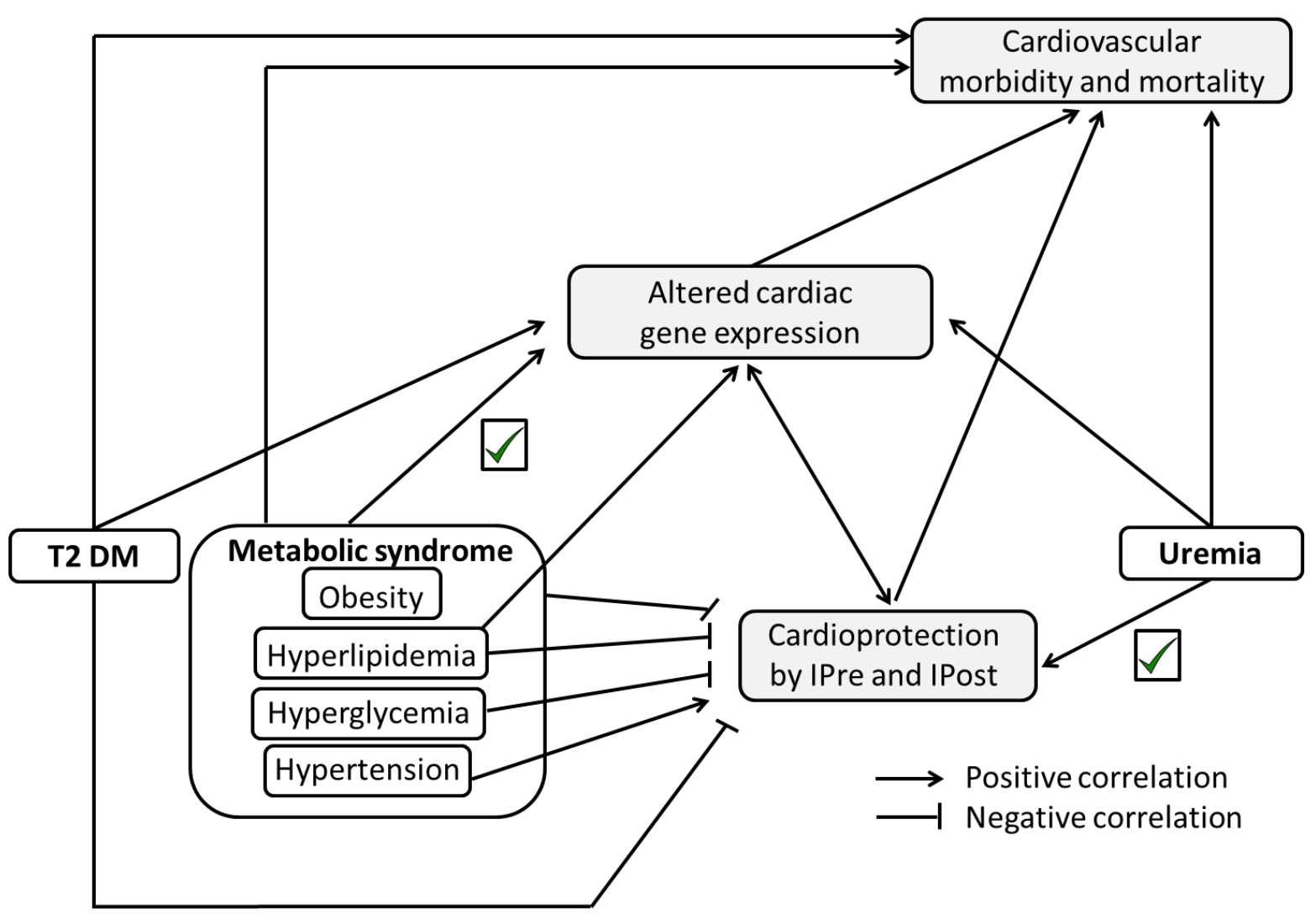

15. Figure Conclusion of the present thesis: Metabolic syndrome alters cardiac gene expression pattern and cardioprotection is preserved by ischemic preconditioning (IPre) in prolonged uremia. (Ischemic postconditioning (IPost), T2DM type 2 diabetes mellitus). 


\section{ACKNOWLEDGEMENT}

This work was supported by grants from the National Office for Research and Technology (MED_FOOD, Baross DA-TECH-07-2008-0041; TÁMOP-4.2.2/A-11/1/KONV-2012-0035 TÁMOP-4.2.1/B-09/1/KONV-2010-0005), the Hungarian Scientific Research Fund (OTKA K79167), and co-financed by the European Regional Development Fund and VÁTI Hungarian Nonprofit Limited Liability Company for Regional Development and Town Planning (HURO/0901/137/2.2.2-HU-RO-TRANS-MED). The publication was supported by the European Union and co-funded by the European Social Fund. Project title: "Broadening the knowledge base and supporting the long term professional sustainability of the Research University Centre of Excellence at the University of Szeged by ensuring the rising generation of excellent scientists." Project number: TÁMOP-4.2.2/B-10/1-2010-0012. Marta Sarkozy holds an "Ányos Jedlik Predoctoral Fellowship". This thesis was realized in the frames of TÁMOP 4.2.4. A/2-11-1-20120001 National Excellence Program - Elaborating and operating an inland student and researcher personal support system. The project was subsidized by the European Union and co-financed by the European Social Fund.

I greatly acknowledge to Professor László Dux for providing possibility to work at the Department of Biochemistry, and to Professor Péter Ferdinandy for providing possibility to carry on research in the Cardiovascular Research Group as well as in the Pharmahungary Group and for the support and guideline he gave me.

I would like to give the expression of my sincere gratitude to my supervisor, Tamás Csont for his scientific guidance and helpful suggestions he gave me during my $\mathrm{PhD}$ years. Apart from excellent scientific advice, he greatly helped me improve my analytical thinking and reasoning.

I would like to give my special thanks to my co-author, Gabriella Kocsis-Fodor for her encouragement she gave me in the uremic project.

I am grateful to Ágnes Zvara and Professor László Puskás for the co-operation in the DNAmicroarray and qRT-PCR experiments.

I would like to give my thanks to all of my present and past colleagues and friends for the scientific support and the kind atmosphere. 


\section{REFERENCES}

1. Pranavchand R, Reddy BM: Current status of understanding of the genetic etiology of coronary heart disease. J Postgrad Med 2013, 59:30-41.

2. Roger VL, Go AS, Lloyd-Jones DM, Benjamin EJ, Berry JD, Borden WB, Bravata DM, Dai S, Ford ES, Fox CS, Fullerton HJ, Gillespie C, Hailpern SM, Heit JA, Howard VJ, Kissela BM, Kittner SJ, Lackland DT, Lichtman JH, Lisabeth LD, Makuc DM, Marcus GM, Marelli A, Matchar DB, Moy CS, Mozaffarian D, Mussolino ME, Nichol G, Paynter NP, Soliman EZ, Sorlie PD, Sotoodehnia N, Turan TN, Virani SS, Wong ND, Woo D, Turner MB, American Heart Association Statistics Committee and Stroke Statistics Subcommittee: Executive summary: heart disease and stroke statistics--2012 update: a report from the American Heart Association. Circulation 2012, 125:188-197.

3. Ferdinandy P, Schulz R, Baxter GF: Interaction of cardiovascular risk factors with myocardial ischemia/reperfusion injury, preconditioning, and postconditioning. Pharmacol Rev 2007, 59:418-458.

4. Levey AS, Coresh J: Chronic kidney disease. The Lancet 2012, 379:165-180.

5. Go AS, Chertow GM, Fan D, McCulloch CE, Hsu CY: Chronic kidney disease and the risks of death, cardiovascular events, and hospitalization. N Engl J Med 2004, 351:1296-1305.

6. Foley RN, Parfrey PS, Sarnak MJ: Clinical epidemiology of cardiovascular disease in chronic renal disease. Am J Kidney Dis 1998, 32:S112-119.

7. Durrington P: Dyslipidaemia. Lancet 2003, 362:717-731.

8. European Association for Cardiovascular Prevention \& Rehabilitation, Reiner Z, Catapano AL, De Backer G, Graham I, Taskinen MR, Wiklund O, Agewall S, Alegria E, Chapman MJ, Durrington P, Erdine S, Halcox J, Hobbs R, Kjekshus J, Filardi PP, Riccardi G, Storey RF, Wood D, ESC Committee for Practice Guidelines (CPG) 2008-2010 and 2010-2012 Committees: ESC/EAS Guidelines for the management of dyslipidaemias: the Task Force for the management of dyslipidaemias of the European Society of Cardiology (ESC) and the European Atherosclerosis Society (EAS). Eur Heart J 2011, 32:1769-1818.

9. Kuklina EV, Yoon PW, Keenan NL: Trends in high levels of low-density lipoprotein cholesterol in the United States, 1999-2006. JAMA 2009, 302:2104-2110.

10. Varga ZV, Kupai K, Szucs G, Gaspar R, Paloczi J, Farago N, Zvara A, Puskas LG, Razga Z, Tiszlavicz L, Bencsik P, Gorbe A, Csonka C, Ferdinandy P, Csont T: MicroRNA-25-dependent up-regulation of NADPH oxidase 4 (NOX4) mediates hypercholesterolemia-induced oxidative/nitrative stress and subsequent dysfunction in the heart. J Mol Cell Cardiol 2013, 62C:111-121.

11. Csont T, Bereczki E, Bencsik P, Fodor G, Gorbe A, Zvara A, Csonka C, Puskas LG, Santha M, Ferdinandy P: Hypercholesterolemia increases myocardial oxidative and nitrosative stress thereby leading to cardiac dysfunction in apoB-100 transgenic mice. Cardiovasc Res 2007, 76:100-109. 
12. American Diabetes Association: Standards of medical care in diabetes - 2011. Diabetes Care 2011, 34:S11-61.

13. Zimmet P, Alberti KG, Shaw J: Global and societal implications of the diabetes epidemic. Nature 2001, 414:782-787.

14. Wild S, Roglic G, Green A, Sicree R, King H: Global prevalence of diabetes: estimates for the year 2000 and projections for 2030. Diabetes Care 2004, 27:1047-1053.

15. Astrup A, Finer N: Redefining type 2 diabetes: 'diabesity' or 'obesity dependent diabetes mellitus'? Obes Rev 2000, 1:57-59.

16. Danaei G, Finucane MM, Lin JK, Singh GM, Paciorek CJ, Cowan MJ, Farzadfar F, Stevens GA, Lim SS, Riley LM, Ezzati M, Global Burden of Metabolic Risk Factors of Chronic Diseases Collaborating Group (Blood Pressure): National, regional, and global trends in systolic blood pressure since 1980: systematic analysis of health examination surveys and epidemiological studies with 786 country-years and 5.4 million participants. Lancet 2011, 377:568-577.

17. Whiting DR, Guariguata L, Weil C, Shaw J: IDF diabetes atlas: global estimates of the prevalence of diabetes for 2011 and 2030. Diabetes Res Clin Pract 2011, 94:311-321.

18. Ramani K, Lust WD, Whittingham TS, Lesnefsky EJ: ATP catabolism and adenosine generation during ischemia in the aging heart. Mech Ageing Dev 1996, 89:113-124.

19. Aguilar D, Solomon SD, Kober L, Rouleau JL, Skali H, McMurray JJ, Francis GS, Henis M, O'Connor CM, Diaz R, Belenkov YN, Varshavsky S, Leimberger JD, Velazquez EJ, Califf RM, Pfeffer MA: Newly diagnosed and previously known diabetes mellitus and 1-year outcomes of acute myocardial infarction: the VALsartan In Acute myocardial iNfarcTion (VALIANT) trial. Circulation 2004, 110:1572-1578.

20. Zairis MN, Lyras AG, Makrygiannis SS, Psarogianni PK, Adamopoulou EN, Handanis SM, Papantonakos A, Argyrakis SK, Prekates AA, Foussas SG: Type 2 diabetes and intravenous thrombolysis outcome in the setting of ST elevation myocardial infarction. Diabetes Care 2004, 27:967-971.

21. Sethi SS, Akl EG, Farkouh ME: Diabetes mellitus and acute coronary syndrome: lessons from randomized clinical trials. Curr Diab Rep 2012, 12:294-304.

22. Alberti KG, Zimmet P, Shaw J, IDF Epidemiology Task Force Consensus Group: The metabolic syndrome--a new worldwide definition. Lancet 2005, 366:1059-1062.

23. Alberti KG, Eckel RH, Grundy SM, Zimmet PZ, Cleeman JI, Donato KA, Fruchart JC, James WP, Loria CM, Smith SC,Jr, International Diabetes Federation Task Force on Epidemiology and Prevention, Hational Heart, Lung, and Blood Institute, American Heart Association, World Heart Federation, International Atherosclerosis Society, International Association for the Study of Obesity: Harmonizing the metabolic syndrome: a joint interim statement of the International Diabetes Federation Task Force on Epidemiology and Prevention; National Heart, Lung, and Blood Institute; American Heart Association; World Heart Federation; International Atherosclerosis Society; and International Association for the Study of Obesity. Circulation 2009, 120:1640-1645. 
24. Grundy SM: Pre-diabetes, metabolic syndrome, and cardiovascular risk. J Am Coll Cardiol 2012, 59:635-643.

25. Reaven GM: Insulin resistance, the insulin resistance syndrome, and cardiovascular disease. Panminerva Med 2005, 47:201-210.

26. Mensah GA, Mokdad AH, Ford E, Narayan KM, Giles WH, Vinicor F, Deedwania PC: Obesity, metabolic syndrome, and type 2 diabetes: emerging epidemics and their cardiovascular implications. Cardiol Clin 2004, 22:485-504.

27. Cameron AJ, Shaw JE, Zimmet PZ: The metabolic syndrome: prevalence in worldwide populations. Endocrinol Metab Clin North Am 2004, 33:351-75, table of contents.

28. Amuna P, Zotor FB: Epidemiological and nutrition transition in developing countries: impact on human health and development. Proc Nutr Soc 2008, 67:82-90.

29. de Onis M, Blossner M: Prevalence and trends of overweight among preschool children in developing countries. Am J Clin Nutr 2000, 72:1032-1039.

30. Ford ES, Giles WH, Dietz WH: Prevalence of the metabolic syndrome among US adults: findings from the third National Health and Nutrition Examination Survey. JAMA 2002, 287:356-359.

31. Abdul-Ghani MA, Williams K, DeFronzo RA, Stern M: What is the best predictor of future type 2 diabetes? Diabetes Care 2007, 30:1544-1548.

32. Singh AK, Kari JA: Metabolic syndrome and chronic kidney disease. Curr Opin Nephrol Hypertens 2013, 22:198-203.

33. He J, Ogden LG, Bazzano LA, Vupputuri S, Loria C, Whelton PK: Risk factors for congestive heart failure in US men and women: NHANES I epidemiologic follow-up study. Arch Intern Med 2001, 161:996-1002.

34. Lakka HM, Laaksonen DE, Lakka TA, Niskanen LK, Kumpusalo E, Tuomilehto J, Salonen JT: The metabolic syndrome and total and cardiovascular disease mortality in middle-aged men. JAMA 2002, 288:2709-2716.

35. Sattar N, Gaw A, Scherbakova O, Ford I, O'Reilly DS, Haffner SM, Isles C, Macfarlane PW, Packard CJ, Cobbe SM, Shepherd J: Metabolic syndrome with and without C-reactive protein as a predictor of coronary heart disease and diabetes in the West of Scotland Coronary Prevention Study. Circulation 2003, 108:414-419.

36. Malik S, Wong ND, Franklin SS, Kamath TV, L'Italien GJ, Pio JR, Williams GR: Impact of the metabolic syndrome on mortality from coronary heart disease, cardiovascular disease, and all causes in United States adults. Circulation 2004, 110:1245-1250.

37. Ford ES, Giles WH, Mokdad AH: Increasing prevalence of the metabolic syndrome among US adults. Diabetes Care 2004, 27:2444-2449.

38. Kassi E, Pervanidou P, Kaltsas G, Chrousos G: Metabolic syndrome: definitions and controversies. BMC Med 2011, 9:48-7015-9-48. 
39. Sarnak MJ, Levey AS, Schoolwerth AC, Coresh J, Culleton B, Hamm LL, McCullough PA, Kasiske BL, Kelepouris E, Klag MJ, Parfrey P, Pfeffer M, Raij L, Spinosa DJ, Wilson PW, American Heart Association Councils on Kidney in Cardiovascular Disease, High Blood Pressure Research, Clinical Cardiology, and Epidemiology and Prevention: Kidney disease as a risk factor for development of cardiovascular disease: a statement from the American Heart Association Councils on Kidney in Cardiovascular Disease, High Blood Pressure Research, Clinical Cardiology, and Epidemiology and Prevention. Circulation 2003, 108:2154-2169.

40. Zhang QL, Rothenbacher D: Prevalence of chronic kidney disease in population-based studies: systematic review. BMC Public Health 2008, 8:117-2458-8-117.

41. Coresh J, Selvin E, Stevens LA, Manzi J, Kusek JW, Eggers P, Van Lente F, Levey AS: Prevalence of chronic kidney disease in the United States. JAMA 2007, 298:2038-2047.

42. Coritsidis GN, Linden E, Stern AS: The role of the primary care physician in managing early stages of chronic kidney disease. Postgrad Med 2011, 123:177-185.

43. Whaley-Connell A, Shlipak MG, Inker LA, Kurella Tamura M, Bomback AS, Saab G, Szpunar SM, McFarlane SI, Li S, Chen SC, Norris K, Bakris GL, McCullough PA, Kidney Early Evaluation Program Investigators: Awareness of kidney disease and relationship to end-stage renal disease and mortality. Am J Med 2012, 125:661-669.

44. Foley RN, Murray AM, Li S, Herzog CA, McBean AM, Eggers PW, Collins AJ: Chronic kidney disease and the risk for cardiovascular disease, renal replacement, and death in the United States Medicare population, 1998 to 1999. J Am Soc Nephrol 2005, 16:489-495.

45. Sindhu RK, Ehdaie A, Vaziri ND, Roberts CK: Effects of chronic renal failure on caveolin-1, guanylate cyclase and AKT protein expression. Biochimica et Biophysica Acta (BBA) Molecular Basis of Disease 2004, 1690:231-237.

46. Banerjee D, Ma JZ, Collins AJ, Herzog CA: Long-term survival of incident hemodialysis patients who are hospitalized for congestive heart failure, pulmonary edema, or fluid overload. Clin J Am Soc Nephrol 2007, 2:1186-1190.

47. Foley RN, Parfrey PS, Sarnak MJ: Epidemiology of cardiovascular disease in chronic renal disease. J Am Soc Nephrol 1998, 9:S16-23.

48. Herzog CA, Ma JZ, Collins AJ: Poor long-term survival after acute myocardial infarction among patients on long-term dialysis. N Engl J Med 1998, 339:799-805.

49. Perrelli MG, Pagliaro P, Penna C: Ischemia/reperfusion injury and cardioprotective mechanisms: Role of mitochondria and reactive oxygen species. World J Cardiol 2011, 3:186200.

50. Balakumar P, Babbar L: Preconditioning the hyperlipidemic myocardium: fact or fantasy? Cell Signal 2012, 24:589-595.

51. Murry CE, Jennings RB, Reimer KA: Preconditioning with ischemia: a delay of lethal cell injury in ischemic myocardium. Circulation 1986, 74:1124-1136. 
52. Zhao ZQ, Morris CD, Budde JM, Wang NP, Muraki S, Sun HY, Guyton RA: Inhibition of myocardial apoptosis reduces infarct size and improves regional contractile dysfunction during reperfusion. Cardiovasc Res 2003, 59:132-142.

53. Ovize M, Baxter GF, Di Lisa F, Ferdinandy P, Garcia-Dorado D, Hausenloy DJ, Heusch G, Vinten-Johansen J, Yellon DM, Schulz R, Working Group of Cellular Biology of Heart of European Society of Cardiology: Postconditioning and protection from reperfusion injury: where do we stand? Position paper from the Working Group of Cellular Biology of the Heart of the European Society of Cardiology. Cardiovasc Res 2010, 87:406-423.

54. Hausenloy DJ, Yellon DM: Reperfusion injury salvage kinase signalling: taking a RISK for cardioprotection. Heart Fail Rev 2007, 12:217-234.

55. Byrne CJ, McCafferty K, Kieswich J, Harwood S, Andrikopoulos P, Raftery M, Thiemermann $\mathrm{C}$, Yaqoob MM: Ischemic conditioning protects the uremic heart in a rodent model of myocardial infarction. Circulation 2012, 125:1256-1265.

56. Lecour S: Activation of the protective Survivor Activating Factor Enhancement (SAFE) pathway against reperfusion injury: Does it go beyond the RISK pathway? J Mol Cell Cardiol 2009, 47:32-40.

57. Suleman N, Somers S, Smith R, Opie LH, Lecour SC: Dual activation of STAT-3 and Akt is required during the trigger phase of ischaemic preconditioning. Cardiovasc Res 2008, 79:127133.

58. Penna C, Settanni F, Tullio F, Trovato L, Pagliaro P, Alloatti G, Ghigo E, Granata R: GHreleasing hormone induces cardioprotection in isolated male rat heart via activation of RISK and SAFE pathways. Endocrinology 2013, 154:1624-1635.

59. Kupai K, Csonka C, Fekete V, Odendaal L, van Rooyen J, Marais de W, Csont T, Ferdinandy P: Cholesterol diet-induced hyperlipidemia impairs the cardioprotective effect of postconditioning: role of peroxynitrite. Am J Physiol Heart Circ Physiol 2009, 297:H1729-1735.

60. Gerczuk PZ, Kloner RA: Protecting the heart from ischemia: an update on ischemic and pharmacologic conditioning. Hosp Pract (Minneap) 2011, 39:35-43.

61. Rezkalla SH, Kloner RA: Preconditioning in humans. Heart Fail Rev 2007, 12:201-206.

62. Ungi I, Ungi T, Ruzsa Z, Nagy E, Zimmermann Z, Csont T, Ferdinandy P: Hypercholesterolemia attenuates the anti-ischemic effect of preconditioning during coronary angioplasty. Chest 2005, 128:1623-1628.

63. Ferdinandy P, Csonka C, Csont T, Szilvassy Z, Dux L: Rapid pacing-induced preconditioning is recaptured by farnesol treatment in hearts of cholesterol-fed rats: role of polyprenyl derivatives and nitric oxide. Mol Cell Biochem 1998, 186:27-34.

64. Szilvassy Z, Ferdinandy P, Szilvassy J, Nagy I, Karcsu S, Lonovics J, Dux L, Koltai M: The loss of pacing-induced preconditioning in atherosclerotic rabbits: role of hypercholesterolaemia. J Mol Cell Cardiol 1995, 27:2559-2569. 
65. Ferdinandy P, Szilvássy Z, Horváth LI, Csont T, Csonka C, Nagy E, Szentgyörgyi R, Nagy I, Koltai M, Dux L. Loss of pacing-induced preconditioning in rat hearts: role of nitric oxide and cholesterol-enriched diet. J Mol Cell Cardiol. 1997, 29:3321-3333.

66. Kyriakides ZS, Psychari S, Iliodromitis EK, Kolettis TM, Sbarouni E, Kremastinos DT: Hyperlipidemia prevents the expected reduction of myocardial ischemia on repeated balloon inflations during angioplasty. Chest 2002, 121:1211-1215.

67. Iliodromitis EK, Zoga A, Vrettou A, Andreadou I, Paraskevaidis IA, Kaklamanis L, Kremastinos DT: The effectiveness of postconditioning and preconditioning on infarct size in hypercholesterolemic and normal anesthetized rabbits. Atherosclerosis 2006, 188:356-362.

68. Liu Y, Thornton JD, Cohen MV, Downey JM, Schaffer SW: Streptozotocin-induced noninsulin-dependent diabetes protects the heart from infarction. Circulation 1993, 88:1273-1278.

69. Tosaki A, Engelman DT, Engelman RM, Das DK: The evolution of diabetic response to ischemia/reperfusion and preconditioning in isolated working rat hearts. Cardiovasc Res 1996, 31:526-536.

70. Kersten JR, Toller WG, Gross ER, Pagel PS, Warltier DC: Diabetes abolishes ischemic preconditioning: role of glucose, insulin, and osmolality. Am J Physiol Heart Circ Physiol 2000, 278:H1218-1224.

71. Ishihara M, Sato H, Tateishi H, Kawagoe T, Shimatani Y, Kurisu S, Sakai K, Ueda K: Implications of prodromal angina pectoris in anterior wall acute myocardial infarction: acute angiographic findings and long-term prognosis. J Am Coll Cardiol 1997, 30:970-975.

72. Lee TM, Chou TF: Impairment of myocardial protection in type 2 diabetic patients. J Clin Endocrinol Metab 2003, 88:531-537.

73. Przyklenk K, Maynard M, Greiner DL, Whittaker P: Cardioprotection with postconditioning: loss of efficacy in murine models of type-2 and type-1 diabetes. Antioxid Redox Signal 2011, 14:781-790.

74. Lacerda L, Opie LH, Lecour S: Influence of tumour necrosis factor alpha on the outcome of ischaemic postconditioning in the presence of obesity and diabetes. Exp Diabetes Res 2012, 2012:502654.

75. Miki T, Itoh T, Sunaga D, Miura T: Effects of diabetes on myocardial infarct size and cardioprotection by preconditioning and postconditioning. Cardiovascular Diabetology 2012, 11:67.

76. Suh YH, Kim Y, Bang JH, Choi KS, Lee JW, Kim WH, Oh TJ, An S, Jung MH: Analysis of gene expression profiles in insulin-sensitive tissues from pre-diabetic and diabetic Zucker diabetic fatty rats. $\mathrm{J}$ Mol Endocrinol 2005, 34:299-315.

77. Garnett KE, Chapman P, Chambers JA, Waddell ID, Boam DS: Differential gene expression between Zucker Fatty rats and Zucker Diabetic Fatty rats: a potential role for the immediateearly gene Egr-1 in regulation of beta cell proliferation. J Mol Endocrinol 2005, 35:13-25. 
78. Kristiansen SB, Lofgren B, Stottrup NB, Khatir D, Nielsen-Kudsk JE, Nielsen TT, Botker HE, Flyvbjerg A: Ischaemic preconditioning does not protect the heart in obese and lean animal models of type 2 diabetes. Diabetologia 2004, 47:1716-1721.

79. Bouhidel O, Pons S, Souktani R, Zini R, Berdeaux A, Ghaleh B: Myocardial ischemic postconditioning against ischemia-reperfusion is impaired in ob/ob mice. Am $\mathrm{J}$ Physiol Heart Circ Physiol 2008, 295:H1580-1586.

80. Oosterlinck W, Dresselaers T, Geldhof V, Nevelsteen I, Janssens S, Himmelreich U, Herijgers P: Diabetes mellitus and the metabolic syndrome do not abolish, but might reduce, the cardioprotective effect of ischemic postconditioning. J Thorac Cardiovasc Surg 2013, 145:15951602.

81. Kocsisne GF, Bencsik P, Fekete V, Varga ZV, Monostori P, Turi S, Ferdinandy P, Csont T: The influence of chronic renal failure on the cardioprotective effect of postconditioning in rats with partial nephrectomy. Cardiovasc Res 2010, 87:S135 (Abstract).

82. Csont T, Ferdinandy P: Letter by Csont and Ferdinandy regarding article, "Ischemic conditioning protects the uremic heart in a rodent model of myocardial infarction". Circulation. 2012, 126:e212

83. Dikow R, Kihm LP, Zeier M, Kapitza J, Tornig J, Amann K, Tiefenbacher C, Ritz E: Increased infarct size in uremic rats: reduced ischemia tolerance? J Am Soc Nephrol 2004, 15:1530-1536.

84. Weiss JB, Eisenhardt SU, Stark GB, Bode C, Moser M, Grundmann S: MicroRNAs in ischemia-reperfusion injury. Am J Cardiovasc Dis 2012, 2:237-247.

85. Onody A, Zvara A, Hackler L,Jr, Vigh L, Ferdinandy P, Puskas LG: Effect of classic preconditioning on the gene expression pattern of rat hearts: a DNA microarray study. FEBS Lett 2003, 536:35-40.

86. Kocsis GF, Csont T, Varga-Orvos Z, Puskas LG, Murlasits Z, Ferdinandy P: Expression of genes related to oxidative/nitrosative stress in mouse hearts: effect of preconditioning and cholesterol diet. Med Sci Monit 2010, 16:BR32-9.

87. Voisine P, Ruel M, Khan TA, Bianchi C, Xu SH, Kohane I, Libermann TA, Otu H, Saltiel AR, Sellke FW: Differences in gene expression profiles of diabetic and nondiabetic patients undergoing cardiopulmonary bypass and cardioplegic arrest. Circulation 2004, 110:II280-286.

88. Vijaya M, Manikandan J, Parakalan R, Dheen ST, Kumar SD, Tay SS: Differential gene expression profiles during embryonic heart development in diabetic mice pregnancy. Gene 2013, 516:218-227.

89. Mak RH, Chang SL, Draksharapu A, Pak YK: Gene expression in uremic left ventricular hypertrophy: effects of hypertension and anemia. Exp Mol Med 2004, 36:251-258.

90. Bray GA: The Zucker-fatty rat: a review. Fed Proc 1977, 36:148-153.

91. Belin de Chantemele EJ, Vessieres E, Guihot AL, Toutain B, Maquignau M, Loufrani L, Henrion D: Type 2 diabetes severely impairs structural and functional adaptation of rat resistance arteries to chronic changes in blood flow. Cardiovasc Res 2009, 81:788-796. 
92. Kurtz TW, Morris RC, Pershadsingh HA: The Zucker fatty rat as a genetic model of obesity and hypertension. Hypertension 1989, 13:896-901.

93. Gustavsson C, Soga T, Wahlstrom E, Vesterlund M, Azimi A, Norstedt G, Tollet-Egnell P: Sexdependent hepatic transcripts and metabolites in the development of glucose intolerance and insulin resistance in Zucker diabetic fatty rats. $\mathrm{J}$ Mol Endocrinol 2011, 47:129-143.

94. Corsetti JP, Sparks JD, Peterson RG, Smith RL, Sparks CE: Effect of dietary fat on the development of non-insulin dependent diabetes mellitus in obese Zucker diabetic fatty male and female rats. Atherosclerosis 2000, 148:231-241.

95. Leonard BL, Watson RN, Loomes KM, Phillips AR, Cooper GJ: Insulin resistance in the Zucker diabetic fatty rat: a metabolic characterisation of obese and lean phenotypes. Acta Diabetol 2005, 42:162-170.

96. Richard G. Peterson, Walter N. Shaw, Mary-Ann Neel, Leah a. Little, and J. Eichberg: Zucker Diabetic Fatty Rat as a Model for Non-insulin-dependent Diabetes Mellitus. ILAR Journal 1990, V32.

97. Unger $\mathrm{RH}$, Orci L: Diseases of liporegulation: new perspective on obesity and related disorders. FASEB J 2001, 15(2):312-321.

98. Csont T, Balogh G, Csonka C, Boros I, Horvath I, Vigh L, Ferdinandy P: Hyperlipidemia induced by high cholesterol diet inhibits heat shock response in rat hearts. Biochem Biophys Res Commun 2002, 290:1535-1538.

99. Matthews DR, Hosker JP, Rudenski AS, Naylor BA, Treacher DF, Turner RC: Homeostasis model assessment: insulin resistance and beta-cell function from fasting plasma glucose and insulin concentrations in man. Diabetologia 1985, 28:412-419.

100. Gayoso-Diz P, Otero-Gonzalez A, Rodriguez-Alvarez MX, Gude F, Cadarso-Suarez C, Garcia F, De Francisco A: Insulin resistance index (HOMA-IR) levels in a general adult population: curves percentile by gender and age. The EPIRCE study. Diabetes Res Clin Pract 2011, 94:146155.

101. Barr EL, Cameron AJ, Balkau B, Zimmet PZ, Welborn TA, Tonkin AM, Shaw JE: HOMA insulin sensitivity index and the risk of all-cause mortality and cardiovascular disease events in the general population: the Australian Diabetes, Obesity and Lifestyle Study (AusDiab) study. Diabetologia 2010, 53:79-88.

102. Chinen I, Shimabukuro M, Yamakawa K, Higa N, Matsuzaki T, Noguchi K, Ueda S, Sakanashi M, Takasu N: Vascular lipotoxicity: endothelial dysfunction via fatty-acid-induced reactive oxygen species overproduction in obese Zucker diabetic fatty rats. Endocrinology 2007, 148:160-165.

103. Zoja C, Cattaneo S, Fiordaliso F, Lionetti V, Zambelli V, Salio M, Corna D, Pagani C, Rottoli D, Bisighini C, Remuzzi G, Benigni A: Distinct cardiac and renal effects of ETA receptor antagonist and ACE inhibitor in experimental type 2 diabetes. Am J Physiol Renal Physiol 2011, 301:F1114-1123. 
104. Sarkozy M, Zvara A, Gyemant N, Fekete V, Kocsis GF, Pipis J, Sz Cs G, Csonka C, Puskas LG, Ferdinandy P, Csont T: Metabolic syndrome influences cardiac gene expression pattern at the transcript level in male ZDF rats. Cardiovasc Diabetol 2013, 12:16.

105. Morrison AB, Howard RM: The functional capacity of hypertrophied nephrons. Effect of partial nephrectomy on the clearance of inulin and PAH in the rat. J Exp Med 1966, 123:829844.

106. Kocsis GF, Pipis J, Fekete V, Kovacs-Simon A, Odendaal L, Molnar E, Giricz Z, Janaky T, van Rooyen J, Csont T, Ferdinandy P: Lovastatin interferes with the infarct size-limiting effect of ischemic preconditioning and postconditioning in rat hearts. Am J Physiol Heart Circ Physiol 2008, 294:H2406-2409.

107. Gavras I, Gavras H: Angiotensin II as a cardiovascular risk factor. J Hum Hypertens 2002, 16:S2-6.

108. Israili ZH: Clinical pharmacokinetics of angiotensin II (AT1) receptor blockers in hypertension. J Hum Hypertens 2000, 14:S73-86.

109. Jin Y, Kuznetsova T, Thijs L, Schmitz B, Liu Y, Asayama K, Brand SM, Heymans S, Brand E, Fagard R, Staessen JA: Association of left ventricular mass with the AGTR1 A1166C polymorphism. Am J Hypertens 2012, 25:472-478.

110. Munger MA: Use of Angiotensin receptor blockers in cardiovascular protection: current evidence and future directions. P T 2011, 36:22-40.

111. Wright JW, Mizutani S, Harding JW: Pathways involved in the transition from hypertension to hypertrophy to heart failure. Treatment strategies. Heart Fail Rev 2008, 13:367-375.

112. Csonka C, Kupai K, Kocsis GF, Novak G, Fekete V, Bencsik P, Csont T, Ferdinandy P: Measurement of myocardial infarct size in preclinical studies. $\mathrm{J}$ Pharmacol Toxicol Methods 2010, 61:163-170.

113. Kasiske BL, O'Donnell MP, Garvis WJ, Keane WF: Pharmacologic treatment of hyperlipidemia reduces glomerular injury in rat 5/6 nephrectomy model of chronic renal failure. Circ Res 1988, 62:367-374.

114. Liu J, Rigel DF: Echocardiographic examination in rats and mice. Methods Mol Biol 2009, 573:139-155.

115. Dunn SR, Qi Z, Bottinger EP, Breyer MD and Sharma K: Utility of endogenous creatinine clearance as a measure of renal function in mice. Kidney Int 2004, 65:1959-1967.

116. Lynch KM, Sellers TS and Gossett KA: Evaluation of an automated pyrogallol redmolybdate method for the measurement of urinary protein in rats. Eur $\mathrm{J}$ Clin Chem Clin Biochem 1996, 34:569-571.

117. Cury DP, Dias FJ, Sosthenes MC, Dos Santos Haemmerle CA, Ogawa K, Da Silva MC, Mardegan Issa JP, Iyomasa MM, Watanabe IS: Morphometric, quantitative, and threedimensional analysis of the heart muscle fibers of old rats: Transmission electron microscopy 
and high-resolution scanning electron microscopy methods. Microsc Res Tech 2013, 76:184195

118. Kuhlmann J, Neumann-Haefelin C, Belz U, Kalisch J, Juretschke HP, Stein M, Kleinschmidt $\mathrm{E}$, Kramer W, Herling AW: Intramyocellular lipid and insulin resistance: a longitudinal in vivo 1H-spectroscopic study in Zucker diabetic fatty rats. Diabetes 2003, 52:138-144.

119. Shimamura M, Nakagami H, Shimosato T, Moritani T, Nakagami F, Osako MK, Miyake T, Koriyama H, Shimizu H, Morishita R: Irbesartan improves endothelial dysfunction, abnormal lipid profile, proteinuria and liver dysfunction in Zucker diabetic fatty rats independent of glucose and insulin levels. Exp Ther Med 2011, 2:957-961.

120. Perez-Martinez P, Garcia-Rios A, Delgado-Lista J, Gjelstad IM, Gibney J, Kiec-Wilk B, Camargo A, Helal O, Karlstrom B, Blaak EE, Hall W, Riserus U, Dembinska-Kiec A, Defoort C, Saris WH, Lovegrove JA, Drevon CA, Roche HM, Lopez-Miranda J: Gene-nutrient interactions on the phosphoenolpyruvate carboxykinase influence insulin sensitivity in metabolic syndrome subjects. Clin Nutr 2013, 32:630-635 .

121. Fredersdorf S, Endemann DH, Luchner A, Heitzmann D, Ulucan C, Birner C, Schmid P, Stoelcker B, Resch M, Muders F, Riegger GA, Weil J: Increased aldosterone levels in a model of type 2 diabetes mellitus. Exp Clin Endocrinol Diabetes 2009, 117:15-20.

122. Leguisamo NM, Lehnen AM, Machado UF, Okamoto MM, Markoski MM, Pinto GH, Schaan BD: GLUT4 content decreases along with insulin resistance and high levels of inflammatory markers in rats with metabolic syndrome. Cardiovasc Diabetol 2012, 11:100-2840-11-100.

123. Fiordaliso F, Leri A, Cesselli D, Limana F, Safai B, Nadal-Ginard B, Anversa P, Kajstura J: Hyperglycemia activates p53 and p53-regulated genes leading to myocyte cell death. Diabetes 2001, 50:2363-2375.

124. Laakso M: Hyperglycemia and cardiovascular disease in type 2 diabetes. Diabetes 1999, 48:937-942.

125. Ishiko K, Sakoda T, Akagami T, Naka T, Doi T, Tsujino T, Masuyama T, Ohyanagi M: Hyperglycemia induced cell growth and gene expression via the serum response element through RhoA and Rho-kinase in vascular smooth muscle cells. Prep Biochem Biotechnol 2010, 40:139-151.

126. Uehata M, Ishizaki T, Satoh H, Ono T, Kawahara T, Morishita T, Tamakawa H, Yamagami K, Inui J, Maekawa M, Narumiya S: Calcium sensitization of smooth muscle mediated by a Rhoassociated protein kinase in hypertension. Nature 1997, 389:990-994.

127. Kovacs P, Szilvassy Z, Hegyi P, Nemeth J, Ferdinandy P, Tosaki A: Effect of transdermal nitroglycerin on glucose-stimulated insulin release in healthy male volunteers. Eur $\mathrm{J}$ Clin Invest 2000, 30:41-44.

128. Toblli J, Cao G, Rivas C, Munoz M, Giani J, Dominici F, Angerosa M: Cardiovascular protective effects of nebivolol in Zucker diabetic fatty rats. J Hypertens 2010, 28:1007-1019.

129. van Zwieten PA: Diabetes and hypertension: experimental models for pharmacological studies. Clin Exp Hypertens 1999, 21:1-16. 
130. Cosson E, Valensi P, Laude D, Mesangeau D, Dabire H: Arterial stiffness and the autonomic nervous system during the development of Zucker diabetic fatty rats. Diabetes Metab 2009, 35:364-370.

131. Grinblat L, Pacheco Bolanos LF, Stoppani AO: Decreased rate of ketone-body oxidation and decreased activity of D-3-hydroxybutyrate dehydrogenase and succinyl-CoA:3-oxo-acid CoA-transferase in heart mitochondria of diabetic rats. Biochem J 1986, 240:49-56.

132. Durgan DJ, Smith JK, Hotze MA, Egbejimi O, Cuthbert KD, Zaha VG, Dyck JR, Abel ED, Young ME: Distinct transcriptional regulation of long-chain acyl-CoA synthetase isoforms and cytosolic thioesterase 1 in the rodent heart by fatty acids and insulin. Am $J$ Physiol Heart Circ Physiol 2006, 290:H2480-2497.

133. Onody A, Csonka C, Giricz Z, Ferdinandy P: Hyperlipidemia induced by a cholesterol-rich diet leads to enhanced peroxynitrite formation in rat hearts. Cardiovasc Res 2003, 58:663-670.

134. Escobales N, Crespo MJ: Oxidative-nitrosative stress in hypertension. Curr Vasc Pharmacol 2005, 3:231-246.

135. Kaneki M, Shimizu N, Yamada D, Chang K: Nitrosative stress and pathogenesis of insulin resistance. Antioxid Redox Signal 2007, 9:319-329.

136. Pacher P, Obrosova IG, Mabley JG, Szabo C: Role of nitrosative stress and peroxynitrite in the pathogenesis of diabetic complications. Emerging new therapeutical strategies. Curr Med Chem 2005, 12:267-275.

137. Goodwin BL, Pendleton LC, Levy MM, Solomonson LP, Eichler DC: Tumor necrosis factor-alpha reduces argininosuccinate synthase expression and nitric oxide production in aortic endothelial cells. Am J Physiol Heart Circ Physiol 2007, 293:H1115-1121.

138. Goodwin BL, Corbin KD, Pendleton LC, Levy MM, Solomonson LP, Eichler DC: Troglitazone up-regulates vascular endothelial argininosuccinate synthase. Biochem Biophys Res Commun 2008, 370:254-258.

139. Haines RJ, Corbin KD, Pendleton LC, Meininger CJ, Eichler DC: Insulin transcriptionally regulates argininosuccinate synthase to maintain vascular endothelial function. Biochem Biophys Res Commun 2012, 421:9-14.

140. Wang Y, Lam KS, Lam JB, Lam MC, Leung PT, Zhou M, Xu A: Overexpression of angiopoietin-like protein 4 alters mitochondria activities and modulates methionine metabolic cycle in the liver tissues of $\mathbf{d b} / \mathbf{d b}$ diabetic mice. Mol Endocrinol 2007, 21:972-986.

141. Staiger H, Haas C, Machann J, Werner R, Weisser M, Schick F, Machicao F, Stefan N, Fritsche A, Haring HU: Muscle-derived angiopoietin-like protein 4 is induced by fatty acids via peroxisome proliferator-activated receptor (PPAR)-delta and is of metabolic relevance in humans. Diabetes 2009, 58:579-589.

142. Yamada T, Ozaki N, Kato Y, Miura Y, Oiso Y: Insulin downregulates angiopoietin-like protein 4 mRNA in 3T3-L1 adipocytes. Biochem Biophys Res Commun 2006, 347:1138-1144.

143. Misra MK, Sarwat M, Bhakuni $P$, Tuteja R, Tuteja $\mathrm{N}$ : Oxidative stress and ischemic myocardial syndromes. Med Sci Monit 2009, 15:RA209-219. 
144. Douglas KT: Mechanism of action of glutathione-dependent enzymes. Adv Enzymol Relat Areas Mol Biol 1987, 59:103-167.

145. L'Ecuyer T, Allebban Z, Thomas R, Vander Heide R: Glutathione S-transferase overexpression protects against anthracycline-induced $\mathrm{H9C2}$ cell death. Am J Physiol Heart Circ Physiol 2004, 286:H2057-2064.

146. Puskas LG, Nagy ZB, Giricz Z, Onody A, Csonka C, Kitajka K, Hackler L,Jr, Zvara A, Ferdinandy P: Cholesterol diet-induced hyperlipidemia influences gene expression pattern of rat hearts: a DNA microarray study. FEBS Lett 2004, 562:99-104.

147. Ivanovic-Matic S, Mihailovic M, Dinic S, Martinovic V, Bogojevic D, Grigorov I, Poznanovic G: The absence of cardiomyopathy is accompanied by increased activities of CAT, MnSOD and GST in long-term diabetes in rats. J Physiol Sci 2010, 60:259-266.

148. Hung J, McQuillan BM, Chapman CM, Thompson PL, Beilby JP: Elevated interleukin-18 levels are associated with the metabolic syndrome independent of obesity and insulin resistance. Arterioscler Thromb Vasc Biol 2005, 25:1268-1273.

149. Okamoto A, Iwamoto Y, Maru Y: Oxidative stress-responsive transcription factor ATF3 potentially mediates diabetic angiopathy. Mol Cell Biol 2006, 26:1087-1097.

150. Jennings RB, Reimer KA: Lethal myocardial ischemic injury. Am J Pathol 1981, 102:241255.

151. Kloner RA, Przyklenk K, Whittaker $P$ : Deleterious effects of oxygen radicals in ischemia/reperfusion. Resolved and unresolved issues. Circulation 1989, 80:1115-1127.

152. Hartman MG, Lu D, Kim ML, Kociba GJ, Shukri T, Buteau J, Wang X, Frankel WL, Guttridge D, Prentki M, Grey ST, Ron D, Hai T: Role for activating transcription factor 3 in stress-induced beta-cell apoptosis. Mol Cell Biol 2004, 24:5721-5732.

153. Qi L, Saberi M, Zmuda E, Wang Y, Altarejos J, Zhang X, Dentin R, Hedrick S, Bandyopadhyay G, Hai T, Olefsky J, Montminy M: Adipocyte CREB promotes insulin resistance in obesity. Cell Metab 2009, 9:277-286.

154. Kim JY, Lee SH, Song EH, Park YM, Lim JY, Kim DJ, Choi KH, Park SI, Gao B, Kim WH: A critical role of STAT1 in streptozotocin-induced diabetic liver injury in mice: controlled by ATF3. Cell Signal 2009, 21:1758-1767.

155. Kim JY, Song EH, Lee S, Lim JH, Choi JS, Koh IU, Song J, Kim WH: The induction of STAT1 gene by activating transcription factor 3 contributes to pancreatic beta-cell apoptosis and its dysfunction in streptozotocin-treated mice. Cell Signal 2010, 22:1669-1680.

156. Fevre C, Bellenger S, Pierre AS, Minville M, Bellenger J, Gresti J, Rialland M, Narce M, Tessier C: The metabolic cascade leading to eicosanoid precursors--desaturases, elongases, and phospholipases A2 - is altered in Zucker fatty rats. Biochim Biophys Acta 2011, 1811:409417.

157. Chahal J, Chen CC, Rane MJ, Moore JP, Barati MT, Song Y, Villafuerte BC: Regulation of insulin-response element binding protein-1 in obesity and diabetes: potential role in impaired insulin-induced gene transcription. Endocrinology 2008, 149:4829-4836. 
158. Colomer JM, Mao L, Rockman HA, Means AR: Pressure overload selectively up-regulates Ca2+/calmodulin-dependent protein kinase II in vivo. Mol Endocrinol 2003, 17:183-192.

159. Chen $\mathrm{NH}$, Wang YL, Ding JH: Increased heart microsomal $\mathbf{N a}(+) \mathbf{K}(+)$-transporting ATPase activity by tetrandrine in spontaneously hypertensive rats. Zhongguo Yao Li Xue Bao 1993, 14:320-325.

160. Boot-Handford RP, Tuckwell DS, Plumb DA, Rock CF, Poulsom R: A novel and highly conserved collagen (pro(alpha)1(XXVII)) with a unique expression pattern and unusual molecular characteristics establishes a new clade within the vertebrate fibrillar collagen family. J Biol Chem 2003, 278:31067-31077.

161. Omelchenko $\mathrm{T}$ : Regulation of collective cell migration by RhoGAP myosin IXA. Small GTPases 2012, 3:213-218.

162. Zhang Y, Resneck WG, Lee PC, Randall WR, Bloch RJ, Ursitti JA: Characterization and expression of a heart-selective alternatively spliced variant of alpha II-spectrin, cardi+, during development in the rat. $\mathrm{J}$ Mol Cell Cardiol 2010, 48:1050-1059.

163. Yurube T, Takada T, Suzuki T, Kakutani K, Maeno K, Doita M, Kurosaka M, Nishida K: Rat tail static compression model mimics extracellular matrix metabolic imbalances of matrix metalloproteinases, aggrecanases, and tissue inhibitors of metalloproteinases in intervertebral disc degeneration. Arthritis Res Ther 2012, 14:R51.

164. Boengler K, Konietzka I, Buechert A, Heinen Y, Garcia-Dorado D, Heusch G, Schulz R: Loss of ischemic preconditioning's cardioprotection in aged mouse hearts is associated with reduced gap junctional and mitochondrial levels of connexin 43. Am J Physiol Heart Circ Physiol 2007, 292:H1764-1769.

165. Przyklenk K, Maynard M, Darling CE, Whittaker P: Aging mouse hearts are refractory to infarct size reduction with post-conditioning. J Am Coll Cardiol 2008, 51:1393-1398.

166. Zheng J, Chin A, Duignan I, Won KH, Hong MK, Edelberg JM: Growth factor-mediated reversal of senescent dysfunction of ischemia-induced cardioprotection. Am $J$ Physiol Heart Circ Physiol 2006, 290:H525-530.

167. Ferdinandy P, Szilvassy Z, Baxter GF: Adaptation to myocardial stress in disease states: is preconditioning a healthy heart phenomenon? Trends Pharmacol Sci 1998, 19:223-229.

168. Ferdinandy P, Szilvassy Z, Horvath LI, Csont T, Csonka C, Nagy E, Szentgyorgyi R, Nagy I, Koltai M, Dux L: Loss of pacing-induced preconditioning in rat hearts: role of nitric oxide and cholesterol-enriched diet. J Mol Cell Cardiol 1997, 29:3321-3333.

169. Giricz Z, Lalu MM, Csonka C, Bencsik P, Schulz R, Ferdinandy P: Hyperlipidemia attenuates the infarct size-limiting effect of ischemic preconditioning: role of matrix metalloproteinase-2 inhibition. J Pharmacol Exp Ther 2006, 316:154-161.

170. Przyklenk K, Maynard M, Greiner DL, Whittaker P: Cardioprotection with postconditioning: loss of efficacy in murine models of type- 2 and type- 1 diabetes. Antioxid Redox Signal 2011, 14:781-790. 
171. Stack AG, Bloembergen WE: A cross-sectional study of the prevalence and clinical correlates of congestive heart failure among incident US dialysis patients. Am J Kidney Dis 2001, 38:992-1000.

172. Koleganova N, Piecha G, Ritz E, Bekeredjian R, Schirmacher P, Schmitt CP, Gross ML: Interstitial fibrosis and microvascular disease of the heart in uremia: amelioration by a calcimimetic. Lab Invest 2009, 89:520-530.

173. Bai Y, Sigala W, Adams GR, Vaziri ND: Effect of exercise on cardiac tissue oxidative and inflammatory mediators in chronic kidney disease. Am J Nephrol 2009, 29:213-221.

174. Li Y, Takemura G, Okada H, Miyata S, Maruyama R, Esaki M, Kanamori H, Li L, Ogino A, Ohno T, Kondo T, Nakagawa M, Minatoguchi S, Fujiwara T, Fujiwara H: Molecular signaling mediated by angiotensin II type $1 \mathrm{~A}$ receptor blockade leading to attenuation of renal dysfunction-associated heart failure. J Card Fail 2007, 13:155-162.

175. Michea L, Villagran A, Urzua A, Kuntsmann S, Venegas P, Carrasco L, Gonzalez M, Marusic ET: Mineralocorticoid receptor antagonism attenuates cardiac hypertrophy and prevents oxidative stress in uremic rats. Hypertension 2008, 52:295-300.

176. Vaziri ND: Effect of chronic renal failure on nitric oxide metabolism. Am J Kidney Dis 2001, 38:S74-79.

177. Vaziri ND, Ni Z, Oveisi F, Liang K, Pandian R: Enhanced nitric oxide inactivation and protein nitration by reactive oxygen species in renal insufficiency. Hypertension 2002, 39:135141.

178. Goncalves AR, Fujihara CK, Mattar AL, Malheiros DM, Noronha Ide L, de Nucci G, Zatz R: Renal expression of COX-2, ANG II, and AT1 receptor in remnant kidney: strong renoprotection by therapy with losartan and a nonsteroidal anti-inflammatory. Am $\mathrm{J}$ Physiol Renal Physiol 2004, 286:F945-954.

179. Pantos CI, Davos CH, Carageorgiou HC, Varonos DV, Cokkinos DV: Ischaemic preconditioning protects against myocardial dysfunction caused by ischaemia in isolated hypertrophied rat hearts. Basic Res Cardiol 1996, 91:444-449.

180. Speechly-Dick ME, Baxter GF, Yellon DM: Ischaemic preconditioning protects hypertrophied myocardium. Cardiovasc Res 1994, 28:1025-1029.

181. Ebrahim Z, Yellon DM, Baxter GF: Ischemic preconditioning is lost in aging hypertensive rat heart: independent effects of aging and longstanding hypertension. Exp Gerontol 2007, 42:807-814.

182. Ebrahim Z, Yellon DM, Baxter GF: Attenuated cardioprotective response to bradykinin, but not classical ischaemic preconditioning, in DOCA-salt hypertensive left ventricular hypertrophy. Pharmacol Res 2007, 55:42-48.

183. Ghosh S, Standen NB, Galinianes M: Failure to precondition pathological human myocardium. J Am Coll Cardiol 2001, 37:711-718.

184. Kitakaze M, Hori M: It is time to ask what adenosine can do for cardioprotection. Heart Vessels 1998, 13:211-228. 
185. Kopecky SL, Aviles RJ, Bell MR, Lobl JK, Tipping D, Frommell G, Ramsey K, Holland AE, Midei M, Jain A, Kellett M, Gibbons RJ, AmP579 Delivery for Myocardial Infarction REduction study: A randomized, double-blinded, placebo-controlled, dose-ranging study measuring the effect of an adenosine agonist on infarct size reduction in patients undergoing primary percutaneous transluminal coronary angioplasty: the ADMIRE (AmP579 Delivery for Myocardial Infarction REduction) study. Am Heart J 2003, 146:146-152. 
13 ANNEX 